Florida International University FIU Digital Commons

$3-2-2018$

\title{
The Lived Experiences of Caregivers of Lung Transplant Recipients
}

Joy Adella Glaze

jglaz004@fiu.edu

DOI: $10.25148 /$ etd.FIDC006913

Follow this and additional works at: https://digitalcommons.fiu.edu/etd

Part of the Nursing Commons

\section{Recommended Citation}

Glaze, Joy Adella, "The Lived Experiences of Caregivers of Lung Transplant Recipients" (2018). FIU Electronic Theses and Dissertations. 3683.

https://digitalcommons.fiu.edu/etd/3683

This work is brought to you for free and open access by the University Graduate School at FIU Digital Commons. It has been accepted for inclusion in FIU Electronic Theses and Dissertations by an authorized administrator of FIU Digital Commons. For more information, please contact dcc@fiu.edu. 


\section{FLORIDA INTERNATIONAL UNIVERSITY}

Miami, Florida

\section{THE LIVED EXPERIENCES OF CAREGIVERS OF LUNG TRANSPLANT RECIPIENTS}

A dissertation submitted in partial fulfillment of the requirements for the degree of

DOCTOR OF PHILOSOPHY

in

NURSING

by

Joy Glaze

2018 
To: Dean Ora Strickland

College of Nursing and Health Sciences

This dissertation, written by Joy Glaze, and entitled The Lived Experiences of Caregivers of Lung Transplant Recipients, having been approved in respect to style and intellectual content, is referred to you for judgment.

We have read this dissertation and recommend that it be approved.

JoAnne Youngblut

Jean Hannan

Timothy Page

Dorothy Brooten, Major Professor

Date of Defense: March 2, 2018

The dissertation of Joy Glaze is approved.

Dean Ora Strickland
College of Nursing and Health Sciences

College of Nursing and Health Sciences

Andrés G. Gil

Vice President for Research and Economic Development and Dean of the University Graduate School

Florida International University, 2018 


\section{DEDICATION}

I would like to dedicate this dissertation to my family, friends and colleagues who have supported and encouraged me throughout this journey.

To my parents who are no longer with us, you are gone but not forgotten. Thanks for instilling in your children the value of education and providing us with a firm educational background. Your memories will forever be cherished. 


\section{ACKNOWLEDGMENTS}

First, I want to thank God for giving me the strength and endurance to complete this dissertation. Despite the many challenges and adverse events encountered you had kept me through this program and the completion of the doctoral degree in nursing.

I would like to extend my sincere gratitude to my dissertation chair Dr. Dorothy Brooten, for her dedication, honesty, guidance and continued support throughout this dissertation journey. Sometimes the journey appeared futile and there was no end in sight, but her kind words of encouragement gave me the desire to continue. For this I am truly grateful, without your help I would not be able to complete this journey.

To my committee members, Dr. JoAnne Youngblut, Dr. Jean Hannan and Dr. Timothy Page, thanks for your honest feedback and valuable insights that guided me through this journey. Your willingness to share and your commitment to my project is commendable.

A special thanks to my family for their endurance, support and encouragement. To my husband and children thanks for allowing me to exchange the role of a mother and wife for a student as I pursue this journey. Your caring attitude and love gave me the strength to continue. To my research assistant Eunice Hernandez, Transplant Nurse Practitioner, your hard work, dedication and enthusiasm made this dissertation possible. Your role in assisting with Spanish speaking participants and reviewing Spanish documents proved your value to the research team. Finally, I would also like to thank the study participants who willingly share their experiences and time with me and ultimately contribute to nursing knowledge. 


\section{ABSTRACT OF THE DISSERTATION \\ THE LIVED EXPERIENCES OF CAREGIVERS OF LUNG \\ TRANSPLANT RECIPIENTS

\author{
By \\ Joy Glaze
}

Florida International University, 2018

Miami, Florida

Professor Dorothy Brooten, Major Professor

Lung transplantation is a treatment for patients with end stage lung disease; they will not survive without such surgery. A caregiver is essential for a patient to become eligible for a lung transplant and the caregiver plays an essential role in the transplant recipient's care both before and after transplant surgery. Most caregiver research has been conducted on caregivers of persons with Alzheimer's disease, dementia or on elderly patients, however, it is important to examine caregivers' experiences caring for other patient groups with disabling conditions. Caregivers of transplant recipients are one such group.

The purpose of this qualitative study, using a hermeneutic phenomenological approach, was to examine the lived experiences of caregivers of lung transplant recipients pre- and post-lung transplantation. The study used semi- structured, face to face, tape recorded in- depth interviews to document the experiences of a purposive sampling of 20 caregivers of lung transplant recipients. Interviews (English, Spanish) were transcribed verbatim and analyzed for emerging themes. The resulting 4 themes and 12 sub themes were: 1) Establishing the diagnosis; 2) Caregivers roles; 3) Caregivers psychological and psychosocial Issues; and 4) Support. The 12 sub themes were:1) Caregivers reaction to transplant option; 2) Caregivers' lack of basic knowledge as related to lung transplant 3) Disease progression: Reality of unanticipated changes/fear of death; 4) Pre- transplant 
experiences; 5) Hospital course; 6) Home care; 7) Lifestyle changes and Social activities;

8) Physical health and Emotional health ; 9) Financial and Employment issues;10)

Family/Friends;11) Professional support; 12) Support groups. Study results demonstrated caregivers' lack of knowledge about transplantation, dramatic changes in caregivers' family life, social activities, employment, and often financial status. Results also demonstrated a need for health care providers and policy makers to recognize caregivers' stressful life changes and implement informational, psychological and emotional interventions and policies to assist these caregivers during their stressful and tedious experiences. 


\section{TABLE OF CONTENTS}

CHAPTER

PAGE

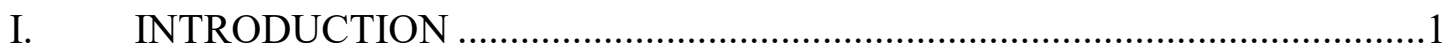

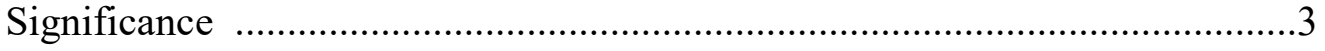

Purpose of Statement ......................................................................... 7

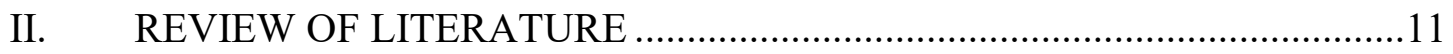

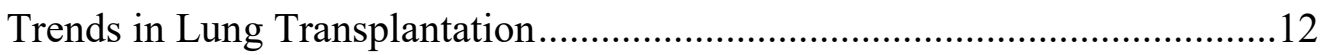

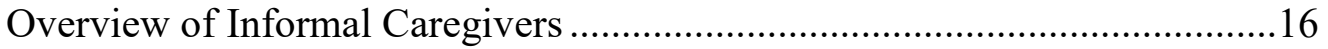

Caregivers of Lung Transplant Recipients ..................................................22

Spouse as Caregiver ..............................................................................29

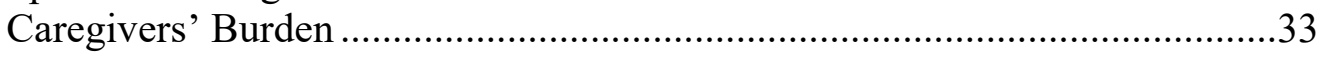

Financial Challenges of Caregivers of Lung Transplant Recipients ..............43

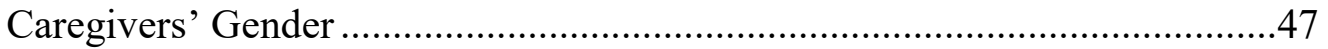

Caregivers' Health ................................................................................50

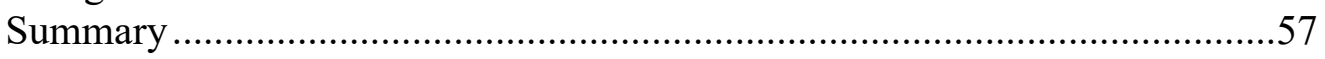

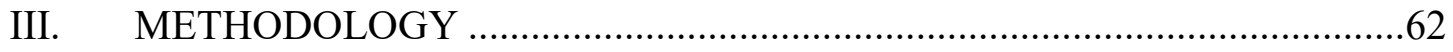

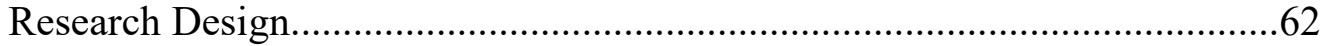

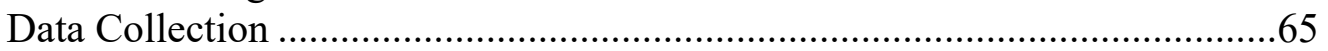

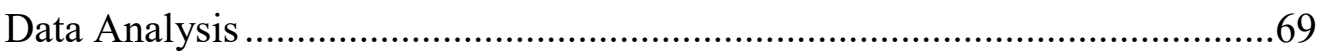

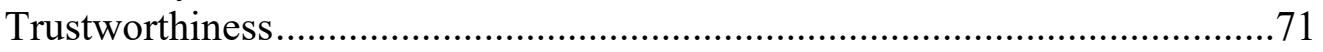

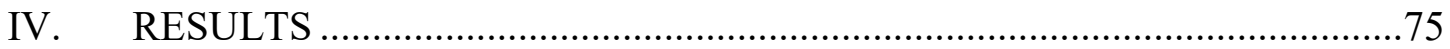

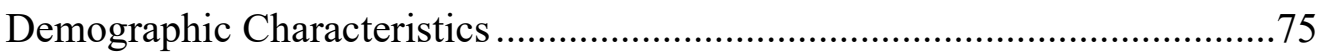

Theme \# 1: Establishing the Diagnosis....................................................... 78

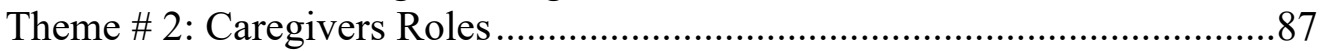

Theme \# 3: Caregivers Psychological and Psychosocial Issues ......................94

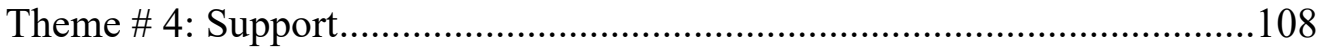

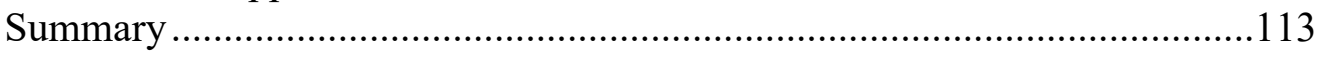

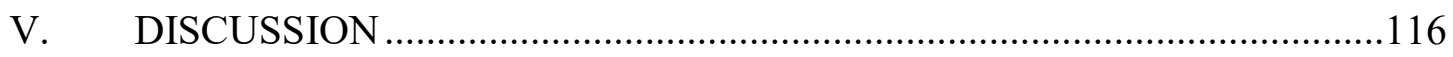

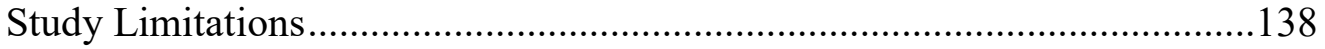

Recommendations for Future Research and Implications for Practice..........139

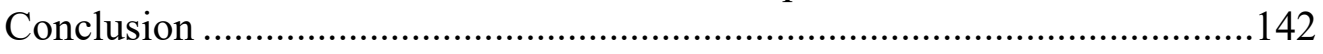

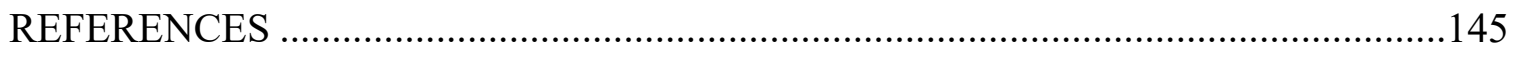

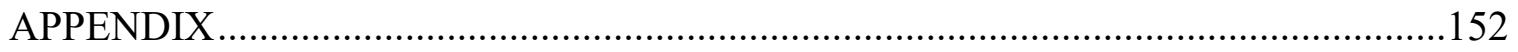

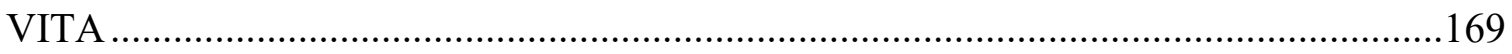




\section{CHAPTER I}

\section{INTRODUCTION}

Lung transplantation has now become an important treatment method for patients who have had end stage lung diseases and who would have never survived without such surgery. As lung transplantation becomes a sustainable and effective treatment intervention for end stage organ disease, presence of one or more caregivers is an essential component of the transplant recipient's post- operative success. However, studies on caregivers have shown that caregiving can be physically and psychologically demanding, affecting caregiver's health and quality of life which can affect the care they provide. (Collins, White-William \& Jalowiec, 2000, Kurz, 2001, Pinquart \& Sorensen, 2003, Martensson et al 2003).

Caregivers play an essential role in the delivery of health care in the USA. They provide care valued at 470 billion per year to millions of individuals who require assistance with health and daily care. Approximately $30 \%$ of the US household population is affected by a caregiver's responsibility (National Alliance for Caregiving and AARP, 2015). More than 50 million unpaid caregivers provide care to someone aged 18 or older or who is ill and has a disability. According to Grady \& Makulowich in 2000 informal caregiver services accounted for approximately $80 \%$ of home care services in the USA providing care to elderly family members or those who had a chronic or acute illness. Most caregiver research has been conducted on caregivers of Alzheimer's, dementia or elderly patients, however it is important to examine caregivers of other patient groups with conditions that are prevalent and often disabling (Holkup \& 
Buckwalter, 2001, Wallsten, 2000). Caregivers of transplant recipients are one such group.

Transplant recipients require lifelong therapy to maintain the viability of the transplanted organ, therefore these patients continue to require support from family and caregivers in order to survive (UNOS, 2012). Since lung transplantation remains an effective treatment for patients with end-stage lung disease, it is essential that one or more committed caregivers become an essential component of the patient's pre-operative well-being and post-operative success (Feure, Harrison, Pinson, 2002, Lanuza \& McCabe, 2001). Caregivers play an important role in the success of transplantation as recipient's progress through recovery, beyond the period of hospitalization and require extensive care at home following transplantation. The prolonged recuperation time after transplant, the subsequent recovery and return to normal functioning require the caregiver to be an active presence in the recipient's life. Additionally, rapid hospital discharges post-surgery and a longer post-transplant life span may pose additional challenges to caregivers including increased levels and duration of caregiving responsibilities (Dew \& Myaskovsky, 2005).

Caregivers of lung transplant recipients are recognized as an integral part of the patient's success during the lung transplantation process, however most research in lung transplantation is focused on transplant recipients rather than transplant caregivers (Parekh, Blumenthal, Babyak, 2003). Caregiver's distress during the transplant process may sometimes be recognized by the transplant team but the effects on the caregiver is rarely measured. As a result, caregivers of lung transplant recipients often do not receive the psychological and practical support they need. Research is needed to gain an 
understanding of the caregiver's experiences from the caregiver's perspective. Such data will provide information to guide interventions to improve caregivers' quality of life and may prove beneficial to both transplant recipients and their caregivers. There is evidence from the non- transplant population such as caregivers of patients with Dementia, Alzheimer's, and various types of cancers that show that psychological interventions for caregivers of patients with chronic illness may improve caregiver's mental health and coping (Selwood,2007). The presence of one or more dedicated caregivers is essential in ensuring patient's success with lung transplant since patients initially are highly dependent on their caregivers during the transplant process. Because so many resources are put forth to save a patient's life with a transplant it is important to ensure that adequate support and resources are provided to the caregivers.

\section{Significance}

It is estimated that 43.5 million caregivers have provided unpaid care to an adult or child in the last 12 months. More than 30 million people annually need assistance after acute care and discharge from hospitals. Family caregivers spend an average of 24.4 hours per week providing care with $40 \%$ of caregivers providing care in high burden situations, (providing an average of 51.6 hours of care per week, assist with 3 out of 6 ADL's), $18 \%$ in medium burden (providing 9.6 hours of care per week and assist with 2 out of 6 ADL's), and $41 \%$ in low burden ( providing 4,9 hours of care per week and assist 0.2 out of 6 ADL's) based on the Level of Care Index (National Alliance for Caregiving and AARP, 2015). According to the National Alliance for Caregiving and AARP (2015), $60 \%$ of caregivers are females, $62 \%$ are Non- White and $17 \%$ are 
Hispanics. The Decima research conducted in 2002 suggests that caregivers have become a common occurrence in society and the numbers are growing.

Changing health care policy, an aging population, an increased focus on early discharge and providing care at home have made the issue of caregiving a national priority. Most disease conditions that were fatal in the past are now managed through innovations in medical treatment or highly technological treatment resulting in increased chronicity in the population and an increased need for caregiver's support. With the improvements and advancements in medical treatment and changes in health care financing there are shorter hospital stays and extended life expectancy. These changes place increased responsibilities on caregivers and family members including those of lung transplant recipients (Canning et al 1996). Lung transplant candidates are required to have adequate caregivers support prior to being listed for a lung transplant, for assistance at home, as well as transportation to appointments and tests (Lanuza \& McCabe, 2001, Feurer, Speroff, Harrison \& Pinson, 2002).

Lung transplant caregivers provide crucial supports for maintaining the patient's physical and mental health throughout the transplant process. During the transplant process patients may experience severe illness and disability and caregivers will participate in activities that patients often take for granted in daily life such bathing, feeding, medication administration. The exposure to chronic stress of transplantation may affect both the caregivers and recipients' quality of life, resulting in caregivers experiencing lower quality of life than non-caregiver adults (Rodrigue \& Baz, 2007)

The stress of caregiving can negatively affect a caregiver's health, and behaviors to promote or manage their own health and survival. Although lung transplant caregivers 
may be in good health initially and have a good quality of life they experience major adverse effects both physically and psychologically as a result of the long term caring responsibilities (Myaskovsky et al, 2012).

The bulk of the caregivers' responsibilities has now shifted from the healthcare setting to home, hence lung transplant caregivers are now faced with overwhelming experiences that are laden with uncertainty about caregiving itself, as well as physical, psychological and economical challenges. The lung transplant caregivers will need support to balance the demand of everyday life activities with the new caregiving responsibilities.

Both caregivers and the recipients undergo the transplant evaluation, if the transplant candidate is successfully listed as a potential lung transplant candidate, the caregiver and the candidate begin the wait for a suitable organ. According to the Organ Procurement and Transplantation Network (OPTN ), as of February 23,2017, the number of patients waiting for a lung transplantation is approximately 1600 (United Network for Organ Sharing, 2016). The majority of these candidates are female (70\%) and white (81\%). Candidates between the ages of 50-64 years account for $60 \%$ of the candidates on the waiting list. (Organ Procurement and Transplantation Network, 2015). The waiting period for an organ for a lung transplant can sometimes be lengthy with high mortality rates. According to the organ of procurement of transplantation network annual data report in 2015, the time spent on the waiting list varies from less than 1 month to 3 years, with a mean waiting period of 12 months. (Organ Procurement and Transplantation Network, 2015). Approximately $25 \%$ of lung transplant candidates die while waiting for transplant, demonstrating the severity of the disease and the need to conduct research on caregivers of these recipients during transplant process. According to the United Network 
of Organ Sharing, over 34,000 organ transplantations were performed in the United States in 2016 of which approximately 2,400 were adult lung transplantations and approximately 20 were combined adult Heart and Lung transplantation. (UNOS, 2016).

The transplant process is time laden with heightened feelings of anxiety, depression, fear, and anger for caregivers as well as compromised quality of life as they prepare for the possibility of the patient's death versus prolonged life with a transplant (Dew et al, 2000; Claar et al 2005). Similarly, heightened fatigued, mood instability, physical health problems, and relationship strains among the caregivers may compromise the patient's adaptation throughout the post-transplant process (Rodrigue \& Baz, 2007). During the transplant process from the time of listing for transplant, the potential transplant candidate is usually comforted by a caregiver. Closely monitoring the recipient's health status, ensuring optimal compliance with medications and life style changes, communicating regularly with the transplant team, being an advocate for the recipient, providing transportation to and from clinics and providing emotional support are some of the responsibilities that are assumed by these caregivers during the post- transplant period. The care provided by the caregivers is always comforting to the recipients, however it can be physically and psychologically demanding, and adversely affect the caregiver's life. This eventually compromises the caregiver's health status and in turn adversely affects the quality of care provided by the caregiver (Collins, White-Williams, \& Jalowiec, 2000; Kurz, 2001; Pinquart \& Sorensen, 2003).

With the growing numbers of lung transplantations annually, the need for adequate and effective care for these recipients has become a priority. However, comparing research on caregivers of patients with chronic diseases differs from that of 
caregivers of transplant recipients since the transplant recipient's medical course is usually improved dramatically. Although the bulk of the caregiving research is conducted on caregivers of other chronic diseases such as caregivers of Alzheimer, dementia or the elderly, it is especially important to examine caregivers of lung transplant recipients as the conditions are equally prevalent and sometimes disabling.

Surprisingly very few studies have explored the experience of caregivers during the lung transplantation process (Claar et al, 2005; Kurz, 2001; Kurz \& Cavanaugh, 2001; Meltzer \& Rodrique, 2001; Mayaskovsky et al, 2005, Ulrich, Jansch, Schmidt, Struber, \& Niedermeyer, 2004). These studies conducted on caregivers of lung transplant recipients used a quantitative approach. The majority of participants were female and white. A qualitative approach with participants who are male and from different races and ethnicities is needed, to gain a better understanding of the lived experiences of the transplant caregivers and to explore the subjective meaning caregivers give to their experiences. A qualitative design allows insight into caregiver's quality of life and how caregiver's experiences affect the recipient's survival outcomes. Ultimately it will also assist health care providers to implement support programs and interventions to assist caregivers with their caregiving roles during these stressful events.

\section{Purpose Statement}

The purpose of this study was to explore and examine the lived experiences of caregivers of lung transplant recipients during the pre and post lung transplant process using a qualitative Hermeneutic phenomenological design. The study sought to address the following research aims: 
1. Describe the caregiver's perceptions in caring for the lung transplant recipients and life changes after taking responsibility for the lung transplant recipient

2. Describe the sociodemographic characteristics of the caregivers of lung transplant recipients, including age, gender, marital status, employment status, socioeconomic status, and ethnicity.

Phenomenology as a methodological framework has evolved into a process that seeks reality in individual's narratives of their lived experiences of phenomena (Cilesiz, 2009, Husserl, 1970, Moustakas, 1994). It was formally introduced by Edmund Husserl at the beginning of the twentieth century (Moran, 200, Giugnon, 2006, Moustaskas, 1994). His conception of phenomenology has been criticized and developed not only by himself but also by students such as Edith Stein, Martin Heidegger and Merleau-Ponty. Phenomenology is the study of the "essences" (Merleau-Ponty, 1962). Essences are the essential elements of a phenomena, those things which makes it recognizable as such (van Manen, 1990). Phenomenology does not look for cause -effect nor does it seek to generalize. It is process of observing and analyzing "the things themselves" (Husserl, 1992). Phenomenology includes different philosophies consisting of transcendental, existential and hermeneutic theories (Cilesez, 2010). The transcendental philosophy is often connected with being able to go outside of the experience, as if standing outside of ourselves to view the world from above. The existential philosophy reflects the need to focus on our lived experiences, while the hermeneutic phenomenology emphasizes interpretation as opposed to just description (Moustakas, 1994, Langdrige, 2007). This study will use the philosophical and methodological framework of hermeneutic 
phenomenology to explore the lived experiences of caregivers of lung transplant recipients (Denzin \& Lincoln, 2000, Moustakas, 1994, van Manen, 1990).

Hermeneutics phenomenology was developed by Martin Heidegger who stated that this physiological framework seeks to interpret the data that goes beyond description and attempts to uncover the hidden meaning. (Moustakas, 1994). The Hermeneutic phenomenology is the study of lived experience as it is immediately experienced, however it cannot be understood until reflected upon (van Manen, 1990). It describes the meaning of an experience, of a concept or a phenomenon for several individuals, describes what all have in common as they experience the phenomenon, and reduces the individual experiences to a description of the universal essence of what is experienced and how it is experienced (Moustakas, 1994). Hermeneutics phenomenology highlights what makes an experience unique, it does not attempt to generalize or create a theory, rather it allows the essence of the experience to emerge from the data. It also uses the uniqueness of the individual 's lived experience as a means for better understanding the social, cultural, political or historical context in which the experiences occur (Polit \& Beck, 2010).

Using this hermeneutic framework allows the researcher to explore the phenomenon that is sensitive (transplant caregiver's experiences), and to explore the meanings of the caregivers' experiences in a natural environment (Chenail, 2011). This framework provides a structure for understanding of the caregiver's lived experiences, through the interview process. It explored the experiences of the caregivers in their lived experiences, as well as how they interpreted their experience. Hermeneutic 
phenomenology also gives a voice to the human experiences as the caregiver's experiences the phenomena. Additionally, it provides an understanding of the meaning or essence of the person's experience of the lived world with careful portrayal of the experience, rather than a casual description (Van der Zalm \& Bergum, 2000). The hermeneutic framework involves six activities which van Manen (1990) describes as:

- Selecting a phenomenon in which one is strongly interested and committed

- Investigating experience as it is lived (by caregivers of lung transplant recipients), not as we think it is

- Reflecting on the essential themes of the phenomenon we investigate

- Writing and rewriting about the phenomenon

- Having a strong and ongoing orientation to the fundamental question - Considering the parts and the whole of research in order to maintain balance

With the limited amount of qualitative research on lung transplant caregivers, a qualitative design allows the researcher to explore this special unit and gain an understanding of the personal experiences of caregiving from the perspective of the caregivers. Results of this study will provide health care professionals working with these caregivers a better understanding of the lung transplant caregivers' needs and experiences in order to develop interventions to help caregivers cope with this stressful situation. Study findings may also provide data that will inform health policy. 


\section{CHAPTER II \\ REVIEW OF LITERATURE \\ INTRODUCTION}

Lung transplantation is known as an effective medical intervention for many patients with end- stage pulmonary diseases since 1980 when advances in immunosuppressant therapy made rejection less likely and patient's survival was limited to 48-72 months. As an acceptable and vital option for patients with end stage lung disease, transplantation offers the recipients a chance for increased survival and an improvement in their quality of life. It is a risky procedure that requires the highest skill level, high performance equipment and experienced support staff (Levy et al 2009). While lung transplantation is now routinely performed in the US, not enough is known about the ability of caregivers of lung transplant recipients to effectively and adequately perform the care required and how these caregivers are affected by their commitment to caregiving.

With the growing numbers of lung transplantations that are performed annually, the need for adequate and effective care for these recipients now becomes a priority. Although caregivers may be in good health and sometimes have a good quality of life they also experience major adverse effects both psychologically and physically because of long term caregiving which may last beyond the recipients expected 1-2 years' recovery period. Though the insult to caregivers caused by constant distress during the transplant process may sometimes be recognized by the transplant team it is generally underestimated. As a result, caregivers of lung transplant recipients do not receive the psychological and practical support they need (Claar et al, 2005). Clearly, there is the need to develop knowledge by engaging in research which aims to gain understanding of 
the caregivers' experience specifically from the perspective of the caregivers of lung transplant recipients. The purpose of this chapter reviews the literature on caregivers of lung transplant recipients. The literature review includes:-Trends in lung transplantation an overview of informal caregivers, caregivers of lung transplant recipients, caregiver's roles (in pre and post transplantation phase), spouse as caregivers, caregivers burden, caregivers gender and caregiver's health.

The literature search was conducted using the Cumulative Index to Nursing and Allied Health Literature (CINAHL), Psychological Abstracts (PsycINFO), PubMed, Health Source: Nursing/Academic Edition, ProQuest, Dissertations Abstracts International and Goggle Scholar. Terms used in the search included caregivers, lung transplantation, lung transplant recipients, organ transplantation, caregiver burden, caregiver health, caring for another. The search was limited to works in the English Language.

\section{Trends in Lung Transplantation}

Pulmonary disease remains a burden to society as the incidence continues to increase and now ranks firmly among the leading causes of death. (Lozano et al, 2013). Following the 1980's, lung transplantation has matured as a successful treatment option for selected patients with end stage lung diseases. Lung diseases for which transplantation is the only treatment option include: chronic obstructive pulmonary disease (COPD), cystic fibrosis, pulmonary fibrosis, sarcoidosis, and idiopathic pulmonary disease, sarcoidosis, pulmonary hypertension 
This success of lung transplantation is attributed to careful donor management, improved immunosuppressant therapy, organ preservation and recipient management (Christie et al 2012). In the early 1940's, attempts at lung transplantation began when a Soviet scientist, Vladimir Demikhovc attempted a single lung transplant in a dog (Langer, 2011). This transplant failed due to bronchial anastomosis dehiscence. Difficulties with anastomosis remained a problem with lung transplantation for the next 40 years. On June 11, 1963, Dr. James Hardy attempted the first lung transplantation in humans at the University of Mississippi. The surgery was performed on a patient with bronchogenic squamous cell carcinoma; the patient survived 18 days. (Ramsey, Trulock, Hollingsworth, 2016). The failure of this early experience in lung transplantation was related to inadequate immunosuppression and bronchial anastomosis.

The advent of cyclosporine brought about significant improvement in patient survival rates following liver and kidney transplantation (Yeung \& Keshavjee, 2014). This led to a resurgence of interest in heart and lung transplantation at Stanford and lung transplantation in Toronto (Starzl et al, 1981). In 1981, Dr. Bruce Reitz at Stanford University performed the first successful combined heart and lung transplant on a patient with pulmonary arterial hypertension. In 1983, Dr. Joel Cooper from the Toronto Lung Group performed the first successful single lung transplant in a patient with a diagnosis of Idiopathic pulmonary fibrosis. Research performed by a group in Toronto showed that corticosteroid use appeared to be a significant factor in the weakness of the bronchial anastomosis. With the introduction of the use of cyclosporine, use of corticosteroids was reduced leading to improved bronchial healing. Cooper continued to experiment with bilateral lung transplantation until 1989, when he along with Dr. Pasque from 
Washington University performed the first double lung transplantation. They did this transplant first with an en bloc technique that used a tracheal anastomosis, and then evolved into the bilateral sequential transplantation technique that not only improved airway healing but also had the additional benefit of avoiding cardiopulmonary bypass. (Copper et al, 1987, Patterson et al, 1988). This remains the standard technique used today.

Since lung transplantation began, there has been significant progress and success in the field, which can be attributed to improvement in surgical techniques, immunosuppressive regimens, recognition and treatment of allograft rejection and the development of multidisciplinary and collaborative surgical and medical teams providing optimal long-term care (Kirby \& Hayes, 2014, Ramsey, Trulock \& Hollingsworth, 2015).

According to the Registry of the International Society for Heart and Lung Transplantation in 2015, there has been a steady growth in the numbers of annual adult and pediatric transplant procedures performed worldwide. In 2014, approximately 51,400 adult lung transplantations and 3,820 combined adult heart and lung transplantations were performed worldwide. Of the 51,400 adult transplantations in 2014, $49,422(96.1 \%)$ had a primary lung transplantation and 2,108(3.9\%) had lung retransplantation. In the United States organ transplantation, had reached a milestone in 2016, in which more than 33,500 organ transplantations were performed. Approximately 2400 were adult lung transplantation and approximately 25 were combined heart and lung transplantation. This represented a $20 \%$ increase in organ transplantation over a 5 years period. (Organ Procurement and Transplantation United Network 2017). As of February 23, 2017, a total of 1,600 lung transplanted candidates are listed for a lung 
transplantation. More than $70 \%$ of the candidates are female and are between the ages of 50-64 years old. The time spent on the waiting list varies from less than 1 month to 3 years, with a mean waiting period of 12 months (Organ Procurement and Network, 2016).

According, to the United Network of Organ Sharing (UNOS, 2017), there are currently 118,629 candidates waiting for a solid organ transplantation. When organs become, available and are transplanted, the survival of post-transplant recipients is primarily dependent on their support systems to care for them, including their caregivers and their health status prior to their transplant of recipients. According, to the registry of the ISHLT (2014), the median survival rate for lung transplant recipients between 1990 and 2013 was 5.7 yrs., with survival rates of $89 \%$ at 3 months, $80 \%$ at 1 year, $65 \%$ at 3 yrs., $54 \%$ at 5 yrs. and $31 \%$ at 10 yrs. Recipients who received a bilateral lung transplant had a better survival than those who had a single lung transplant, with a median of 7.1 yrs. vs 4.5 yrs. Post-transplant recipients require lifelong therapy to maintain the viability if the transplanted organ, hence these recipients continue to require the attention and care from their family members and caregivers in order to survive (UNOS, 2016). As the recipients receive continued care, caregivers also require care and attention themselves so that they will be able to continue providing care and support to their loved ones. Studies on the experiences of caregivers of lung transplant recipients are limited, despite the increase in the numbers of lung transplant procedures (Claar et al, 2005; Kurz, 2001; Kurz \& Cavanaugh, 2001; Meltzer \& Rodrique, 2001; Mayaskovsky et al, 2005, Ulrich, Jansch, Schmidt, Struber, \& Niedermeyer, 2005; Kugler et al 2004; Taylor, Nolan \& Dudley-Brown, 2006). Literature on caregivers of heart transplant and other solid organs 
transplantations is more extensive, thus a review of these studies was necessary to understand caregiver's issues that may be common across transplantations.

While there are differences in these transplant groups, these patients have similarly effects of their pre- transplant diagnosis, survival rates, infection control and complications. They also experience end stage disease with concomitant anticipation for a change in health status after their transplant. It is important to examine the characteristics and experiences of caregivers of lung transplant to optimize the use of support or interventions to reduce negative impacts on caregiver's lifestyle and quality of life.

\section{Overview of Informal Caregivers.}

An informal caregiver is usually a family member, or a close friend who provided physical or emotional care to one who is in need. Reports estimated that in 2015, at least 43.5 million adults provided informal care to an adult or child in the prior 12 months, and as the baby boomers, the need for family caregiving will increase (National Alliance for Caregiving, 2015, AARP, 2015). Seventy five percent of all caregivers are female and spend as much as $50 \%$ of their time providing care to their family (Institute of Aging, 2016). The average caregiver is approximately 50 years old, $50 \%$ are employed, $59 \%$ are married and more than half lives less than 20 minutes from their care recipient. Caregivers spend an average of 24.4 hours per week providing care, and most caregivers have provided care for at least 4 years (National Alliance of Caregivers, 2015).

Over the last decade the value of service provided by informal caregivers has steadily increased with the estimated value to be 470 billion in 2013, an increase from 450 billion in 2009 (AARP Public Policy Institute 2051). At 470 billion in 2013, the value of unpaid 
service surpasses the value of Medicaid spending in that same year (National Alliance of Caregiving, 2015). As the population ages, those 64 years and older will grow from 40.3 million in 2010 to 55 million in 2020 , a $36 \%$ increase. These caregivers will continue to be the largest group of long term caregivers (AARP, 2011)

According, to Lim \& Zebrack, (2004), as a result of the health care reforms in which there is shorter length of stay in the acute care settings, more adults with long term illness are cared for at home. Informal caregivers while providing care to their loved ones are confronted with increased financial, emotional, physical and health issues. They also are faced with restrictions in their social life, isolation and reduced or loss of employment (Brazil, Bainbridge \& Rodriquez, 2010) The Family Caregiver Alliance, 2015, noted that $70 \%$ of working caregivers suffered work related difficulties with $12 \%$ reducing work hours and approximately 10\% relinquishing their job completely (Family Caregiver Alliance, 2015).

According, to Pinquart \& Sorensen, (2003) many caregivers are faced with severe psychological distress. Often these caregivers are forced to deal with verbal and physical aggression, confusion, and anger which is associated with some chronic illness such as dementia or terminal cancer diseases (Pinquart \& Sorensen, 2003). The emotional distress from watching their loved one suffering from pain as their condition deteriorates, anticipatory grief, anticipation of a negative outcome, feelings of guilt, resentment, and disappointment all have a profound impact on caregiver's mental health (Waldrop et al 2005). The National Alliance of Caregiving \& AARP, (2015), indicated that caregiver's activities include providing physical care such as dressing changes, administering medication, managing finances, completing routine household chores, assisting with 
activities of daily living, transporting the patients to and from appointments and being present for emotional support.

Knoll \& Johnson, (2000) using a qualitative design explored the experiences of caregivers whose spouses had an early discharge from the hospital after undergoing cardiac surgery. The participants were six females and two males, and were English speaking. The caregiver's ages ranged from 58 to 80 years old. These eight participants were described as either primary or secondary participants by the researchers. Primary caregivers were those who provided care during the first eight days after the early discharge, while the secondary participants were those who provided care to early discharged cardiac surgery patients about a year ago. Two themes were identified by the researchers, the process of caregiving in the home setting and the effects of caregiving on the caregiver. The researchers noted that the spouse's ability to return to good health and their close pre- existing relationship with the caregivers was a factor that influenced the caregiving experiences among these caregivers. Caregivers reported their experience was enhanced with teaching materials such as booklets and pamphlets they received. This enabled them to be better prepared for the caregiving role since they knew what to expect at different times during the caregiving experiences. Additionally, caregivers reported the experience as stressful resulting in feelings of exhaustion. These findings confirm that caregiver's previous caregiving experiences and a preexisting considerate spousal relationship can help to support a caregiver, however the stress of caregiving can still affect the caregiver's health.

Using a cross-sectional, descriptive correlational design. Mathews, et al (2004), examined the association between health protective behavior and caregiver's quality of 
life in persons caring for patients with cancer. The participants were recruited from local cancer caregiving breakfasts, local hospitals, and a national cancer survivor's network. Data were obtained from 152 caregivers providing on going care to their loved ones with cancer for less than 20 years of caregiving. Eighty six percent of the participants were older Caucasian female spouses, who were well educated, employed and reported midlevel incomes. The researchers used the Life Orientation Test to evaluate the caregiver's general feelings of positive expectancies and the Quality of Life for Family Caregivers tool to measure the caregiver's physical well-being, psychological well-being, social well-being and spiritual well-being. The researchers found that caregivers who maintain a positive health protective stance using positive behavior while providing care, were more likely to predict a better caregiving quality of life. Additionally, they also found that caregivers who provided care for shorter periods of time and at earlier stages of the partner's disease process had greater associated quality of life. Less isolation, fewer feelings of overload, and fewer feelings of being trapped were predictors of better quality of life for the caregivers. The authors concluded that given the increased numbers of informal caregivers involved in providing care to spouses, attention to the caregiver's experience will support and improve the caregiver's quality of life during the caregiving experiences, thereby helping to ensure better caregiving is provided.

Sims-Gould and Martin -Matthews, 2008, in order to better understand the dynamics of caregiving, conducted a research to examine the provision of family caregiving by extending analyses beyond the typical dyadic focus. In this study the researchers analyzed verbatim data collected from 55 caregiver participants. Five themes were identified in caregiving, (a) The presence and importance of caregivers, (b) the presence 
of multiple caregivers, (c) participation of men, (d) the balance of direct and assistive help, (e) pain helpers in caregiving networks. The investigators defined absent caregivers as those family members who are present but do not participate in the caregiver's role. The absent caregivers are important to consider since they contribute to the stress and overall experience of the primary caregiver. The researchers' findings illustrated the complexities associated with caregiving, regarding direct and assistive in caregiving and the demands of multiple demands within the family.

\section{Informal Caregivers Burden.}

Caregiver burden is differentiated as subjective and or objective burden (Chappell et al 2014; Davis et al, 2014; Hunt, 2003) depending on the circumstances associated with the caregiving experiences. According to Chou, (2000) the experience of caregiver burden is situational and varies with the caregiver's perceived demands and resources. In addition, several studies specify caregiver burden as a unique concept associated with caregiving, specific to the caregiver role, frequently identified as sacrifice of the caregivers' time, job, role and energy (Chappell et al, 2014, Nguyen, 2009).

Objective burden as described by Davis et al (2014) as the burdens emanating from the care rendered. These include activities of daily living such as bathing, feeding, toileting and time spent on caregiving tasks such as laundry, financial duties, and taking the care recipients to health visits. Subjective burden is the psychological and emotional strain placed upon the caregivers. This burden entails the caregiver's feelings, attitudes or emotional reactions to the caregiving experience. Subjective burden places the caregiver at a greater risk for the-development of negative health consequences. 


\section{Informal Caregivers Health}

Caregivers' stress stems from emotional strain that can produce feelings of anger, guilt, and frustration which can lead to depression, anxiety, poor physical health, higher levels of obesity and a higher risk for mental decline. Prolonged caregiving stress can lead to lower quality of care or in some cases abuse of the care recipients (Beach et al 2005). Caregivers' physical and emotional health is frequently comprised due to the related stressors and burdens associated with the caregiving role. Often family caregivers are reluctant to seek assistance to help cope with the stress of caregiving because they do not identify themselves with the caregiving or they may feel ashamed to ask for help. Studies identify informal caregivers at a higher risk for chronic illness due to their caregiving roles (Mathews, et al (2004, Pinquart \& Sorensen, 2003). Scott, (2013), noted that caregivers did not participate in health prevention activities such as seeking physicians' assistance for health maintenance checkups, exercises, and eating healthy diets hence resulting in the use of over the counter medications and treatments by the caregivers. Health conditions, including heart disease, diabetes, weight loss, fatigue, sleep problems and arthritis are common among the informal caregiver population.

Beach et al (2005) saw the importance of identifying and paying attention to the adverse mental consequences associated with family caregiving. The investigators a cross-sectional analysis of family caregivers to an adult. The purpose of the survey was to identify family caregivers associated with improved mental health. The investigators reported that caregivers with low caregiver burden reported less stress and less depressive symptoms and caregivers with a higher number of caregiver's tasks produced a higher level of stress. The authors concluded that individuals who cared for a recipient with a 
mental disability or behavioral disorder experienced significantly higher caregiver distress. The importance of caregivers having a good mental health both in the beginning phase and continuing through the process of caregiving is paramount.

\section{Caregivers of Lung Transplant Recipients}

Lung transplantation has now evolved from being an experimental procedure in the early 1990s to become an effective intervention for patients with end stage lung diseases Lung transplant surgery and its subsequent recovery period not only affects the recipients but also the caregivers who may be spouses, children, and friends. These caregivers play an important role in the overall success of the recipient's recovery process and transplantation since the recipient's progress extends beyond the immediate period of hospitalization to requiring extensive care at home. For each transplanted recipient, there is caregiver who shares this stressful and unique experience with the recipient.

While there are many definitions of caregivers (Bohachick, Reeder, Taylor \& Anton, 2002; Kurz \& Cavanaugh, 2001; McCurry \& Thomas, 2002; Dew et al,2004; Myaskovsky et al, 2005), for this paper a caregiver will be referred to as the person who has been identified by the patient as the one he or she relies on for assistance and care. Caregivers in lung transplantation are a unique group because the patient's illness necessitates both acute and chronic care (Lefaiver, Keough, Letiza \& Lanuza, 2009. Transplant recipients require lifelong therapy to maintain the viability of the transplanted organ, therefore these patients continue to require support from family and care givers in order to survive. (UNOS, 2012). Since lung transplantation remains an effective treatment for patients with end-stage lung disease, it is imperative that one or more 
committed caregivers become an essential component of the patient's pre- operative wellbeing and post- operative success. Patients are required to have adequate caregiver support prior to being listed for a lung transplant for assistance at home as well as transportation to tests and appointments. (Feure, Harrison, Pinson, 2002, Lanuza \& McCabe, 2001).

With the current trend in medical treatment and healthcare economics resulting in shortened hospital stays, and extended life expectations for transplant recipients, increased responsibilities are placed on the caregivers of transplant recipients (Myaskovsky, et al, 2012). However, most research on caregivers has been conducted on populations of caregivers of Alzheimer, dementia or elderly patients. Additionally, although caregivers are recognized as an integral part of patient's success with lung transplant, most research is focused on the patients undergoing transplantation rather than on their caregivers. (Parekh, Blumenthal, Babyak, 2003). The literature on caregivers of patients with lung transplantation is limited. Literature on caregivers of heart transplants and other solid organs transplants is more extensive, thus a review of these studies was necessary to understand caregivers' issues that may be common across transplantations. While there are differences in these transplant groups, these patients relate similarly to the effects of their pre-transplant diagnosis, survival rates, infection control and complications. They also experience end stage disease with concomitant anticipation for a change in health status after their transplant. It is important to examine the characteristics and experiences of caregivers of lung transplant in order to optimize the use of support or interventions to reduce negative impacts on caregiver's lifestyle and quality of life. 


\section{Caregiver's Roles}

The transplant caregivers' role begins immediately when the decision is made by the potential candidate to receive a transplant. Lung recipients are faced with a complex, detailed medical regime after transplantation. This may include taking multiple lifelong medications, performing self-monitoring, communicating changes in their condition to the transplant team in a timely manner, maintaining routine assessment and frequent follow up clinic appointments. These are few of the reasons a caregiver is important in the survival of a transplanted recipient. Both caregiver and potential transplant candidate undergo a tedious and lengthy process while awaiting a suitable donor. Caregivers provide practical and emotional support to transplant candidates during the various phases of the transplant process, and they play an integral role in ensuring successful survival outcomes. (Olbrisch, Benedict, Ashe, Levinson, et al, 2002).

Prior to receiving a transplant, the potential transplant candidates are carefully evaluated by a multidisciplinary team of physicians, nurses, psychologists, social workers and they receive a financial assessment. This is a very stressful period for both caregivers and candidates since being placed on a waiting list for a transplant is the only hope for survival. While on the waiting list the candidates and caregivers experience a period of uncertainty as they wait for an organ to become available. During this time the potential recipients' health deteriorates and both caregiver and potential candidate struggle with the issue of receiving an organ from another person, meaning "someone must die in order to live" (Meltzer \& Rodrigue, 2001). 


\section{Caregiver Role Pre-transplant}

The role of a caregiver of a lung transplant recipient differs during the pre-transplant and post-transplant period. In the pre-transplant evaluation period caregivers tend to minimize their problems and distress in fear their family member may not be listed for transplant if they admit to their concerns or problems. They may perceive the evaluation assessment as an avenue to demonstrate their incompetence and mental health rather than as an opportunity to seek support and resources to address their challenges and concerns associated with their caregiving (Goetzinger et al (2012),

The caregivers' role in the pre-transplant phase includes a variety of tasks including accompanying the candidate to and from medical appointments and diagnostic testing, resulting in the caregivers rearranging their work schedule, planning for family and other personal demands and occasionally relocating temporarily to be closer to the hospital. If the hospital is a distance away from home this separates them from their local support system and the comfort of their home. Goetzinger et al (2012), conducted a study that examined the stress and coping in caregivers of patients awaiting solid organ transplant. Participants were 621, primary caregivers of potential candidates for lung, $(n=317)$, liver $(n=147)$, heart $(n=115)$ and kidney $(n=42)$ transplant. Most the caregivers were female (73\%), married, Caucasian and the spouse of the transplant candidate. The study results

demonstrated that caregivers of solid organ transplants experienced elevated symptoms of depression and anxiety during the pre-transplant evaluation. The practical demands associated with the care rendered by the caregiver were negatively associated with caregivers' psychological well-being. Additionally, during the pre- transplant phase as the transplant candidates' practical needs increase, they become more ill and physically 
decompensated requiring more care, and caregivers tend to experience significantly more psychological distress. During the pre- transplant phase caregivers, have reported feelings of isolation, uncertainty and fear of the patient's death while waiting for an available organ (Kurz and Cavanagh 2001). Although the results of these studies provided meaningful data and information that could assist the caregivers in coping with their caregivers' role and responsibilities, the studies lack information that would improve the credibility of the results, minimize bias and subsequently enhance the generalizability of the findings. In the Goetzinger et al (2012), study the participants were self- selected, and likely may have failed to report adequately symptoms of psychological distress, because the fear of doing so may jeopardize the potential transplant patients' listing status. Caregivers who tend to under report burden or emotional stress, may not have their needs identified and they are less likely to be referred to appropriate support services. Additionally, the use of a cross sectional design did not allow for analysis of stress and coping throughout the entire transplant period. Using a longitudinal design would be useful to assess if caregivers' burden and their ability to adjust would change over time; (during pre, peri and post- transplant period). Investigating the negative consequences of transplant caregiving is important, however transplant caregivers may also experience benefits from caregiving such as feeling useful, needed and developing their inner strength. Research aimed at exploring the extent of these positive consequences/benefits of caregiving can be used to buffer the stress associated with caring for a transplant recipient. The study sample size varied by organ type, particularly kidney which was under represented in comparison to the total sample, and may influence the generalizability of the results to other populations. In comparison to the study conducted 
by Kurz \& Cavanaugh (2001), participants were recruited via letter from a transplant center or website. However, the sample was limited to heterosexual spouses with middle to high incomes and who may have had access to many resources. As a result of the participant's socioeconomic status it is possible that during the interview the participants may neglect to identify their sources of emotional distress and their coping strategies for fear of being labelled. Future research with families of lower socio-economic levels and other family members would help with the generalizability of the findings to other socioeconomic groups.

\section{Caregiver Role Post- Transplant}

When the transplant recipient is discharge from hospital there are an array of inter related and permanent post-transplant tasks and activities that the caregiver will share with the transplant recipient. These tasks include daily medications, blood pressure monitoring, dietary guidelines, physical exercises, periodic medical tests and invasive procedures such as lung biopsies. For the lung transplant caregiver, sharing this burden can be stressful which can lead to negative mental health outcomes. In a study on psychological distress among caregivers of heart transplant recipients, the Canning et al, study (1996) revealed that during the first year post- transplant the caregivers experienced a significantly higher distress level than those found in normative sample. However, after the first year the distress levels tended to return to normal and remained throughout the post-transplant phase. The authors also noted that the strongest predictors of heightened distress during the early post-transplant period were related to the caregiver's employment status, perceived time constraints imposed by caregiving and the quality and relationship with the recipient. These predictors all involve potentially negative 
constraints and high distress levels. Unemployed caregivers felt that caregiving intruded on their personal domain and perceived their relationship with the recipients to be poor

During the post transplantation phase the transplant recipients' emotional and physical well-being is enhanced by the stability and availability of a caregiver. Caregivers assume daily activities that were once the responsibilities of the recipient. They are sometimes forced to relinquish social activities and employment in order to immerse themselves in care of the recipient. Before and during the transplant process caregivers' health needs and psychological well-being are sometimes overlooked as the patient's health issues take precedence as the primary focus. Dealing with the patients' worsening health and increasing functional disability now become the caregiver's top priority. They often disregard their own needs, experience high levels of burden and are more susceptible to psychological distress, depression, interpersonal conflicts and somatic symptoms. Following transplant, caregivers continue to provide emotional and practical care to patients. Distress and psychological adjustment concerns may persist among the caregivers particularly in the early postoperative period (Goetzinger, Blumenthal, O'Hayer, Babyak et al, 2012).

Closely monitoring the recipient's health status, ensuring optimal compliance with medications and life style changes, communicating regularly with the transplant team, being an advocate for the recipients, providing transportation to and from clinics and providing emotional support are some of the responsibilities that are assumed by these caregivers during the post- transplant period. The care provided by the caregivers are always comforting to the recipients, however it can be physically and psychologically demanding, hence adversely affecting the caregiver's life. This eventually compromises 
the caregiver's health status and in turn adversely affects the quality of care provided by the caregiver. Rodriquez \& Baz, (2007) indicated that caregiver's exposure to the chronic stresses of caregiving and transplantation may cause caregivers to experience a lower quality of life than non- caring adults. Additionally, caregivers may feel confined and inconvenienced, because of the demand to be available to help their loved one at all times. Although performing the caregivers' activities can be gratifying, adjusting to changing family dynamics, additional household responsibilities and job related capacities associated with transplant may mask the discrete burden of caring as caregiver's report spending less of their day in a positive mood as compared to the recipient (Rodrigue, Widows \& Baz, 2007). Alternately, some caregivers reported positive outcomes of caregiving such as discovering inner strength and support from others and realizing the important things in life. (Rodrigue, Baz, 2007)

\section{Spouse as Caregiver}

The experience of a spouse performing the role of a transplant caregiver has been explored by several researchers with mixed results. Rodrigue \& Baz, (2007), examined caregiving strain, benefit and social intimacy among 73 spousal caregivers of lung transplant recipients. Participants were spousal caregivers who were predominantly white, high school graduates and employed with a mean age of 48.3 years. Perceptions of general health, caregiver's quality of life, the caregiver strain, and social Intimacy were measured between the spouse and the potential candidates. Results indicated that spousal caregivers were more negatively affected by the caregiving demands than caregivers who may be parents, adult children or siblings. Additional they also found that these caregivers experience significant impairment in social functioning and those with high 
levels of caregiver strain are likely to be more emotionally distressed as well. Although these findings indicated that spousal caregivers were negatively affected by the demands of caregiving, using a sample that was not restricted to spouse caregivers would be helpful. Such findings may differ with a more heterogeneous group of caregivers that includes adult children, parent, siblings, and extended family members. Although the participation rate was high, the spouses were self- selected and these findings may be biased toward those with lower-levels of psychological distress. Using a cross sectional design did not permit examining caregivers' adjustment changes throughout the entire transplant experience.

Saxe-Braithwaite, and Chapman (1992) used a grounded theory method to study the experience of 5 support persons caring for a lung transplant recipient. In their study, the support persons were a mother, son, a husband and two wives. Support persons described their experiences as "Life on Hold", with the support persons going through 5 phases of the transplant process; pre-acceptance, assessment, pre-transplant, post-transplant and convalescence. Findings revealed that the support persons often rearranged their lives to focus their attention solely on the care of the transplant recipient. Similar findings were reported by Kurz (2001) in his study on well spouses as caregivers after a lung transplantation. In this qualitative study the researcher analyzed transcripts of telephone interviews of 12 spouses of lung transplant recipients exploring their experiences after a partners' lung transplant. Study results suggested that there was an overriding theme among the caregivers' experiences described as a "Roller Coaster Ride". They progressed through five phases: the transplant event, cocooning, normalizing, branching out and settling down. The spouses described their experience as "ups and downs" while caring 
for the transplant recipient and at the same time appreciating their moments and togetherness with the recipients and findings ways to cope with the negative consequences. The spouses indicated their intent to stay healthy because they were needed to care for the patient and they felt that they and the recipients were a team committed to care for each other (Kurtz, 2001). Although the spouses felt togetherness with the recipient they still experienced feelings of loneliness with the perception that others were not interested in their welfare, concerns or questions.

Spouses who are caregivers of transplant recipients report a variety of concerns in regard to assisting and the administration of medications after transplant. McCurry \& Thomas (2002), in their qualitative study explored the lived experiences of spouses of heart transplant recipients. A purposeful sampling technique was used to recruit seven, English speaking female spouses whose husbands were heart recipients. Ages of the participants ranged from 43-65, with years of education between 11- 16 years. The time of marriage was less than 1 year to 47 years. The transplanted recipients received their transplant an average of 4.5 years prior to the study. Data were obtained via in-depth interview; transcripts were analyzed and various themes emerged. Main themes were changes in roles in regards to medication administration, and changes in the recipient's personalities and demeanors. According to the wives their spouses has been laid back, relaxed but suddenly the effect of the medication had changed them into in "animals", with frequent temper tantrums.

According to Olbrisch, Benedict, Ashe \& Levenson, 2002, spouses reported compromised quality of life in comparison to a normative sample (non- spousal caregivers). In the study conducted by Kurz \& Cavanaugh in 2001, on the stress and 
coping strategies used by well spouses of lung transplant recipients, a total of 13 spouses, eight women and five men participated. All were white, non- Hispanics with ages ranging from 36-67years. Study results indicated that the major stressors reported by the spouses fell into several groups. The waiting and the unknown future, work, insurance, routine responsibilities, ongoing demands of relationships with families and the partner's decline in health. The most stressful part of the caregiving experience reported by the spouse was waiting and not knowing.

Meltzer \& Rodrigue, in (2001), conducted a study on psychological distress in caregivers of lung and liver transplant recipients. In their study a total of 52 caregivers, 11 males and 41 females participated. The majority of participants were white (85\%) and (78\%) were married. The results of this study suggested that caregivers experience both benefits and stressors related to caring for a transplant recipient. The most common stressors reported by the caregivers were the uncertainty of the post treatment expectations, the waiting period, fears and worry. Kurz \& Cavanaugh in (2001) found that caregivers were frequently relinquishing desired activities and took on additional responsibilities to care for the transplant recipient. Some caregivers considered their jobs as a "breath of fresh air" while others considered them as stressful. These researchers used their qualitative research to explore the coping skills related to stress affecting spouses of lung transplant candidates. Participants were five spouses from the transplant center and eight from the Internet. All participants were Caucasian, U.S citizens and English Speaking. Their mean age was 44, they had an average of 15 years education and were married between 15-43 years. The authors reported positive aspects for caregiving including support of-family and friends, learning to cope with unpredictably, and growing 
closer to recipients. Meltzer \& Rodrigue (2001) identified the benefit of caregiving as merely helping the patient. Authors also noted that although caregiving is generally reported as positive experience for couples, there are some negative aspects reported as well (Kurz \& Cavanaugh, 2001). Spousal caregiving of transplanted recipients often requires the caregivers needing physical and psychosocial assistance in performing some of the daily required tasks or assistance in maintaining their own energy and comfort levels (Kurz, 2002). Adhering to the rigid time schedule for medications, laboratory tests, and doctor visits as well as meeting the daily needs of the transplant recipients can be stressful and exhausting. This is especially true for the older transplant recipients which means that their spouses who are the caregivers are old as well (UNOS, 2015).

\section{Caregivers' Burden}

Burden is a unique domain of the caring experience. Pearlin et al (1990), defined burden as primary stressors affected by caregiver's history, socioeconomic characteristics and eventually affected outcomes such as depression and physical health. Montgomery, (1989) defined burden as a consequence of caregiving, including stress effects, caregiving consequences and the caregiving act. Caregivers' burden is a multidimensional phenomenon that includes physical, psycho emotional, social and financial consequences of caring for a family member (George, Gwyther, 1986). Caregivers' stress or burden is a response to the physical, mental emotional, social, financial stress that is associated with giving care to someone with a long-term illness and this can result in impaired physical health and depression (Alspack, 2009, Lefaiver et al, 2009 \& Nguyen, 2009). Multiple psychological variables can affect caregiver's emotional well-being, which in turn, may indirectly affect the recipient's overall health and adjustment 
(Canning et al, 1996) These variables include depression, stress, social support, and role function changes, family disturbances, low martial quality, illness related coping styles and quality of perceived social support. In this review caregiver burden was viewed as subjective and objective burden. Subjective burden is associated with the emotional cost, caregivers' attitude and the emotional reaction to caregiving, Objective burden is the disruption in the caregiver's life as well as tasks and activities related to providing care.

Caregivers play an integral part in facilitating successful transplant outcomes through the provision of care and emotional support to patients during the various phases of the transplant process (Obrist, Benedict, Ashe Levinson, 20002). While trying to balance the patient's care needs and trying to maintain a healthy life style the caregivers may be faced with challenging situations. Caring for the lung transplant recipients is similar to caring for chronic ill family members. It is regarded as demanding and stressful as caregivers report more somatic complaints and greater affective disorders when compared to non-caregivers (Pinguart, Sorensen, 2003, Rodrique \& Baz, 2007).

Rodrique \& Baz (2007), in a cross-sectional study with 73 spousal lung transplant caregivers attempted to assess the caregivers' quality of life, mood, caregiving strain and benefit, social of spouses while waiting for a lung transplantation. The caregiver's demographic revealed a mean age of 48.3 years, with more than half $(66 \%)$ were white. Gender was equal between male and female. $50 \%$ of the caregivers were employed. The most common lung diagnosis was COPD (35\%) followed by Pulmonary Fibrosis (12\%) and Alpha - Antritrypsin deficiency (12\%). The caregivers completed the SF-36 Health Survey, The Profile of Mood State, Caregiver Strain Index, Caregiver Benefit index and Miller Social Intimacy Scale. The researchers found that relative to the normative sample, 
spouses reported significantly lower physical $(\mathrm{z}=4.01, \mathrm{p}<0.001)$ and emotional $(\mathrm{z}=7.01$, $\mathrm{p}<0.001)$ quality of life. However, over half $(52 \%)$ had clinically elevated caregiving strain. Other factors that contributed most to the caregiver's strain were heightened physical strain (80\%), inconvenience (79.5\%), feeling confined (72.7\%), while discovering inner strength (60.3\%), support from others (53.4\%), and realizing what is important in life $(42.5 \%)$ were contributors to the caregiver's benefits. Higher caregiving strain was associated with more overall emotional distress ( $r=-0.39, \mathrm{p}<0.002)$, and less social intimacy between spouse and the patients $(\mathrm{r}=-0.37, \mathrm{p}<0.002)$, and longer disease duration $(\mathrm{r}=.55, \mathrm{p}<0.001)$. In concluding the researchers suggested that the findings from their study highlighted the need to develop effective interventions to reduce caregiver strain and emotional distress, especially during the pre- transplant phase.

Pinquart \& Sorenson, (2003), undertook a meta-analysis of articles to evaluate the differences between caregivers and non-caregivers in psychological and physical health. In this meta-analysis, the authors integrated results from 84 articles on the differences between caregivers and non-caregivers perceived stress, depression, general subjective wellbeing, physical health and self-efficacy. The results of the meta-analysis revealed that caregivers fare worse than non-caregivers. Caregivers were more stressed ( $\mathrm{g}=.55)$, depressed $(\mathrm{g}=.58)$ they had lower self-efficacy $(\mathrm{g}=.54)$ and lower levels of subjective well- being and physical health. In concluding, the authors suggested that the differences between caregivers and non -caregivers were greater among caregivers for stress, selfefficacy, depression and subjective wellbeing and physical health because the stress indicates immediate negative effects of caregiving on the caregivers. 
Chappel \& Reid (2002), conducted a quantitative research on burden and wellbeing among caregivers examining the distinction. Sample consisted of 243 caregivers who provided care dementia and non-dementia care recipients. The mean age of caregivers was 51.2 years, and only (28\%) resided with the care recipients. More than half $(67 \%)$ of caregivers were female and (56\%) of caregivers were employed. The results from the study indicated that caregivers who are distressed commonly report feelings of exhaustion, being overwhelmed, angry, resentful, depressed and anxious. The number of hours of informal care had a direct effect on the caregiver's burden, increased in caregiving hours leads directly to caregiver's burden. In concluding the researchers noted that caregivers of patients with chronic illness such as dementia who tend to exhibit behavioral problems, the behavior can be a primary determinant of caregiver burden.

Sadala et al, (2013), examined the experiences of primary caregivers of heart transplant recipients using a phenomenology approach and in depth interviews with 11 caregivers of heart transplant recipients. The participants were female, married, white and were high school graduates with a mean age of 48 years. Three main themes were identified: the heart transplant world; perceptions of themselves within the heart transplant experience and the relationships with others; the recipient, family members and health care providers. Results indicated that following a transplant, caregiver lives changes drastically and their priority became providing care for their relative. Although the transplant was a success the caregivers feeling of joy is sometimes marred by feelings of uncertainty about the recipient's future, generating significant permanent distress and anxiety among the caregivers. However, some caregivers indicated they had positive perceptions and were able to return to normalization of their life. 
In a mixed method study of psychological distress in caregivers of 28 liver and 24 lung transplant recipients, Meltzer and Rodrigue (2001) measured the relationship among quality of life domains, caregiver strain and psychological distress. Their result indicated caregivers experienced both benefits and stressors from caring for a transplant recipient. This finding was supported by other researchers (Mishel \& Murdaugh, 1987, SaxeBraithwaite, 1992) who reported the most common benefit for being a caregiver was "Helping the Patient "which included physical, financial and emotional help. The most common stressors reported were associated with uncertainty, fears and waiting. Results also indicated that caregivers of liver transplant recipients experienced more caregiver strain than caregivers of lung transplant recipients. Caregiver social functioning was found to be the only significant predictor of caregiver stress with those caregivers who reported greater distress also reporting extreme and frequent interference with normal social activities.

In a retrospective study conducted by Ullrich et al (2004), 39 caregivers; 22 cystic fibrosis and 17 non-cystic fibrosis caregivers explored the experience of the support persons involved in a lung transplant program. The mean age of caregivers of cystic fibrosis patients was 55years and for non-cystic fibrosis patients it was 54. Data were obtained using open ended questionnaires and Likert- type questions on retrospective surveys specific to the recipients or family members. Most of the support persons or caregivers were female. Results indicated that during the post-transplant phase caregivers had significantly more stress than during the waiting period $(\mathrm{p}<0.01)$. Activities reported as burdensome included using vacation time, arranging accommodations, frequent traveling to appointments, and or loss of income in order to stay with the recipient during 
inpatient hospital stay. Caregivers thought that improvement in communications between caregiver and medical staff, access to a social worker and psychological support, and need for information on medications and treatments during the pre-transplant and acute hospitalization would help to alleviate fears and help with their coping ability.

Claar et al, (2005), conducted a study on emotional distress and quality of life in caregivers of patients awaiting lung transplant. A sample of 82 lung transplant caregivers and recipients participated in the study, 65 females and 17 males. The mean age of caregivers and transplant recipients was 47 and 49 respectively. The majority of participants were female, Caucasian and unmarried. The cognitive, affective and somatic symptoms of depression, levels of anxiety, emotional burden and quality of life of caregivers and recipients were measured. Of the 82 caregivers, $14 \%$ reported clinically significant levels of depression and only 2 (2.4\%) clinically significant levels of anxiety. Passive coping strategies such resignation and avoidance were associated with higher levels of emotional distress. Resignation was significantly associated with increased depression, while avoidance was associated with increased anxiety. Caregivers who reported greater perceived caregiver burden experienced higher levels of depression. Caregivers would benefit from adaptive coping strategies such as problem solving, acceptance or positive reappraisal as indicated in these coping strategies are associated with less emotional distress.

In another study Myaskovsky et al. (2005) investigated the quality of life and coping strategies among 114 lung transplant candidates and their caregivers. Approximately half of the sample was females with ages greater than 50 years old. Ninety one percent of participants were European-American and half of the sample had less than a high school 
education. The caregivers coping strategies and quality of life were measured. In this dyad sample of 114 patients and caregivers the researchers noted that there were multiple relationships identified between the patients and their caregivers for quality of life and coping strategies. Canonical correlations between caregivers and patient quality of life showed significantly poorer values on the subscales of general health, physical functioning, vitality, and bodily pain for caregivers. Additionally, caregivers' inability to emotionally cope with caregivers' burden also resulted in poorer quality of life generally reflected in their health, vitality, and social functioning. In this study $90 \%$ of the sample was European American, and generalizing findings to other ethnic groups may not be prudent.

Caregivers who are overly invested in their caregiver role may experience greater burden following the recipient's transplant, more so if the recipients attain independence. Hence in such situations caregivers' behaviors that were previously perceived as protective may be deemed unwanted and subsequently create caregivers' strain (Wicks et al, 1998). Although there is improvement in health status and quality of life following lung transplant, caregiver burden and diminished caregivers' quality of life may persist when there is dissonance between the caregiver and the care recipient (Wicks, et al, 1998). Caregivers may experience burnout as a result of coping with the conflicting demands of work, family and household obligations. In experiencing the loss of personal time, a strain is placed on family relationships with the potential to diminish caregivers 'quality of life, while increasing their burden.

Wicks et al, (1998), investigated the family caregivers' burden, quality of life and health following patients' renal transplantation. Most of the caregivers was spouses 
(62\%), females (76\%), employed (67\%), and lived with the patient (79\%). Almost equal numbers of African-American (54\%) and Caucasian (46\%) caregivers participated in the study. The authors measured the caregiver's subjective responses to caregiving and caregiver's perception of health. The results indicated that in general caregivers reported mild to moderate burden. Additionally, the researchers also noted that the caregivers reported experiencing increased burden when the expectations for improvement in the recipient's health did not materialize or were significantly delayed by post- transplant complications. The caregivers also reported "sadness" about no longer being needed by their family member who now spent significant amounts of time away from home. In contrast, improved health of the recipient increased his/her independence and subsequently resulted in perceived loss of togetherness by the caregiver. Hence a caregiver who is significantly invested in the caregiving role is at risk caregivers' burden when the recipient no longer requires assistance.

The stress from caring occurs when the caregiver perceives his/her abilities, knowledge and skills are not sufficient to deal with a situation faced by the recipient. Lung transplant recipients and their caregivers are faced with chronic stressors such as the unpredictability of graft survival and susceptibility to infections, rejections, cancers and other complications of transplant. Due to the complex, intense and stringent nature in managing the lung transplant recipient's health, caregiving is considered a burdensome task which can intrude on the caregivers quality of life (Xu et al, 2012).The effects of chronic stress of caregiving can negatively affect the caregivers' health, performance of self- care behavior to promote their own health or manage their own health problems and overload caregivers' survival The caregivers' overload and appraisal of the immediate 
impact of care related stress on his/her time and energy such as caring for a recipient with complex medical regimens, can negatively affect the caregivers' health (Son, Emo, Dennis, 2007,Vitaliano et al, 2003, Zhang et al, 2006) .

Son et al (2007), examined the impact of two caregiving stressors, care receivers' behavior problems (an objective stressor) and caregivers' feeling of feelings of overload (a subjective stressor) on three dimensions of caregiver's health. The participants were 234 caregivers of elderly relatives with dementia. Mean age the caregivers was 62.7 years. The majority of the caregivers were female (79.5\%), white (86.3\%) while approximately $56 \%$ of the care receivers were female and (85.6\%) were white. Caregivers have been assisting their relatives for an average of 33 months. The authors used the Weekly Record of Behavior developed by Family CARES to measure the behavioral problems of patient with dementia and the caregiver's health measures and self-reported health, caregivers stress, caregiver's wellbeing were measure by scale developed guided by Pearlin's stress model. The result from the study revealed that the higher level of both objective and subjective stressors were associated with caregiver's health, poorer self-reported health, more negative health and greater use of health services among the caregivers. The association between objective stressors and health was mediated by caregiver's feelings of overload.

$\mathrm{Xu}$ et al in 2012 conducted a study consisting of 21 recipients and their caregivers to explore the daily burdens of recipients and caregivers of lung transplant. Both caregivers and recipients were predominantly females, $57 \%$ and $52 \%$ respectively. Mean age for caregivers was 55.9 years and mean age for recipients was 52.3 years. Ninety-one percent of participants were white and $82 \%$ were spouses of the recipients. The caregiver's 
perception of their quality of life and the impact of the disease and its burden on functional performance were measured. The results of the study demonstrated that both caregivers and recipients demonstrated a mixture of both positive and negative emotions. The recipients reported spending a greater portion of their day in a better mood than the caregivers. Caregivers associated more positive emotions with the performance of activities more than the recipients. The tendency for the recipients to report their positive mood is highly consistent with the elation most recipients experience during their first few months at home after the transplant (DeVito et al, 2004). Caregivers reported positive emotions more often, yet they reported lower overall daily mood. This supports results of previous studies which indicate the caregiving task was typically rewarding for caregivers, but generally care giving in combination with the caregivers' roles and responsibilities can take its toll on the caregiver's quality of life. Low overall caregiver daily mood may also be attributed to the management of complex home regimes and changing family dynamics (Dew et al, 2004, Myaskovsky, 2006, Teichman et al, 2000).

Poor physical health, sleep disturbances, elevated distress, decline in role performance and poor quality of life are associated with increased caregivers' burden among caregivers of lung transplant recipients. (Dew, et al, 2004). Other sources of caregiver's burden experienced by the lung recipients' caregivers include changes in the roles and responsibilities at home, time constraints at home and leisure activities, heightened worry and concern about the recipients' health, social and emotional isolation and financial stress (Dew et al, 2004). Caregivers also reported moderate levels of financial burden related to caring for a lung transplant recipient. The impact of the financial burden is significant and negatively correlated with the overall quality of life of 
the caregivers. The financial burden of transplant is evident particularly after transplant because the medications that the recipients take for survival are very expensive. The degree of caregiver burden experienced is a key mediator in a complex relationship between the recipients and the caregivers' risk factors such as demographics, care situation, social support, duration of caring, patient caregiver relationship and functional impairment and the transplant outcomes (Gaugler et al, 2011). According to Etters et al, (2008) and Pinquart and Sorensen, (2011), the duration of the patient's illness or symptoms, such as behavioral disturbances or activities of daily living, caregiver's relationship with the patient and caregiver's age and gender are related to higher subjective burden. The impact of the financial burden is significantly and negatively correlated with overall quality of life of the caregivers.

\section{Financial Challenges of Caregivers of Lung Transplant Recipients.}

Caregivers providing care to older adult patients, patients with chronic illness and transplant recipients provide care and support in health, social emotional and financial domains, particularly for those who have chronic diseases or who are severely immunocompromised such as transplant recipients (Koh \& McDonald, 2006). While caregivers act as a safety net for family members, research findings consistently indicate the financial costs association with caregiving were a significant factor in caregiving burden (Pinquart and Sorensen, 2011, Acton \& Kang, 2001).

Caregiving affects a caregiver's work and family financial such as balancing a job and providing care to family members (Lai, 2012, Haddock et al, 2006). The financial cost refers to the direct momentary cost related to paying for the caregiving expenses while some are related to the foregone financial or monetary loss in employment due to one 
having to perform a caregiving role. However, not all cost can be measured by momentary values as some of these costs are indicated by the caregivers as perceived financial costs (Lai, 2012). According to the Metropolitan Life Insurance Company, (1999), research findings in the United States estimated significant cost of caregiving to employers, due lost productivity, and for caregivers due to loss of income. In comparison to non-caregivers, caregivers often have to take more time off from work, were interrupted at work more often regarding care recipient's needs, missed more days at work, took more time off without pay and ultimately worked fewer hours than desired (Schultz et al, 2003). Additionally, caregivers may miss out on career advancement and promotion opportunities because of their caregiving obligations at home, while some leave the job to focus more on caring for their loved ones. The financial status of the caregiver can also be affected by the daily cost of caregiving such as expenses incurred from transportation to clinical appointments, nonprescription and prescription medications for caregivers, increased visits to doctors because of increased incidence of illness such as hypertension, depression, medical supplies and equipment's (oxygen, spirometer, blood pressure and blood glucose monitoring devices (Decima Research, 2002, Hollander et al, 2009)

Lai (2012), conducted a quantitative study that examined the effects of financial cost on caregiving burden of family caregivers of older adults. The study participants were randomly selected. A total of 680 participants were included in the study. Over half (52\%) of the participants were caregivers between 35 and 54 years and most (72\%) caregivers were female. About three quarters (73\%) were married ,41\% reported being employed full time and (46.8\%) reported a personal income of CAD \$20,000 to CAD 
$\$ 40,000$. The caregiver's burden was measured with the Zarit burden Item Interview. Cost of Care Index was used to measure effects of caregiving on financial cost of caring for a family member and the Instrumental Activities of Daily Living Scale was used to measure the caregiving task and workloads provided to the care recipients. The authors noted that the results of their study were consistent with other findings indicating that the traditional roles of the caregiver were often expected and performed by a female. Higher levels of caregiving burden experienced by females included the multiple caregiving roles of women and other gender related challenges such as spending more time with care recipients and spending more time and money on physical psychological and health care. (Zhan, Montegomery, 2003, Schultz et al, 2000), Caregivers with higher educational levels are engaged in employment that could be more demanding. This may result in higher levels of stress in combination with caregiving responsibilities resulting in caregiver's spending money for doctor visits and medication to help cope with these stressful situation (Lai, 2012, Stolley et al 2002).

Aoun et al, (2005), conducted a literature review on caregiving for the terminally ill and the associated cost to caregivers. This literature review describes the nature and the extent of the impact of caregiving on the physical, psychosocial and economic aspects of the caregivers' life.

Results indicated that economic costs associated with caregiving have negative implications for the well-being and health of family caregivers. There was indirect cost incurred by caregivers as a result of their caregiving role. These included costs relating to lost employment opportunities, cultural obligations and personal costs related to care recipient's health and well-being. Caregivers who were in paid work were often forced to 
participate in caring tasks around work, negotiating to work from home, using up annual leave and sick leave or taking unpaid leave. Occasionally, caregivers were forced to give up paid work to care; others had their benefits cut because they were unable to actively look for work because of the caregiving responsibilities. While self-employment may allow for some flexibility there were no paid leave provisions. Caregivers also reported incurred costs included physical therapy as a result of back injuries from lifting their family member. Other conditions such as anxiety, depression and insomnia associated with caregiving could also incur financial costs for family doctor visits, and medications needed during the period of providing care. Other direct costs include caregivers paying for services for care recipients included parking and transport costs related to their family member's hospital appointments and admissions. Costs of caregiving can have significant effects on the caregiver's financial status resulting in debt or even bankruptcy. Direct costs including providing transport, food and medication and indirect costs, related to employment, cultural needs and caregivers 'own health, are factors that can adversely effects the caregiver's financial status (Merrny et al, 2012).

For transplant caregivers, the transplant process requires the caregiver to decrease, suspend or end their work, leading to a reduction in or loss of income. Additionally, if the recipient requires copious assistance or supervision, the caregiver may have to terminate employment. Consequently, the caregivers are forced to relinquish their jobs to assume the responsibilities of caring for the recipients. This in turn can negatively affect the household economic status and ultimately result in a household economic burden on both recipients and families. Therefore, a family with a member involved in lung transplantation will likely be faced with an increased financial burden resulting from the 
unemployment of two family members. These situations can adversely affect the quality of life of both caregivers and recipients through a decrease in their work and financial stability (Rianer et al 2010). Along with the cost of regular follow up visits and the necessary immunosuppressive therapy, the expense of readmissions to the hospital for management of complications and infections can be high. This sometimes becomes the financial responsibility of the caregiver. Other costs may include travel, lodging and meals whenever the recipient goes to the transplant center for follow visits or evaluation. The frequent follow up visits may also require a significant amount of uncompensated time away from work for the transplant caregivers resulting in loss of wages

\section{Caregivers' Gender}

Though the long term emotional and physical health consequences of providing care to solid organ transplant recipients has been explored, there is a great deal of variability in levels of distress among caregivers of transplant patients. Gender appears to be an important predictor of this variability, (Schulz, Sherwood, 2008, Vitaliano et al, 2003).

Yee \& Schulz, (2000) conducted a meta-analysis on the gender difference in psychiatric morbidity among caregivers. The author's goal was to review and synthesis the research on caregivers' gender and psychiatric morbidity among females and male caregivers with the aim of answering theses three questions :a) Is there any greater psychiatric morbidity among female than male caregivers) in their study examining gender differences in psychiatric morbidity among transplant caregivers, b)is the excess psychiatric morbidity among female caregivers attributable to caregivers and c) what factors in the caregiving situation contribute to the excessive psychiatric morbidity among female caregivers?. The authors reviewed 30 articles with gender the main focus 
of investigation and the results reported on the gender differences in psychiatric morbidity or factors in the caregiving experiences that account for gender differences along with psychiatric morbidity (such as caregiver burden, role strain, caregiving task performance). The result of most of the studies indicated women caregivers report higher levels of depression and depression and lower levels of life satisfaction than men caregivers. The excess psychiatric morbidity among women caregivers is in part attributed to the caregiving experiences as evidence by the larger depression scores of female caregiver and non-caregiving females. Because women tend to respond differently during stressful situation they are more susceptible to psychiatric morbidity. In conclusion, the researchers noted that women face more caregiving demands than men and they spend more time performing more involved day to day caregiving task than men such as house work and personal care.

Holtzman, Abbey, Singer, Ross \& Stewart in 2011 conducted a study on 93 patient caregiver dyads, to assess patient and caregiver gender effecting symptoms among organ transplant caregivers. Most the caregivers were spouses (72\%), followed by children (14\%), siblings (3\%) and aunts (1\%). The median ages for both recipients and caregivers were 57 years and 42 years respectively. Eighty-eight percent of recipients were Caucasian and $83 \%$ had at least high school education. Results indicated women who were caring for a family member on a waiting list for an organ transplant were at greater risk for depressive symptoms than male. The fact that the women caring for men were at greater risk for depression could not be explained by the nature of the caregiver-patient relationship in this study. That is, depressive symptoms were similarly elevated among women caring for their husbands and women caring for their sons, brothers and fathers. 
Additionally, they also found that women caring for men experienced lower levels of support from their family members and more negative health impact of caregiving. Being a female caregiver of a male transplant candidate was not confounded by age, employment, marital status, duration of caregiving, or patient diagnosis. Navaie-Wailser et al, (2002), suggested that female caregivers may forego respite and social activities in favor of caregiving tasks which may further contribute to the feeling of isolation and lack of support. The perceived lack of family support was noted to be a significant mediator of gender differences in caregiver distress. Since caregiving has traditionally viewed as a female role, men may be more likely to seek and receive assistance when they become a primary caregiver. In contrast family members, may assume that the female caregivers do not require as much assistance because they are expected to be more skilled at providing the care and are more experienced.

The result also indicated that female caregivers had elevated depression scores especially when caring for a male patient $(10.92+-6.83 ; n=48)$. Women caring for other women reported mean depressive symptoms $(8.33+-6.38 ; n=12)$, men caring for women $(7.97+-$ $5.86 ; n=30)$ and men caring for men $(8.00+-5.57 ; n=3)$. In this study, the number of same sex patient-caregiver dyads was small, women caring for women $(\mathrm{n}=12)$, men caring for men $(n=3)$, total of 15 . Thus, the authors were unable to obtain a clear understanding of the same sex partner-caregiver dyads. The sample size prevented the authors from examining factors that had previously been shown to predict depression among male caregivers such as age, socio-economic status, gender and identity (Carpenter \& Miller, 2002). The results from this study suggest that women providing care to male patients may experience higher levels of depression than male caregivers. 
This result shows the need for additional research targeted toward using a more dyadic and contextual approach to study caregiver's distress.

In Lefaiver et al (2009) study, on the quality of life in caregivers providing care for lung transplant caregivers the authors cited caregiver's difference among the sexes. Their study results demonstrated that there were differences between male and female caregivers in the level of tension and confusion while providing care. Male caregivers reported significantly higher levels of tension than female caregivers. The reason for male caregivers increased tension was that they had full time responsibilities at work in addition to caring for a lung transplant recipient. This increased tension may lead to confusion, inability to concentrate, forgetfulness and uncertainty about things which can later complicate the care provided by these male caregivers. The sample characteristics and small size limit the generalizability of the findings. The caregiver sample characteristics, including being white and well-educated with a higher than average income may represent the lung transplant caregivers' population, however, it may be difficult to relate these findings to other caregiving populations demographically.

\section{Caregivers' Health.}

. The issue of caregiver health is important because the well-being of the transplant recipient depends on the care they receive from their caregiver. Caregiver's impaired quality of life and poor health status may lead to negative downstream consequences for the transplant recipient including problems with adherence and increased risk for morbidities and mortality. A caregiver's impaired health status and or poor quality of life can affect the care that is provided to the recipient. (Pinquart and Sorensen, 2003, Kurz, 2001, Collins et al, 2000). Multiple psychological variables such as depression, stress, 
social support and role function changes can affect caregivers' emotional well-being and this can in turn directly affect the caregivers and recipient's health (Canning et al, 1996). Dew et al, (1998) and Canning, (1996) in their studies assessing psychological distress among caregivers of heart transplant recipients and profiles of physical health of caregivers of lung transplants respectively found that decline in caregiver health is related to family mental health history and initial health perceptions and quality of life among these groups of caregivers.

Lefaiver et al, (2009), study the quality of life in caregivers providing care for lung transplant candidates. This descriptive correlational study explores the relationship among the health status of caregivers of lung transplant candidates, caregiver's reactions to caregiving and caregiver's perceptions of life. A convenient sample of 29 dyads of lung transplant candidates and their caregivers were recruited from a Mid-western medical center. Mean age for caregivers and candidates were 50.43 years and 52.72 years respectively. $66 \%$ of study participants were female. Majority of the lung transplant candidates were spouses $(69 \%)$ and $(76 \%)$ of transplant caregivers lived with the transplant candidate. $79 \%$ of the lung transplant caregivers work fulltime and only $17 \%$ of lung transplant candidates worked. The caregivers of the lung transplant candidates completed the Quality of Life Index, Caregiver Reaction assessment, SF-12 Health Short Form and the Profile of Mood States Short Form. The results from the study had shown that caregivers reported favorable quality of life, physical health, mood during the pretransplant waiting phase. However, during this time the caregivers are faced with, fatigue, depression, and the financial impact of the transplant. Depression, caregiver general health, impact of finances and lack of family support had the greatest effect on 
caregiver's quality of life. Caregivers are expected to provide complex care to transplant recipients with little preparation or support.

van Ryn et al (2011), examined objective burden, resources, and other stressors among a total of 677 informal caregivers of lung and colorectal cancer patients. Over half $(63 \%, n=426)$ of the caregivers were married to the patient ( $50 \%$ wives, $13 \%$ husband), while $12 \%(n=83)$ were adult children of the patient (10\% daughters, $2 \%$ sons). Twentyfive percent of the caregivers $(n=167)$ had other relationships to the patient, primarily other family members. Most of the caregivers were women (79\%), and white (75\%) and married (79\%). Caregivers ranged in age from 21 to 80, with most of the sample $(67 \%$, $\mathrm{n}=433$ ) under age 65 . Most caregivers had at least a high school education. The results of this study also suggested that the relationship between objective burden and caregiver mental health and physical health outcomes were found to vary by caregiver resources. The effect of stress on the psychological domain of quality of life will increase emotional distress, anxiety, depression, feelings of helplessness and loss of control and difficulties in coping with the caregiving role Caregivers with significant coping, social, and material resources are less likely to suffer deleterious consequences psychotic behaviors as a result of caregiver demands, while those with few resources are at elevated risk.

Some researchers have suggested that the lack of social support was found to profoundly affect caregivers' health. The lack of family support has been shown to be an important predictor of the family caregiver's health (Tang \& Li, 2008,)

Tang \& Li, (2008) in their prospective longitudinal they examined the trajectory and determinants of the quality of life among 253 caregivers of terminally ill cancer patients. A convenient sampling method was used. The caregivers completed the Caregiver 
Quality of life Index, Antonovsky Scale and the Caregiver Reaction Assessment. Most caregivers were female (68.3\%), married (88.6\%), (74.9\%), living with the patient (74.9\%), (57.8\%) and with an educational level equal to or higher than high school). The mean age of the caregivers was 50.3yearsand the mean age of the care recipient was 65 years. The results from the study indicated that caregiving can take a toll the caregivers; quality of life and causes it to deteriorate significantly over time. This deterioration of a caregivers' quality of life reflects the patient's increasing distress from symptoms, the gradual loss of confidence in caregiving and an increased subjective caregiving burden on the caregivers as the care recipients intensifies or requires more caregiver's involvement. Family support includes feeling loved, feeling that one can count on others, and having a network that is able to provide support in times of need. Caregivers with family support would have time to rest, and restore their energy and health which may help to decrease their depression level and lessen the impact on their health (Tang \& Li, 2008).

Myaskovsky et al in 2012 conducted a study on the Predictors and Outcomes of Health-Related Quality of Life in Caregivers of Cardiothoracic Transplant Recipients. Their study consisted of caregivers of 242 cardiothoracic transplant recipients (lung=134, heart =108), from the University of Pittsburgh Medical Center. Participants were predominantly female and the majority was less than 50 years old. Approximately $92 \%$ of participants were European American and $88 \%$ had less than a high school education. The researchers found that caregiver's quality of life was generally high in the first-year post- transplant with two exceptions and their physical functioning and bodily pain worsened over time. Also, noted by the researchers were several demographics factors, psychosocial resources and caregiver burden variables that significantly predicted the 
caregivers' health related quality of life by the end of the first year, which were responsible for effects on the outcomes. The researchers found that the-younger age, greater optimism, a stronger sense of mastery, lower activity impairment and less perceived personal burden were each independently associated with different aspects of the caregivers' health related quality of life. Overall, greater burden predicted poorer caregiver health related quality of life in the first-year post -transplant. Transplant recipients whose caregivers had lower perceived general health at 12 months' posttransplant had shown poorer survival rates during the 7 years of subsequent follow up care.

Greater impairment in caregiver health perceptions at the end of the first year predicted poorer recipient survival independent of the patient's own health status. The authors speculated that this may occur as caregivers with perceptions of poorer health may be unable to provide the necessary care to their family members so that their health can be maximized. The critical role that the caregivers play in the health and well-being of transplant recipients coupled with the toll that caregivers' responsibilities place on the caregivers' life can adversely affect both caregivers and recipients' quality of life (Meltzer et al 2001, Myaskovsky et al, 2005, Rodrigue \& Baz, 2007, Casida J, 2005, Dew et al, 2000 \& Goetzman et al, 2007).

The chronic stress of caregiving has been found to affect several domains of caregiver health, including self-reported health, health symptoms, illness and medication use (Asada, Kinoshita \& Kakuma,2000, Schultz \& beach,1999, Vitaliano et al,2003, von Kanel et al,2001, Zhang, Vitaliano \& Lin 2006). Shanks-Mc Elroy and Strobino (2001), in their study of male caregivers of spouses with Alzheimer, risk factors and health status, 
suggested that the caregivers experienced a one third increase in negative health symptoms after assuming the caregiver's role and responsibilities. Spouse caregivers reported more days of illness than non- caregivers, due to infectious diseases, primarily upper respiratory tract infections. Schulz et al, 2003 reported that caregivers used more prescription medications than non- caregivers and found that prolonged exposure to the chronic stress of caregiving can lead to changes in sympathetic arousal and cardiovascular reactivity predisposing the caregivers to hypertension and cardiovascular disease. With these changes in the caregivers' health status it is not surprising that the caregivers have a greater risk for mortality than non- caregivers. (Schulz et al, 2003). Caregiving stress can also result in changes in the caregiver's health behaviors used to promote their health and well- being. With the great demand on the transplant caregivers' time and energy, they may neglect their own self care needs such as sleeping, eating too much or too little, not exercising or managing their own health problems. (Schulz et al, 2003, Vitaliano et al, 2003, Schulz \& Beach, 1999). Caregivers neglecting their health care needs are faced with worsening preexisting illness or increased vulnerabilities to new stress related problems. Hence the health services cost incurred as a result of the caregivers change in health status become hidden burdens on the health care system (Burns,2000,Johnson, Davis, \& Bosanquet, 2000, Moore, Zhu \& Clip, 2001).Some studies indicated that caregivers of transplant recipients use more health services than their non- caregiver counterparts, including an increased numbers of physicians visits, increased prescriptions, drug usage and higher incident of inpatient hospitalization ( Fillit,2000, Xu et al, 2012). 
Son and colleagues in 2007, examined the impact of caregiver stress on health outcomes. Participants were 234 caregivers of dementia patients, who completed a comprehensive interview about their current health care situation including their health and stressors. Participants in the study were predominantly female (80\%), white (87\%), and with an average age of 62 . The majority of the caregivers were daughters, daughtersin law or wives. The results from this study suggested that caregiver's feeling of overload, mediated the relation between stressors and health. When the behavior problems resulted in feelings of overload the caregiver may have less time and energy to take care of their own health (Schultz et al, 2003). Feeling more tired and depleted, the caregivers evaluated themselves as less healthy, engaging in less healthy promoting behaviors and using more health services. This finding was also supported by Aneshensel, et al, (2000), who found a similar mediating effect of overload in the relationship between care receivers' behavior problems and caregiver's psychological well-being. However, Vitaliano et al, (2003) found contradictory results suggesting that sometimes caregivers use fewer health services than non- caregivers, because some caregivers may not seek medical care because of their other responsibilities.

Several researchers, (Schulz et al 2003, Vitaliano et al., 2003, Pinquart and Sorensen, 2003, Dilworth Anderson, et al, 2002), have found negative health effects on caregiving. However, despite the various study designs and outcome measures, results indicated that caregivers experience overall poorer psychological and physical health than noncaregivers.

Additionally, caregiving also often involves physical effort, lifting other people and doing physical chores. This effort can lead to physical pain and poor self-assessed health 
in the caregiver. It can also lead to the demands for health care and prescriptions drugs, and out of pocket expenses due to visits to providers and prescription drugs.

Caregiving is associated with burden and may have negative effects on caregiver's health related quality of life leading to an increase in his or her own need for health care (Sjolander et al, 2012). The combination of physical demands of caregiving, prolonged distress and biological vulnerability of caregivers may compromise their physiological functioning and increase their risk for health problems that may lead to increased mortality (Schulz et al 1999). Studies have also shown that there is high risk for adverse physical and mental health and premature mortality among the caregivers (Schulz et al; 1999). Caring for a transplant recipient can have a negative impact on the caregiver's mental health. Schulz et al, (2000), Waite et al (2004), and White et al (2003), suggested some caregivers such as caregivers of dementia patients appeared to be more vulnerable to depression as a consequence of their experience. According to Sawatzky and Fowler Kerry, (2003) caregivers often experience physical problems such as high blood pressure, gastric ulcers and headaches. Sometimes the physical problems may not be directly caused by caregiving responsibilities but are likely aggravated by them.

\section{Summary}

Lung transplantation has now become an effective treatment modality for acute and chronic end-stage lung diseases and it illicit a frightening experience for those involved in the care of these recipients (Kurz, 2000; Rodrique \& Baz, 2007). With improvements and advancements in medical treatment and changes in health care financing there are shorter hospital stays and extended life expectancy for transplant recipients. These changes place increased responsibilities on the caregiver and family members of 
transplant recipients (Canning et al, 1996). Caregiving in the context of organ transplant differs from other research on caregivers of other chronic diseases because the transplant recipient's medical course is usually dramatically improved. The recipient of the new transplanted organ and the caregivers are more likely closely related to the recipient such as a spouse or adult children. Transplant caregiver's well-being, quality of life and health are important issues to address as the transplant recipients' survival is dependent significantly on the care received from the caregivers. Hence transplant programs generally require transplant candidates to have a dedicated caregiver before being listed for a transplant. Caregiver burden and impaired health related quality of life may have a negative impact on the recipient's survival and may lead to problems with adherence and increased risks for morbidity and mortalities. (Claar et al, 2005, Rodrigue \& Baz, 2007). Caring for a transplant recipient is laden with stress in the early days and persists weeks after discharge from the hospital.

Lung transplant caregivers provide crucial supports for maintaining the patient's physical and mental health throughout the transplant process. During the transplant process patients, may experience severe illness and disability and caregivers will participate in activities that patients often take for granted in daily life. The exposure to chronic stresses of transplantation may affect both caregivers and recipients' quality of life, resulting in caregivers experiencing lower quality of life than non-caregiver adults (Rodrigue \& Baz, 2007). According to Claar, (2005) and Goetzinger et al, (2012), approximately $30 \%$ of caregivers of lung transplant recipients reported clinically significant levels of depression and anxiety, both of which were associated with a higher perceived burden of caregiving. Caregivers may feel confined and inconvenienced by 
having to be available to help their loved ones at any time and they may also feel disappointed that the illness had substantially changed their loved on (Rodrique \& Baz, 2007).

$\mathrm{Xu}$, et al, 2012, demonstrated that 35\% of caregiver's daily activities during the first 6 months after transplant were related to supporting their loved one's health. Though performing these caregiver's activities can be self-satisfying and often gratifying, caregivers adjusting the changing family dynamics, household responsibilities and job related capacities associated with transplant may compound the discrete burdens of caregiving. This is evidenced in Xu et al 2012 research study indicating that caregivers reportedly spend less of their day in a positive mood than did the lung transplant recipients for which they care. Simultaneously, caregivers have also reported positive outcomes of caregiving such as discovering inner strength and support from others and realizing the important things in life (Rodrique \& Baz, 2007).

In the transplant literature, the experiences of lung transplant recipients and living donors are often reported. Although research on lung transplant caregivers has begun to be reported there continues to be a gap in the literature concerning caregivers of lung transplant caregivers. Very few studies have explored the lived experience of caregivers during the lung transplantation process (Claar et al, 2005; Kurz, 2001; Kurz \& Cavanaugh, 2001; Meltzer \& Rodrique, 2001; Mayaskovsky et al, 2005, Ulrich, Jansch, Schmidt, Struber, \& Niedermeyer, 2004), Almost all of these studies reported physical and emotional stress experienced by these caregivers. Most included more females than males, these findings may be attributed to male caregivers tending not to verbalize or discuss their level of dissatisfaction with their caregivers. 
Most studies conducted on caregivers of lung transplant recipients used a quantitative design. A qualitative design will allow insight into caregiver's quality of life and how caregiver's experiences affect the recipient's survival. A qualitative approach with participants who are male and from different races and ethnicities will add to the existing body of knowledge of transplant caregivers and will allow health care professionals to gain a better understanding of the lived experiences of the transplant caregivers and to explore the subjective meaning caregivers give to their experiences.

There is a lack of research on non- white, Hispanic and male caregiver's experiences and quality of life as demonstrated in this chapter. The need to explore lung transplant caregivers' experience is evident in findings of aloneness, social withdrawal, and psychological distress experienced by caregivers in related populations (Canning et al, 1996, Mishel \& Murdaugh, 1987; Mc Murry \& Thomas, 2002; Claar et al, 2005; Rodrique \& Baz, 2007, Ullrich et al, 2004). Examination of caregivers who are not spouses or partners could also shed light on other subgroup caregiving experiences. With the majority of lung transplant recipients being female (78\%), it is likely that there will be variation among their caregivers and inclusion of male caregivers is important since this group is largely understudied.

The proposed study is designed to fill these knowledge gaps. It uses a qualitative design to explore the lived experiences of the lung transplant caregivers; it includes a racially/ethnically diverse group of lung transplant caregivers and male caregivers. Data from the study will provide direction for interventions and to help caregivers cope with the many stressors associated with caregiver's roles and responsibilities. 
CHAPTER III

METHODOLOGY 
The purpose of this study was to explore the experiences of caregivers of lung transplant recipients during the pre and post-transplant process. The study examined the caregiver's experiences and their perceptions in order to understand the roles and responsibilities of the caregivers during the transplant process.

\section{Research Design.}

This study used a qualitative hermeneutic phenomenology approach. Hermeneutic phenomenology involves identifying themes in ways of thinking, separating the distinctions between trains of thoughts and focusing on individual perceptions in relation to the lived experiences of the participants. Using hermeneutic phenomenology, the lived experiences and perceptions of caregivers of lung transplant recipients as they provided care to their loved ones are described and the meanings associated with these experiences will be presented.

\section{Setting.}

Caregiver participants (male and female) were recruited from the Transplant Center at Jackson Memorial Hospital in Miami, Florida. Approximately 550 solid organ transplantations are performed annually of which $15 \%$, (80 patients) are lung transplant recipients. From this number, a sample of 20 caregiver participants who met the study criteria were recruited. All lung transplant recipients had an identified and committed caregiver before even being listed for a lung transplant. Twenty was projected as the maximum sample size since Kurz (2001) found data saturation at 12 spouses of caregivers of lung transplant recipients, Kurz \& Cavanaugh (2001) found saturation at 13 spousal caregivers and McCurry \& Thomas (2002) found saturation at 7 spousal caregivers. 


\section{Sample}

Purposive sampling was used to recruit the participants. Using a purposive sampling method, the researcher can select individuals or groups based on their knowledge of a phenomenon for the purpose of sharing that knowledge (Speziale \& Carpenter, 2007). Purposive sampling was used in this study to select 20 participants who had the experience and knowledge of being a caregiver of a lung transplant recipient and who are willing and able to share that experience and knowledge.

Inclusion Criteria: Family members or friends (male or female) who identify themselves as the caregiver of a lung transplant recipient $1-6$ years post-transplant; 18 years or older; ability to understand written and spoken English or Spanish in order to provide a rich detailed description of their experience during the interview.

Exclusion Criteria: Family members or friends who were caregivers of lung transplant recipients who received their transplant less than 1 year prior to the study were included because the challenges of maintaining the graft survivability is associated with increased fatality during the first year post transplantation (UNOS, 2015). More than 6 years presents potential problems with participant recall.

\section{Procedure}

Following IRB approval from Florida International University and Jackson Memorial Health System, 20 caregiver participants were recruited. Caregivers were recruited through invitational flyers posted at strategic locations including the transplant clinic, transplant patient care units, family waiting rooms and local churches. The flyers provided potential participants with a basic description of the study including the 
purpose, data collection process, and requirements (time, and meeting specifics) of the participants.

After obtaining permission from the JMH transplant support group leader to attend the support group meeting both the RA and PI attended the meeting. They provided potential participants a brief overview of the research study and the opportunity to ask questions. At the end of the support group meeting the RA met interested caregivers to ensure they were eligible and understood the study requirements. All caregivers who met the inclusion criteria and expressed a desire to participate had the informed consent discussed with them and any remaining questions answered. The consent form notified the study participants of the purpose of the study, procedures used in the study, duration of the study, voluntary nature of participation, the right to withdraw from the study at any time, the audiotaping of interviews, observational notes taken during the interviews, guarantee of confidentiality and anonymity, notice of risks and benefits and the opportunity to review the information as it relates to each participant contact information (Creswell, 2007). The RA obtained the informed consent from each potential caregiver and a copy of the informed consent was given to the participant. A mutually convenient date and time to conduct the face to face interview was arranged.

Potential caregivers, who called the Principal Investigator (PI) as a result of reading the posted flyers, had the study explained as described above. Informed consent was discussed and any questions answered for those interested in participating. For these potential participants, two copies of the consent forms were mailed to the participants for their review, and signature. One copy was returned in a stamped return envelope to the PI, and the other was kept by the participant for their records. Once the informed consent 
was received the RA called these caregivers and a convenient location and time was arranged to conduct the face to face interview. The PI conducted all English interviews which were the vast majority and the bilingual RA conducted the few Spanish only speaker interviews.

RA Training: RA is a bilingual master prepared nurse who received qualitative research training in her master's courses and who was further trained in qualitative phenomenology by the PI. Her training enabled her to conduct the Spanish qualitative interviews and the demographic data. Prior to any interaction with the caregivers the RA completed the online course for human subjects' protection. The PI met with the RA on a weekly basis to discuss study progress, update and implement any changes if needed.

\section{Data Collection}

Semi structured, face-to face, tape recorded, in depth interviews with open ended questions were used to collect study data allowing for greater scope in the information provided by the participants (Streubert \& Carpenter 2007). In qualitative research, semi structured interviews are the most appropriate and effective data collection method because the research participants can provide an in- depth explanation of their lived experiences plus other data that may be relevant to the study (Creswell, 2012). The face to face interview technique is the most desired because of the potential for accuracy in obtaining first- hand information of individual's perceptions and feelings with the highest rate of reliability and validity. It allows the immediate clarification or expansion of the participant's thoughts and nonverbal cues such as gestures and face expression (Speziale \& Carpenter, 2007, Moustaskas, 1994). 
The open-ended questions were non-leading, geared to allow subjectivity, capturing meaningful responses about the participants' perceptions, feelings and knowledge and allowed the researchers to seek clarification. At the beginning of the interviews the PI had an open dialogue, and exchange of pleasantries that lasted for approximately 10-15 minutes to assist the caregivers to be at ease and build rapport before sharing their personal experiences with the researchers.

Each caregiver was interviewed separately in the language of their preference (Spanish or English). The interview started with PI (English interviews) or RA (Spanish interviews) asking a grand tour question to get the participants talking about the phenomenon of interest. Each caregiver was asked to respond to the grand tour question; "Describe your experience of caring for your loved one before the lung transplant; after the lung transplant. Please describe all your feelings thoughts and emotions as completely as possible. Based on the participant's responses the researcher will probe for additional information with open ended phrases such as "Tell me more or "How would you summarize your experience"? The additional probing questions were used for clarification and focus. Probing questions are not intended to lead the participants but to encourage and elicit examples and meaning about the experiences they are describing. They are orientated to specific instances, situations, events, and persons (van Manen, 2000). Probes are used as needed to clarify the meaning of responses and to encourage in depth descriptions. These probing questions are used to redirect the caregiver's descriptions of their experiences if they deviate from the phenomenon and also help the caregivers to describe the experience in a more detailed manner. 
Some possible probes were:

- Can you tell me about your own health before the lung transplant; after the lung transplant?

- Can you tell me about your social life before the lung transplant; after the lung transplant?

- Can you tell me about your emotions before the lung transplant; after the lung transplant?

- Can you tell me about your financial situation when being a caregiver before the lung transplant and after the lung transplant?

- What area of caregiving (pre, post-transplant) did you find been difficult to perform or find stressful?

- How was it stressful or difficult?

- What areas of caregiving have been rewarding for you?

- What lifestyle changes have you noticed while taking care of a family who receives a a lung transplant?

- What was it like working outside of your home at your place of employment while taking care of a family who receives a lung transplant?

- How were you able to meet your financial needs while taking care of a family who receives a lung transplant?

- Where would you find help if you thought you were no longer able to take care of a family who receives a lung transplant? 
Is there anything else that you would like to tell me about your experience caring for a family who receives a lung transplant that we have not yet discussed? When the caregivers indicated there was nothing more to share the researcher ended the interview by thanking each caregiver for their participation.

All interviews were digitally recorded to preserve their authenticity, and all participants were made aware of the recording device. The interview process for each caregiver lasted for approximately 45 minutes. Data collection for each interview continued until the researcher believes data saturation was achieved. This is the point at which no new information is forthcoming and the data becomes repetitive. According, to hermeneutic phenomenology, experts suggest that data saturation is achieved when discussion or interviews ceased to contribute or clarify an understanding of the experience (Cohen et al. 2000, Laverty, 2000).

Following each interview, the PI and RA used field notes to record observations, including thoughts and feelings about the interview, caregivers and the setting. The use of field notes throughout the data collection and analysis portions of the study have been used effectively in several hermeneutic phenomenology studies (Cohen et al. 2000, Wu, 2008). Field notes are also taken by the researchers to depict aspects of the physical environment, participant's body language, demeanor, dress, and observations not discernable by the transcript. In this study notes taken during the interview helped to remind the PI and the RA about the various non- verbal behaviors noted during the interviews. This helped when the interviews were being transcribed to add to the richness and detail of the data collection process. The RA translated Spanish transcripts into English. Another Spanish speaker (Masters or $\mathrm{PhD}$ educated nurse) who has not read the English translated $20 \%$ of the 
Spanish interviews into English to check for translation accuracy. Any differences/discrepancies were resolved by the second translator and the RA.

The audiotaped interviews were transcribed verbatim by a bilingual transcriptionist who had completed the IRB requirements. The transcriptionist produced a verbatim transcript of each interview. The completed transcription was read twice and then read again while the PI and RA listened to the audio tape. This allowed the PI and the RA to make corrections to the written transcription where necessary. All voice file and electronic copies of the interview that were transcribed from the recorder will be stored in a password protected computer hard drive. The password protected computer hard drive, paper copy of transcription and signed consent are stored securely in a locked filing cabinet at FIU. The transcribed paper copy of the recordings and the signed consent forms will be kept in the locked cabinet for a period of 5 years after completion of the study and then will be destroyed. The participants were informed that no names or any identifiable information will be contained in the document and all data that could identify the participant will be erased.

The RA had all caregivers completed the demographic data form immediately before the interview. Demographic data included the participant's age, education level, marital status, gender, annual family income, ethnicity, and length of time being a caregiver for a lung transplant recipient.

\section{Data Analysis}

Analysis of the data involved identification of themes and placement of themes into categories. In hermeneutic phenomenology, the researchers will discount the notions of phenomenological reduction and bracketing, which is mostly applicable to the philosophy 
of Husserl, who removed the researcher's influence from the investigation (Cohen et al, 2000). With the Heidegger ontological views of hermeneutic phenomenology, preunderstanding is a structure for being in the world. Pre-understanding is the meanings or organizations of a culture that are present before we understand and become part of our background. It is not something a person can step outside or put aside as it is understood as being with us in the world (Laverty, 2003).

The initial step of this research started with data collection through semi structured interviews and open- ended questions, followed by all interviews transcribed verbatim by the transcriptionist. Procedures for conventional content analysis were used to allow codes and themes to come from the data rather than imposing preconceived categories (Hsieh \& Shannon, 2005). The PI, RA and $1 \mathrm{PhD}$ educated nurse (with relevant clinical and cultural expertise) individually read and re-read 6 randomly chosen transcripts and made notes on potential initial codes. Then, these individuals came together as a group to discuss and compare their individual thoughts and notes about each of the 6 transcripts. Through this discussion, the group created an agreed upon a set of codes with operational definitions. The PI and the RA separately used these resulting codes and operational definitions to code each of the transcripts, and then met to compare their coding and resolve any coding inconsistencies. The themes emerged from the codes and were placed into categories by the PI.

The PI sent copies of the caregiver's transcripts along with the summary of the researcher's perceptions of the interview to a subsample of 4 caregiver participants to validate, clarify and elaborate on their own experiences if necessary. Having the participants validating the researcher's interpretations allowed the PI to acknowledge that 
the findings were interpreted correctly and are a representation of the participant's experiences. Any new data obtained from the participants' validation were incorporated into the previous data to attain congruency with the lived experience of the participants studied.

\section{Ensuring Trustworthiness}

In qualitative studies ensuring trustworthiness of the data is essential. This study did as follows. To help ensure trustworthiness in hermeneutic phenomenological research, the researcher uses techniques of pre- understanding, audit trail, (reflexivity), thick description and peer review (Laverty, 2003). Developing a rapport, expressing interest in their experiences and assuring confidentiality will increase the likelihood that the participants will honestly share their lived experiences. The use of a consistent protocol of data collection will help to increase the trustworthiness of the data collected (Macnee \& McCabe, 2008). The PI consulted with the dissertation chair to obtain her expertise and review findings throughout the study. This is essential given the nature of the hermeneutic phenomenology and the important role the researchers play during the collection, immersion and data analysis. The PI was careful to ensure the study reflects the lived experience of the participants and not that of the researchers based on previous experience.

The dissertation chair provided feedback. If the dissertation chair detects any researcher subjectivity during the data analysis, she consulted with the committee members and the PI will be required to revisit the audio recording and transcriptions of interview.

\section{Credibility:}

This component of trustworthiness in the qualitative research is congruent with the PI's intention of thoroughly explaining various steps in the research process. Credibility 
can be achieved by the full disclosure of the steps taken to recruit participants, how the interview will be conducted as well as how data will be collected and analyzed. The PI maintained credibility in the study by consulting with the chair and committee members about the translation of themes from the transcribed interviews to ensure accuracy and supportive reasoning. (Reiners, 2012). Credibility can also be achieved through the consistency and cohesiveness of the data. Employing member checks increased credibility and collecting participant feedback after initial finding and interpretation will help to validate the accuracy of the data collected (Macnee \& McCabe, 2008), Member checking provides the participants the opportunity to review the themes which make up the composite description of the experience and to test their fit based on the participant's actual experience.

\section{Dependability}

Dependability relies on the researcher's ability to clearly and effective conduct the steps in the data collection process, aligning this with the audit trail (Shank, 2006). Ensuring dependability of a qualitative study reflects research findings that are consistent and accurate thus providing reliability of the study (Guba, 1985). In this study dependability was maintained: researchers clearly articulating the process of interviewing using the hermeneutic phenomenological approach (Shank, 2006) and, interviews conducted with open ended questions with probes designed to elicit an in-depth picture of the phenomenon. Notes taken during the interview helped to remind the researcher about the various non- verbal behaviors noted during the interviews. This helped when the interviews are being transcribed to add to the richness and detail of the data collection process. 


\section{Confirmability}

Confirmability was achieved by asking the dissertation chair to periodically review the data and emerging themes to help ensure external validation of findings (Polit \& Beck, 2012). With this system of comparing the findings, the chair will be aware that the PI and RA are subject to redirection, editing and advice regarding data, data collection and analysis when warranted. Although the role of the researchers in a hermeneutic phenomenology research is important, care must be taken that the participants' experiences are not replaced by the researcher's experiences. Through the careful reflection and recording of personal experiences and impression in the field notes, themes that emerge from this study are indicative of the participant's own experiences. To enhanced confirmability the researcher thoroughly explained how interpretations were discovered during the data analysis (Whitehead, 2004).

\section{Transferability}

Transferability focuses on how well the study results can be generalized to the greater population from which the sample was drawn and is similar to the concept of external validity (Patton, 2007). This study and its findings are specific to the lived experiences of caregivers of lung transplant recipients and while this data cannot be generalized to the entire population this research will serve as an example of an important segment in the transplantation population. Providing detailed information and descriptions of each step of the research process, including the methods of data collection and analysis could provide a guideline others could follow. Researchers who are in different settings can decide which steps are applicable and steps that may require modification based on their settings. For example, researchers, may want to better 
understand the lived experiences of caregivers of another transplanted organ other than lung. Following the steps outlined in this research study help to provide guidelines for a similarly structured hermeneutic phenomenological study. 


\section{CHAPTER IV \\ RESULTS}

This study used a phenomenology approach to explore and investigate the lived experiences of caregivers of lung transplant recipients. In this research four common themes and their sub themes were identified reflecting the meaning and essence of each participant's caregiving experience. Each theme was derived from the verbatim transcripts of each participant's interview. The question that guided this study was: Describe your experience of caring for your family member before the lung transplant and after the lung transplant? Additional probing questions were used. This chapter includes demographic data describing the participants, and the major findings and common themes. The thick rich descriptions provided by the participants provide a deeper understanding of the lived experiences of lung transplant caregivers.

\section{Demographic Characteristics}

The sample consisted of 20 lung transplant caregivers. More than half were female, 65 years and older, married, English speaking, had completed at less high school, worked full time and had an annual income greater than $\$ 25,000$. See Table 1 . There was an almost equal representation of Hispanic, White and Black participants. Fifty percent of the caregivers were spouses. The years of caregiving ranged from 1 year to 6 years.

Table 1.

\begin{tabular}{llcc}
\hline Variable & Category & N & \% \\
\hline \multirow{2}{*}{ Age } & & & \\
& 21 to 29 & 0 & 0 \\
& 30 to 49 & 5 & $25 \%$ \\
50 to 64 & 6 & $30 \%$ \\
65 and over & 9 & $45 \%$
\end{tabular}


Gender

$\mathrm{F}$

$M$

Marital Status

Single

Married

Divorced

Separated

Widowed

Ethnicity

African-American

Asian-American

Hispanic

White

\section{Level of Education}

11

9

$55 \%$

$45 \%$

$15 \%$

$75 \%$

$10 \%$

$0 \%$

$0 \%$

$0 \quad 0 \%$

6

$30 \%$

$0 \%$

$35 \%$

$35 \%$

$\begin{array}{ll}7 & 35 \%\end{array}$

\section{Language}

Level of Education

Elementary

Some high school

Completed high

school

Some College

College graduate

Graduate/

professional

$0 \%$

$\begin{array}{ll}2 & 10 \% \\ 8 & 40 \%\end{array}$

$4 \quad 20 \%$

$3 \quad 15 \%$

$315 \%$

$\begin{array}{lcc}\text { English } & 15 & 75 \% \\ \text { Spanish } & 5 & 25 \% \\ \text { Other } & 0 & 0 \%\end{array}$

Annual Family

Income

Less than 25,000
$25,000-49,999$
$50,000-99,999$
$100,000-250,000$

$25 \%$

$30 \%$

$30 \%$

$\begin{array}{ll}6 & 30 \% \\ 3 & 15 \%\end{array}$


Relationship

$\begin{array}{lcc}\text { Spouse } & 10 & 50 \% \\ \text { Sibling } & 3 & 15 \% \\ \text { Parent } & 2 & 10 \% \\ \text { Friend } & 2 & 10 \% \\ \text { Other } & 3 & 15 \%\end{array}$

Years of being a

caregiver

$\begin{array}{lcc}1 \text { to } 2 & 4 & 20 \% \\ 2 \text { to } 4 & 10 & 50 \% \\ 4 \text { to } 6 & 6 & 30 \%\end{array}$

Employment Status

Full-time $\quad 10 \quad 50 \%$

Part-time $\quad 0 \%$

Not working $\quad 10 \quad 50 \%$

\section{Themes}

There were four major themes and twelve sub themes identified in this study that revealed the caregivers' experiences while caring for individuals who received a lung transplantation. The major themes were: 1) Establishing the Diagnosis; 2) Caregivers Roles; 3) Caregivers Psychological and Psychosocial Issues; and 4) Support. There were twelve sub themes that directly related to the experience of caring for a family member or friend who received a lung transplantation. The sub-themes were:1) Caregivers Reaction to Transplant option; 2) Caregivers' lack of basic knowledge as related to Lung Transplant; 3) Disease Progression: Reality of unanticipated changes/Fear of death; 4) Pre -transplant experiences; 5) Hospital Course; 6) Home Care; 7) Lifestyle Changes and Social Activities; 8) Physical Health and Emotional Health; 9) Financial and Employment issues;10) Friends/Family; 11) Professional Support; 12) Support Groups. 
The quotes in this chapter are verbatim excerpts from the participant's interviews without editing for grammar.

\section{Theme \# 1. Establishing the Diagnosis.}

Themes that arose after learning of the diagnosis of end stage lung disease were a transplant being an option, caregivers' lack of basic knowledge about lung transplant, and progression of the disease accompanied with the reality of unanticipated changes and fear of death.

\section{Transplant as an option}

The diagnosis of an end stage lung disease marks the beginning of a tedious, complex and stressful experience for most caregivers and their families. Most of the caregivers expressed feelings of uncertainty, nervousness, and frustration when they first heard their family member needed a transplant. One caregiver described this experience as a "brand new adventure" for him

"it was a brand-new adventure to me because we were going to this pulmonologist who was taking care of her, of course, I was not fully aware of the full impact of her illness until one day, ....and then she told me that the doctor could not do anything more for her and that she would was recommending her for a lung transplant. I never heard of lung transplant then and so immediately I got out of my the car and then I went back to the office of the doctor and I saw him and he told me that, there was not much more that he could do for her and that he was recommending her for a lung transplant."

Another caregiver responded after hearing that her husband needed a transplant thought they were lucky because he was diagnosed with cancer but after learning about the disease they weren't lucky it was not cancer. She also felt that the doctor had not given them any hope, he had "he just wrote us off"

"when he was first diagnosed it was May of 2015. The doctor who he had been going to, pulmonary doctor, for so long, when he gave us the diagnosis, he said there is 
nothing we can do for you; is there medicine, no; no medicine, no treatment and he just gave us this really grim outlook and..., we still knew the serious of it and we had said on our way home, boy, we're lucky this isn't cancer, but then after we understood the disease, we aren't lucky that it wasn't cancer, ---- but then after there was no hope it was like this doctor just wrote us off and we couldn't understand it and he began to get worst."

One caregiver referred to her father has a very active person and on learning about her fathers need for a transplant she "went crazy"

"Yes he was doing everything and even after he found out... he didn't tell us until, I would say maybe two weeks later is when he told my sister about it...my younger sister we had no idea he did mentioned that they told them that he has, maybe, three to five years of life left, of course, my father is our life so we went crazy and we started looking for a second opinion and ah someone referred us to a doctor and he confirmed and...he was ok, he continue his routine but then like four or five months later is when he started feeling out of breath and very quickly he had to get on that breathing machine on the oxygen fulltime and everything just went downhill from there; he wasn't able to do a lot of the things that he was used to doing".

A wife who was the caregiver for her husband stated she had no idea that her husband needed a lung transplant they discovered this during a school trip. Prior to this her husband had no indication that he was ill.

"Well we discovered taking a...our seniors and juniors at the school on a trip and my husband started... after we got there for a couple days and we went out on Mall in Washington, DC and one of the young girls had to go to the restroom ...we had to walk and he decide to go with me .... and the next time I look around he look he was...like he was so tired and I was like ... a strange look; I just said well you sit there till we come back cause we've been doing a lot of walking, but I noticed when I got back ... he was dragging so we went to see his lung specialist in Sarasota and they told me, you probably would have been dead because the...the level of oxygen that he is getting in his body will kill you and that moment they made the preparations for us to start him on oxygen; so that was like 2009 and that's when I had to start, you know, put more attention on him".

"Basically, was just so shocking for how he started out, you know, and we just thought it was just something small... but ended up after a time at one hospital and then later on at another hospital. It was just kind a little overwhelming at times but thank God, he got himself...got settle where he could go through all of the procedures to put him on the transplant list".

(sigh) "Ok, when he started getting sick I thought he was just something that could be taken care of quickly and then when I was told... when we went to hospital to get his lung 
biopsy, they told us he needed a transplant. I couldn't believe it and I...I just couldn't believe it, it had gotten that bad and I... and I kept telling myself I didn't sign up for this, I didn't sign up for this, cause I expected him to be healthy, I didn't understand cause he was supposed to take care of me, not the other way around. I kept getting angry; because I was by myself".

\section{Caregivers' lack of basic knowledge as related to lung transplant}

As the need for the lung transplant became eminent, approximately $30 \%$ of the caregivers realized that they did not know much about a lung transplantation nor did they know what to expect during this period of their loved one's illness. Caregivers subsequently tried to seek information on lung transplantation and were eager to find information on the internet and from medical professionals. A husband whose wife was given the news that transplant was the only option for his survival, responded:

"when we got home, we just started on the internet; we've never heard of this disease and it was quite as grim as he said".

Other caregivers shared their experiences as they attempted to gain information on lung transplant.

"he told my sister about it...my younger sister and then right away they went to look it up in the internet to see what it was; we had no idea. I was the one making the phone calls I was the one doing the research because of my flexible schedule as a teacher, so I was able to take more time off to do these things, but it was very hard".

"I go to the clinic, talk to the doctors, talk to the surgeons, everyone was great, they were very informative of any questions that you had".

"It took me a while until I realize because we never heard of a lung transplant before, you hear about a heart transplant, you hear about the kidneys, things like this but I never heard of a lung transplant; I know that I had some friends of mine that say they had lung cancer and one them had a piece taken out but we never heard of lung transplant. She started studying it, and looking into it on the internet. We talked about it and she explained to me, she saw all the movies. She did educate herself very well about it, before we did not know anything". 


\section{Disease Progression: Reality of unanticipated change/fear of death}

During the waiting phase for an organ, caregivers experienced worsening of their loved ones lung disease. The caregivers suffered as a result of their loved ones progressive loss of their basic physical capabilities and their inability to participate effectively in their activities of daily living. This period was characterized by fear, frustration and uncertainty including fear of not getting the organ on time and fear of transplant outcomes. The reality of unanticipated changes and fear of death was evident and clear in the caregiver's responses.

"he continued his routine but then like four or five months later is when he started feeling out of breath and very quickly he had to get on that breathing machine on the oxygen fulltime and everything just went downhill from there; he wasn't able to do a lot of the things that he was used to doing he couldn't breathe he...I mean he would sit all day because if he gets up the oxygen level would go down, he started visiting the hospitals a lot more often, you know, it was like on monthly basis and then started going every two weeks and then within a year my father almost passed. I mean so fast, we saw his health diminished and not being able to breathe enough seeing him he couldn't sleep in his bed anymore we had to buy him a recliner cause he had to sleep sitting up and at night, sometimes we wouldn't sleep watching him to make sure he wouldn't pass during the night; so, it was very, very scary".

Other participants commented:

"we started to discover when her stamina was bad and she wasn't walking well and.... and so forth, so as she's... got more and more where she couldn't get around and she couldn't walk yet...that's when you....all of a sudden the caregiving starts, , and you realize that you have to help her out to do simple tasks like ...clean the house and lot became ...my jobs and cooking dinner, and doing laundry ....as she kept going it kept getting worse she couldn't...... she was trying just to just to take of herself. She started to get real bad where she probably was like bed-ridden really or she...to get her up out of the bed and just walk her to the bathroom... she could get there, I had to help her; you had to hold her, you had to help her so she just couldn't breathe, and then her bones starting to hurt, her legs were starting to hurt and stuff like that so she...she deteriorated to the point where the lung transplant...you know, came in at that point".

"He was teaching school and teaching um...in the K through 12. I was teaching at the same school and then he was teaching at the junior college, chemistry, and so that was a lot for him and he would even go with his tanks and the students would come out and 
pull his machine inside in order for him to continue to teach but it got so difficult that he had to think about making the steps so we had to stop and so it was something I would never imagine, I'd never...you hear about it but you never think that it's gonna be you and so it...it made a change for the whole".

"Before, you know he just progressively got worse and the difficulty there was knowing there isn't much we could do and that the outcome would be...I would finally lose him. Well before I was just very scared not from the diagnosis time but towards the end as he was getting sicker and sicker and then we couldn't leave the house and I couldn't leave him and it was very scary".

"Before the lung transplant it was very hard on her, just to watch her trying to breathe, trying to walk, trying to do everything; the only thing she could do for herself is take a shower; she couldn't do chores, she couldn't do anything, she couldn't laugh, she had no wind, she couldn't cry; she tried crying one day she couldn't (pause/crying). When she got worst we couldn't do anything, we'll stay home, we'll watch TV all day that's the, only thing she could do; she couldn't walk around, she couldn't go outside, she couldn't do anything. I just watch her; she got so frail, so little from all that coughing and coughing, she lost so much weight, she was so little so we didn't really have a social life at all".

"He was waiting but he got worst, he really got bad, I think he had a few more months and that was it; maybe, not even a few more months because I saw him getting worse and worse. I kept telling him, you can't do this, you got to keep going, you got to encourage even if you know it couldn't happen; it can happen. You gotta help him because if he sees you (sigh) my God, crying all the time that is not good".

"Well before the transplant, it was hard watching him degrade over a time, getting worse and worse. My dad was in a wheelchair with oxygen and his lung capacity was at eighty or close...very close going to seventy's where he wasn't gonna be able to be live without the oxygen. I think he wasn't gonna last very much longer, and then the way he was living he was gasping for air every minute make it very scary and frightening”.

"Before it was a very, very hard for us to handle him because for me, it was terrible, you know, at home and he was not able to do anything not even taking a shower. Because he, you know, I used to wake up and see him some day he will tell me, I'm not...I going to give, up I'm not going to care, I don't want to live that way. Another thing we used to go to the hospital almost every month... every week we have to go to the emergency; maybe for a day or two days and sometimes for two or three weeks. No, it was terrible because for me, I think maybe today is gonna be his last day, because you don't know if he's gonna make it or not especially when he go, outside and it is raining he refused to go out because he cannot afford to get sick. Every time we go to the hospital, for him it looks like this is gonna be the last time; that's the way that he lives". 
“It was very hard cause I'm not used to seeing him like that; a 6'2" almost 300 pounds man reduced to nothing, it was a very hard I... I say, this can't be happening, this can't be happening, we got to keep on because we didn't signed up for this and one day he tells me, let me die, I said no you can do this"

\section{Oxygen Use}

As the health of the transplant candidate continued to get worse, oxygen became an essential treatment modality and a means of survival for most individuals. Caregivers began to assume increased responsibilities regarding oxygen therapy. Their concerns were centered on the proper management of the oxygen supply and ensuring oxygen would always be available when needed by their loved ones. Particular attention was given to the heaviness of the oxygen equipment and difficulty in handling the tanks.

A husband who took care of his wife awaiting a lung transplant described his experience of taking care of his wife while she was on oxygen and travelling to a transplant center that was about seven hours away from home. He described his experience as:

"Eventually we did get a call from the Mayo Clinic saying that they wanted to see her and ah....and, of course, you know, Jacksonville seven hours away; it was her survival so we had to do whatever we had to do. So, we explore all the avenues and the possibilities that we had to get to Jacksonville, either by train, by plane or driving and at one point, I decided that I was going to go by train, but then, carrying fifteen oxygen tanks, was not an option and then we decided that we were going to drive in our car, and carry all that. Of course, we have the support of all the medical suppliers who did give us all the oxygen that we needed to go and ever... and when and we got to Jacksonville... at the hotel where we were staying, which was nearby, the Mayo Clinic they also had another fifteen tanks of oxygen waiting for us which helped us because on the way up we used about eight tanks. At that point, she was up to four liters per minute and so she was pretty much using all that. When we came back, of course, we had the full fifteen tanks again, and it would be like that for about nine months and every three months we had to go there to be evaluated".

The husband continues to elaborate on his statement: 
"Trying to take care of her with all the oxygen and the equipment, we had to get a big tank in here, we got to get a little one that look like concentrator, a portable concentrator for her to travel with. I mean I had to carry all over the place every time we have to go to clinics. One time coming back from Jacksonville she run out of oxygen on I95 and we're stuck in the middle of traffic, you know, and I was so desperate, because I couldn't get out of the car to switch one tank for the other one, so I have to look for the nearest exist to see if I could get that done and then you learn. So the next time what I did is I just hooked up two tanks at the same time; I had two valves and everything else so one of them run out, the other one, so at that point it was... was a lot more stressful because of that; carrying all the equipment, back and forth...I'm not a big person, ...I'm a small guy".

Other participants commented:

"It's gonna be a change of life and that you have to adjust to these things because we had a tank machine in our house to fill up the tanks because the people got tired of delivering because it was getting so consistent, to fill up...they just brought his tanks, we had the tank and then we had the tank that was giving oxygen out, the little portable one, then he had this one that _....he had three things going up his nose and I watch him...nobody don't want to hear this story, his nose will get so dry that...I mean, he will pull clots out, I'm like, I was sick"

"My experience was it took a toll on me because, I work, and I have to really drive long distances to get her to testing to do all kind of stuff, you know to take to doctor, to be carrying oxygen tanks all the time with me, of course, it became, a nightmare".

"The oxygen, the oxygen he was dependent on it, he couldn't even talk to me without it, I couldn't take him to the park, even just to sit and watch him because he had to have the oxygen with him all the time".

"A mother who cared for her son who received a lung transplant referred to the period her son was using the oxygen as the most stressful part of her caregiving responsibilities".

"The use of the oxygen was the most stressful one for me, cause carrying that around to the different appointments and different places that he had to go, having to carry the oxygen around, to me that was a bit much for me and to making sure that he had enough to get around. Sometimes... before we could reach back home he ended up getting the big tank where he could refill it but before that he had to go and pick up tanks or have them delivered here. Finally, they started delivering but I was always worried about him running out of the oxygen in the tank whenever we went out". 


\section{Call for Transplant}

The wait for an available organ has been cited as the most stressful period for both caregivers and the transplant candidates. Frequently this stress is relieved by the call that a lung is available for transplant. Some caregivers described this experience with mixed feelings. Some described this time as devastating, feeling nervous and confused while others were eager and happy for their loved ones. Unfortunately, after the initial call is made it can be followed by another call in which the transplant is cancelled at the last minute because of incompatibility. These caregivers lived through the experience of receiving a phone call, going to the hospital and being told at some point that the organ was not appropriate or there was no adequate insurance coverage.

"Eventually, we got the phone call that we were waiting for forever. If I can expand on that, I mean, the first call was pretty much devastating for us; it was 1:00 o'clock in the morning when they called us and there was... some lungs available but there were something wrong with those. I was very disappointed because after three years, we've been waiting for three/four years. Then the following Monday it was, April 15, they called us again, 1:00 o'clock in the morning, saying that they had, organs and so we went there. I know Jackson Memorial like the palm of my hand but that day I got lost trying to get to the emergency room I just couldn't find it, I was so nervous and stuff like, it was pretty much a miracle, we got there and they took care of her".

"It was so quick when they called and say you should be on your way and I'm like... I had packed the bag... you hear it, you hear all the things they say would happen but when it finally happens...I started using the stuff in the suitcase, right now, I'm like oh, I don't have everything in there and I was afraid, he was like, my husband a store in Miami you are not thinking, we are running out of time. Then I got our son he's going on his senior thesis in South Africa, we were there getting ready to take him to Tampa and they are asking us to come to Miami; two different ways and I'm like I can't do this, is like you don't know where to go......, I just grabbed the bag, ok, we are going down here, he's going get this heart and double lung”.

"I don't know, you have to be prepared and I guess you never gonna be prepared because we are waiting for him to get the... organs and when we got that call, oh my God, we got so nervous; he call me, I don't know what to do, you tell me, I go, no, no, I'm not 
gonna tell you the responsibility is yours; you are the one...I remember that I was working and I came home and we got so nervous I don't know how many times I went to the bathroom and we got to the hospital, everything was so nice".

"We got a call for one and it didn't work out, we came down in the middle of the night but it didn't work out ...then we got another call about a month later and the same thing, it just didn't work out. We came down, there was an insurance problem, it was the end of the year and my insurance switched over to another one and in the middle of the night you can't get no one on the phone ...but I talked to the CEO of the hospital and they just... wouldn't do it because of the insurance so they...they need to get the lungs to somebody else, so they went on to somebody else. The next time she was sick, we got another call she was sick and... and then ah probably a month later, we got the call and it went through and the transplant happened".

"He went through all the different procedures and then that glorious morning when he got that call, oh my God, we had just gotten back from a family reunion in Orlando and I wasn't feeling well that...during the whole trip so when he called I was like kind a crazy didn't know what was going on; he had to literally tell me what was going on. He asked me if I was ready so, of course, when he told me, I jumped up and...I was basically ready in two seconds, so we went into the hospital, he had the different little procedures we went through, which was very quick to me and then in no time he was wheeled off into surgery".

"She wanted to have the surgery but we just had to wait and wait; sometimes it feels as though she's never gonna live long enough to be called; then one night she was called and... and then we were happy, we were scared; we were happy because she was called but we were scared because we didn't know what was gonna happen; and then they called and said oh, we not gonna do it and then we sad and we were happy at the same time, then we had to go through it again and then she got the second call and then she was able to do the surgery"

"Oh, my God, (pause) I remember, it was six...it was five or six in the afternoon at evening, I was so happy, I say, oh, my God, we got to go, it was like having a baby, we had to rush; I felt like I had to rush before they took it away; I had to be there in person; that's how I felt".

"When we got the call for the transplant I went crazy I go I don't know if we gonna make it, and they say they thought that the lung was high risk; they explained to us we have the... lung for you but this a high risk I ask high risk , but we're gonna take it (laughter) he goes, no, no, don't worry, I gonna take it because I need it and it was nothing because the guy was a perfect match and I...I pray every day and I was so sad...when I find out the person who...who was the donor, oh my God, I feel really sad because he was a very young guy". 


\section{Theme \# 2: Caregivers Roles:}

During the interview, it was evident that the caregiver's roles and responsibilities began at the time when the loved ones diagnosis was established and continued throughout the transplant process. More than half of caregivers described their role as a fulltime job, stressful, and it was their main purpose in life. Caregivers described their caregiving roles during the period of waiting for the transplant, during hospitalization (immediate postoperative period) and continuity of care at home as stressful, frustrating, energy draining and fearful.

\section{Caregivers Pre-transplant Experiences:}

A husband who took care of his wife before the transplant described how caring for his wife suddenly became his job:

"as she got more and more sick where she couldn't get around and she couldn't walk ...that's when you....all of a sudden the caregiving starts, and you realize that you have to help her out to do simple tasks like ...clean the house and a lot became my... job and cooking dinner,, and doing laundry ....as she kept getting worse she couldn't... then the hospital appointment started...the doctor appointments started becoming more frequently as she kept getting worse and worse and worse".

Other participants added

"Pre-transplant towards the end, physically, was just because it was just hard I had to do everything, he just couldn't do anything and... so you have that very difficult, physical as well as emotional".

"Before the transplant it wasn't demanding, obviously, I'll stop and see him, make sure that he needed everything and we talked every day to make sure, cause he was already ill, so I just make sure that everything he was taken care and he was not able to communicate, so, I'm the one who provides for everything whether is gas, lunch, breakfast. Right now, if he needs something to eat on the weekend, then we take him food".

"I had to help her go to the bathroom sometimes and she can only walk twenty or thirty feet without having to stop, I did the laundry and the grocery shopping and everything for her. It was pretty rough there for a while, I mean she couldn't sleep laying down she 
had to sit up all the time, her oxygen she use was high. I did all the housework and everything, I had to help her get dressed too and (pause) there was one or two times I had to clean her up after the bathroom. It was a challenge getting from where we lived to get to Miami to the clinic appointments, because of the distance it's a good two-hundred-mile trip one way, but thank God, we managed to get a car and we could get back and forth. We had some obstacles too; we had the car wrecked one day on our way to the clinic in Miami but we made it, we finally managed to get it all done".

"Before, at the beginning was a little rough because I didn't know exactly what to expect...not knowing that was the biggest problem. It was a little close for me in the beginning by me working at the hospital where he initially started out, he started out at another hospital but ended up at Jackson. That was a little stressful driving from here down south over to the northwest to all of the appointments and everything, especially before the surgery, he had all of that physical therapy that he had to go through so making sure he got there for those appointments and everything and then ever so often, he would have a little crisis where he has to be hospitalized so that was pretty stressful for me".

\section{Hospital Course:}

Hospitalization of the transplant recipient posed several challenges for the caregivers who viewed this phase as a time of commitment, vigilance and stress and frustration.

Five of the caregivers shared their experiences during the hospitalization:

A participant whose wife had spent three months in the ICU described his caregiving responsibilities

"Now you're in to post-transplant we spent a good three months in the ICU. If something could go wrong, it went wrong with my wife... I guess she retained a lot of CO2 which might have been cause of the sleep apnea, we finally found about later that was the problem. They were keeping her there till they could figure out why she was retaining CO2 and treating her for. She spent three months in the ICU ...I did stay down her for a while, on and off for about a month Then my daughter came down from Virginia and helped out but it seemed to me like I needed to be with her because, I wasn't with her she seemed nervous, she seemed like it was affecting her in the hospital so I try to spend as much time with her. If I wasn't there, the nurses told me she was always asking for me. So, it's a rollercoaster; you're up, you're down, you're nervous, some days are good, some days are bad. I would just support, support her the best I can".

Another daughter discussed her caregiving role while her father was hospitalized, 
"While he was here, in the hospital, make sure that he had everything that he needed while he was in the hospital and I know he was being seen by the nurses and doctors but still the companionship, you are in that room by yourself.....first when you're in the hospital, then you're spending your whole days in the hospital you think that is easiest thing to do, it is energy draining; I used to come home tired from sitting on the bed with my father and helping him so physically, you have to help him do things".

One participant voiced her feeling of fear of something bad happening to her husband if she left the hospital; she continued to describe her experience while in the hospital

"We stayed in the hospital; I stay the waiting room, I had a pillow and I put my feet up and then I go and freshen up in the restroom, I'm so afraid that as soon as I leave the compound something bad is going to happen...... I develop relationship with some of the other patients some didn't make it even right beside him I watch people smile at me and we, give words to each other and come back and they are wrapping him up and that was very hard....I couldn't sleep, I was like...I was like oh Lord, please, he can't go anywhere now".

Another participant described spending most of her day at the hospital:

"At the hospital, he likes me to be there most of the day and I knew that and I try to fulfill that as best as I could; going to the hospital I would go early in the morning to be able to spend the time with him".

Although the caregivers were willing and eager to assist their loved one in their recovery process, some appeared dissatisfied with their loved one's progress during the hospital stay. One husband expressed his frustration and desperation regarding his loved one's progress.

"it became frustrating and although everybody at the hospital knew me, and they were nice but it became frustrating... wonder when are we going to get out of here, and at one point I did get desperate enough that I did yell at her - you need to do something, you need to put some effort on your part to get out of here. It was just a moment of frustration and not knowing that I couldn't feel what she was feeling, what she was going through but it was just a moment when you say to myself am I gonna live here forever and that was about it". 


\section{Home Care}

After discharge from the hospital the participants noted that their caregiver role and responsibilities had increased. They were now required to undertake functions that were previously shared by their loved one. Caregivers also shared feelings of fear and not knowing what to do at home. They were no longer able to depend on the transplant team to care for their loved. They were now forced to be more involved in the care of their loved ones.

A wife described her caregiving role when her husband was discharged home as very stressful-- she elaborated:

"when we were given an opportunity to move back to Sarasota, it became really difficult, cause now I don't have you all the transplant team right there if I need any help, I can't do that now and so it was hard cause when we got home...I mean I was so afraid at night to hear him sleep, you know, I'm could see he's jumping sometimes and he had the tremors and things sometimes I didn't sleep very well that first year because I would wake up, cause ...I'm afraid, you know, like that's going to be the last breath so it took a while to get adjusted to him".

Other participants contributed:

"She came home with the trach in her throat, she still needed to be suctioned, and she still needed to check blood pressure and making sure the pills are right. I was doing the pills, I was doing the suctioning, and I was cleaning out her trach. I did have a home nurse that came at...in the beginning three times a week and she was helpful but they only come for a little bit and they do, they make sure everything is ok, they show you how to do stuff but basically you...you're the caregiver and you need to monitor because, you know a lot of things could go wrong if you're not on top of things".

" just becomes chores; it become the chores of taking the pills, making sure the pills are...or doing the pills, you know for a whole week; adjusting the level sometimes when you have to adjust the levels staying on top of it; making sure you're ordering the drugs, even...sometimes fighting with the drug company cause they say you can't have...the doctors changed the prescription but you don't have the pills so now you have to call the drug company it's just steps and steps".

The participants continued to elaborate 
"I hired a cleaning person to come and clean up, maybe once every two weeks/three weeks, whatever it needed but, at the same time I would do a lot, when she came home from the hospital, making sure she is eating; I had to fix all those meals and making sure that, she getting clean, getting bathed and everything like that. It became a chore".

Some participants as they assumed their new caregiver's roles and responsibilities noted that they had to push their family aside and neglect them as they assumed their new caregiving responsibilities

"Before the transplant it wasn't such a demanding; after the transplant, he has been really demanding, when we were released to go home, then pretty much it was with him fulltime. I had to take a little absence from my work to make sure I was with him --make sure that I am preparing meals, finding out what is it that he needed, make sure that he was taking the medicine that he needed to take, make sure that he was eating properly, many other things, making sure that he was exercising cause he had to walk using the walker, make sure that he was getting up, make sure that, clean the cut on his chest; so it's...it was pretty much $24 / 7, \ldots$..you relax for a couple hours you go to sleep but definitely, it was a lot to do with, the time I was with him, I was involved with him 24/7 and I had to push my family a little bit aside to be able to help him throughout _ think he, was not able to, like clean himself, I had to do everything; like driving, him around 24/7; from 7 o'clock in the morning to 8:00 - 9:00 o'clock in the night when he went to bed. So, I have to this day, coordinate every single one of his appointments, every single one of his things, you know, email they sent, whatever it may be...I have to coordinate. To this day it's really stressful because like I said, I have my own life and I have to go and coordinate all that, so it's very difficult to make sure that it doesn't interfere...coming in here to clinic, it doesn't interfere with my kids' life or my kids event or my family. I plan it with him and then, driving an hour two hours back and forth, then it does take a toll on him, so make sure that he is ok, that he's relaxed and then sometimes he feels down".

"I get really frustrated with that and going to the doctor's appointments after the surgery was just...we had to get up so early and I had to get him ready and make sure we had everything we needed and fight that traffic and that was difficult and not knowing how long we'd be there and how... what the shape he was gonna be in by time, you know, we left".

"It was little crazy cause, it was pretty much overwhelming for me to see that much medication and then have to help him schedule them, but with him and myself we work out a system and he put it in his little containers, that was the... scariest part because I didn't know what was what and to sit there with him and try to see the different medications and make sure that he takes them properly, that was the biggest challenge".A Although almost $80 \%$ of participants described their caregiving experience as stressful, 
Approximately, $50 \%$ of these participants also found their caregiving experiences rewarding. They shared their feelings of joy, happiness, gratitude as they observed their family members performing tasks such as cooking, doing other house chores, dancing and simply just not requiring the use of oxygen anymore. Some expressed their delight in seeing their family member being able to take vacation by themselves.

A daughter who cared for her father after receiving his lung transplant stated the most rewarding caregiving experience was to see her father breathing and not using the oxygen.

"he couldn't even talk to me, we couldn't take him to the park, even just to sit and watch him because he had to have the oxygen with him all the time, so now that I...yes, he may be a little bit weak and he has to walk with a cane but at least we can have a conversation on the phone; before I had to...I couldn't have a conversation, because he couldn't hold a conversation he was coughing and short of breath even; and with the oxygen he was short of breath so it's very rewarding to see him to be able to breathe without the oxygen and have a conversation with us. You never be able to imagine, whenever I see my dad, walking without oxygen for the first time, being able to see him without the oxygen you know it is very rewarding".

Other participants added

"To see my dad, he... goes out with some friends, he goes out and talks to them about whatever they talk about; I mean he has his life back again, so he's very happy".

"She's gotten more independent, she's starting to do a lot of things on her own and I used to worry about her or go with her but, I guess in the last year or so I just let her go because she can do it, so nice to see her, in fact she takes off and goes to Zumba and art classes; and then I say, I don't have to worry about her-- she is doing great. That's a plus".

"She is traveling, dancing; she was dancing recently at a party...I can show you video; she was dancing last Saturday; some Panamanian music at a party that we went to and we're going to another party this weekend, for my birthday (laughing) so just to see her smile; to see her enjoy herself doing things that likes such as watching baseball, things like that; I mean that rewarding., Sometimes when I call from work and say what are we going to eat and she goes like I'm cooking; is like, you know, it's...is like we're back to normal"

"I am very pleased and very happy to see my friend, she can walk she is not using oxygen anymore, she can laugh, she can cry, she can play with her kids, she cooks, she is like a new person; she is a new person; sometimes I forget she had the surgery". 
"The most rewarding part now is that I got her back; my wife is back, she can...walk, she's living, she's alive, she's talking, she sees her grandkids it's...it's a miracle"

"just seeing him make those steps with my help to becoming a more normalize life and the expectations that we had and he is getting there, his increased physical, emotional and cognitive self; all three of those things is good to see the improvements. Him becoming more social because he felt better because that's him, and to see his personality comeback and him having more confidence that things are working. The greatest reward was when but we were turned down for a study with another doctor and then she sent us over to the transplant institute and the doctor there saved my husband's life, so that is really a great reward".

"Now my dad takes care of himself he does his food; he cooks for himself, he orders his medication. I let go completely because he's so good with that; he's very good, and I'm very proud of him. Now we're so grateful and thankful but sometimes we can't help to cry when we see him and he gets so excited when his labs come back and they are good".

"Watching him walking around, no oxygen, he may hobbles and wobbles sometimes but I feel a lot better; he is much better than before. I left him alone for four days; I went to New York and I didn't leave until I was sure that he would be able to take care of himself'.

A participant who cared for her husband was very happy when he was able to fulfil his lifelong dreams of going on a vacation to Albuquerque; she commented:

"When he went to Albuquerque, I was like wow, he really did it and our friends, picked him up, take him to where they were and he did well. He really wanted to go on that vacation, and he made it after the transplant, that was a very rewarding experience".

Few of the participants viewed their caregiving experiences as a period in which families were brought together:

"we have always been close but this really just brought us together even more because we had to fall on each other for that strength and some of us are weaker at some points than others and I had to be the rock"

"For me it is been life changing since she became sick, I feel that prior to her illness we were living separate lives in the same house, all we were worried was about obtaining things. This experience brought us closer --although we don't live in the same house I feel 
blessed that I've been able to take care of her, I realized my love for her and this made me appreciate the time we have and I thank God I can take care of her".

"I mean I don't worry about me, it was all about her ...I love my wife we're together thirty-seven years, it's just... we went through a lot of ups and downs in our life; this whole transplant brought us closer together at this time, and .we support one another we always talk about the day that we could spend together; that day just got pushed on us earlier".

\section{Theme \# 3: Caregivers Psychological and Psychosocial and Issues}

The caregiver's responsibilities and roles may necessitate rearranging priorities, shifting roles and responsibilities, lifestyle changes, and redirecting emotional and physical energy. The intensity and frequency of caregiving activities can negatively impact the caregiver's physical health and financial status. Most caregivers reported altering personal plans, making work adjustments and frequent disruptions to family routines because of caregiving demands.

\section{Social Activities and Lifestyle Change:}

Most caregivers admitted that they participated in less socialization with friends, attended fewer social activities and gatherings because of their commitment to take care of their loved one. The caregivers suggested that several lifestyle changes were made to ensure their loved ones received the optimum care. Several caregivers also described how they had to plan their life around their loved ones and neglect their immediate family including their children and spouses to provide care for their loved ones. Caring for their loved one became their priority.

\section{Life styles changes:}

One participant who provided care for her father after his lung transplant shared her experience as: 
"Life changes, once again, how do you manage your life from...your social life your family life. I was his caregiver but I have someone to support me so my husband, a lot of times, had to go around and pick up the...the kids, leave early because I was here; during the first month and a half we brought somebody, my mother-in-law, to help with the kids, because I couldn't help with my own kids because I was helping my father so that was a huge change there; It was very, very difficult because I couldn't even pick up them up from school...so that's, a huge change...to this day too I mean, I have to coordinate everything with him; whatever appointments he has, being able to talk on the phone to find out if he has a doctor's appointment, if I cannot go with him he go with my brother. He speaks no English so have to be involved".

She continued to elaborate

"how do you plan your days; its affect you a lot more when it's closer after the transplant that you have so many appointments and so much follow-up as it... it's been very, very difficult, you don't pretty much have your own life, you have to plan your life around the transplant patient".

Some caregivers expressed fear of their loved ones being exposed to infections, and becoming ill, after receiving the transplant. Therefore, several life style changes were made in order to restrict their loved ones exposure to ill contacts. Other caregivers were forced to make some lifestyle changes that would allow them to have other family members participating in the care of their children and spouses due to their unavailability to do so.

“(sigh) After the transplant we thought we weren't going to be able to handle it, all the medications, the food that the diet that he had to go on...we had to switch everything around in our house to support him making sure everything was clean; we...we were so bad that we wouldn't let anyone visit him; they would visit him through the window outside; we would open the curtain they could visit from outside cause we were terrified that he would catch something. This went on for the first, I would say for the first three months and then we started becoming a little bit more, you know, pleasing to the family, letting them come in they would have to wear the whole full suit and... and the mask and everything um... but they would have to sit in a separate room from him".

She continued to share her experiences as she described some more changes that

were made to facilitate care given to her dad:

"Definitely, the diet changed for all of us cause we have to be supportive of him; we can't eat the sweets in front of him and he's a...he loves sweets and breads, so the diet is definitely different. The furniture in our house; something so simple as that; we had to rearrange the whole thing..... to comfort him to make him, feel better; um seeing him lose 
weight is hard; seeing him...he was this man who was so built and...and so now we see him shrinking like a little raisin and it's...that's hard to see, we knew that there was a price to pay and what's inside it's worth what we see on the outside".

\section{Other caregivers added}

"because you have to give up so much of yourself so that you can focus and do what's best for them; they become the world so... and in the process you know what's happening but you not gonna change it and that happened....well in the house, we put up, handrails in the bathrooms he has a little area where he sits in his recliner and we make sure everything is there for him".

"become a fulltime job and I neglected my family a lot because my father became my priority so it was very hard cause I have two teenagers and they are in high school... at this time they were in high school and it was hard for them not to have me home, you know, their routine at home was down the drain, my husband, thank God, was very helpful; but it was hard. I had my son who became very angry with me, he was also angry with God, asking why God allows grandfather to be sick and taking away his mother from him. It affected him so badly that his school work and grades were greatly affected. During that period, I struggled a lot with some guilt feelings but at the same time I remained committed to my father"

A participant described her life style changes in relation to re-gaining the opportunity to be able to participate in worship at her local church, after her husband underwent the lung transplant.

"Well it is hard to be a caregiver because you make...you want to make sure that everything you do is for their best benefit and really, we didn't go to church during that time and that...I missed that, that's about the only thing I didn't get to do before his transplant that I should have gone ahead and do. I just want to stay there with him and but now in the post, we have been going since...he goes with me to church; so, it's probably about 2 months or so we started going back to the church. It was hard to get going back, you know, after you've missed so long you think to yourself, should I go...go today or should I wait another week, it's just hard but that's such a big thing in my life that I couldn't wait to get back with it and I'm so thankful that everything that God has done for us"

\section{Social Activities.}

More than half of the caregivers reported they were not able to take family vacations or get away for a length of time because of their involvement in the care of their loved 
ones. Few admitted to no changes in their social life during the pre-transplant phase but admitted after the transplant participation in social activities had changed drastically.

"Social life before was just nonstop for both of us; my husband is a very social person; I would say I'm not as social as he is but we have lots of friends and because he was in charge of a business and I had a home-based business, we could travel anytime we wanted to; we didn't have to think of any timeline, so...my business as travel agent and we travelled, minimum, four times a year twenty-one day land-base, cruise base to just a seven day Caribbean cruise. After the transplant, the social aspect changed dramatically and it was difficult for both of us and the social life changed in that people came our house and that was good that we had that but it was also hard because I didn't know how he would be feeling; it was very hard to set up timelines, you know, cause I just would never know".

"So before the transplant my husband and I like to travel, we used to go different places with the kids, only the two of us; after the transplant, you know, the first...the first twelve months, I didn't go nowhere, I stayed in Florida __...I think the furthest I ever went was Orlando, two and a half hours away, because I could not, after a year and six months that he was better, then I talked to my brother and said, I need help me with my dad I need to take these kids somewhere. I couldn't do as much and even now, it's been two years since the transplant pretty much, I still have to, you know, think where am I going to go, communicate with whoever is staying in here to make sure that he's not left alone and he has everything what he needs and stuff so definitely it...it's a huge change cause ...I cannot get up and leave anymore I have to plan very...very detail”.

"Social life was working, having time with family, teaching at school, travelling, helping people...I was also doing community involvement, getting food and clothes for the needy and those that less fortunate. Now I'm...I'm saying at home...before every summer...every year, we did something with our kids, he loved, that we would travel somewhere, if it was just like go to a hotel where they have all the stuff that surrounding the hotel and just give them that...thought of seeing other places to be exposed to things, we would do that a whole lot; after his illness, he couldn't do that but they were...I mean they were much older so they pretty much got together and did things as sister and brother but they pulled in, which was a big help"

Other caregivers added

"Before the lung transplant I had activities that I did, I like to umpire some baseball games and I referee football, I have my friends, would go out, do things together and go out for dinners, and stuff like, after the lung transplant it seems like everything kind a went away; everyone called for a while and said how things going cause you can't...you can't really go out, you can't go nowhere.. It seems like everything has stopped so it's kind of a 
different life, you...you move on ....we're home a lot ...everything revolves around her getting better".

"I would go out with my co-teachers for coffee and but I don't have a social life; I don't; I keep my schedule...my whole schedule open for what-if; I don't even...I don't plan; cause a lot of the times I do plan I have to cancel so I don't like cancelling on people, I just leave it open; I don't even think about social life at all... at all, even with my husband; we are at home and we're just... a routine, we just... leave it open to see what happens; I know my husband has, thank God, he found hobbies so he's out doing his things to give me the time that I need, you know, and I respect that but I see that he's going in one direction and I'm being left behind; waiting (chuckling"

"well not much sports (laughing) not much of a social life ; I mean, I used to hang out with some of the guys, you know but now that's...that's long gone; not because of what happened to her pretty much, I mean in...in part because I'm kind a became separated from them...friend, but that is not...not something that I really enjoy, knowing that she's home; where will I rather be, you know, being out there partying, with my buddies, , instead of being here, I'd much rather be here. Oh, it has been for the best, I mean, before I... sometimes I used to hang out with the guys, because, I mean, you know, normal men type of things that when you see something like what she is going through, I mean, your emotions and then I say, no, I need to be...but I need to dedicated most to my life, you know, to my family".

"my life is just work and home so whatever I had to change is just the fact that I wasn't working as much as I was because I was taking the time to be over there with her, spend all summer with her when school was out, stopped working on the weekends. During the summertime, I would spend all week with her and come up and work on the weekends and then what I did during the school year, I would work during the school year and then go over on the weekends but those are the changes I made to be able to be there to help her".

\section{Emotional Health}

Most participants described the impact of caring on their physical and psychological health. The dialogue among the participants indicated how emotional driven is the caregiver's role, some described the experience as a "rollercoaster". During the interview, some participants became tearful as they shared their emotional experiences. 
"I was nervous that she wasn't gonna make it I believe... the only thing that I was gonna save her was the transplant. Trying to stay positive through that, trying to be with her to be supportive of her, keep her spirits the best...I try to keep it, while waiting for the transplant,... and then after the lung transplant it...it was, being in the hospital so long, they, you know...before the lung transplant they ...they tell you...they give you a book and they tell you the best scenario, I guess, and they tell you that you'll probably be...you'll be up and walking the next day, yah she...she did get up, she got up...they got her up out of the bed; she wasn't walking but they got her out of bed ...but as it goes on...you watch her and they got this big tube in her throat, you know, you say oh almighty it's...it's...it's hard but again you got to stay positive. So, it's...it's a rollercoaster; you're up, you're down, you're nervous ... some days are good, some days are bad".

"Emotions (pause) (sigh) I used get up and cry every five minutes. You know, the story of my dad, he got kicked out of the Tampa program so because of that and I knew how much it affected him. I am not used to see him like that so a lot of times I had to contain whatever I was feeling and just breathe and go outside and cry outside or wait till nighttime and I cried at my house....to this day I do it. I just do not want to show him how upset I am, so is a lot of things that I don't do in front of him so I don't stress him out much as I know what stress can do to him. It helped me a little bit but at the same time when you hold so much in, is not good for you. When it's time for me to cry and feel down and I don't know what to do with him, then it's a bad day it is not an hour it is the whole day because I hold so much so he doesn't see my stress".

The participant continues to add

(Crying) "Dad snap at me constantly, so I had to learn how to not get so offended when he did it but it is very, very difficult, it is very difficult for you to manage. It has been two years and there are days that I just go home and cry because my dad say something that he shouldn't have said to me or anything like that...I think we were coming from one of the visits one time we were closer to the house and I started crying and then I couldn't do it no more because he said that I didn't help him enough and I know he thinks the world of me, but I think he was feeling so bad and so weak and so tired. Most human beings, snap at the person closest to you so that's why it has been stressful to manage, not only my feelings but his; to know when he doesn't really mean it and maybe when he really mean it I need to step up so it is...that's the stressful part “.

Another participant shared similar feelings

"It is not easy, it was frustrating sometimes; sometimes I cry, I go in the bathroom and I just cry and I cry and I was like you can do this and I would say, no, I can't, yes you can, you know, going back and forth with myself, but I just call up, transplant coordinator (laughing) or somebody talk to my husband tell him something. Yes, it can be a challenge sometimes so I would call the principal of the school and he is also a psychologist, because I think I need counselling alone". 
(sigh - pause - crying) "was very hard to not show my emotions cause, I mean, my father is...our mother and our father...my mom is wonderful but our father is our mother and everything else; this man is unbelievable so my emotions are crazy. Like now we're so grateful and thankful but sometimes we can't help to cry when we see him and he gets so excited when his labs come back good. Sometimes I wonder if I am doing the right things and it's just a rollercoaster".

"before I was just very scared not from the diagnosis time but towards the end as he was getting sicker and sicker and then we couldn't leave the house and I couldn't leave him and it was very scary. After the transplant, the first month, it was just ecstasy because he was doing so good and I'm, within that first month, he had off oxygen and his color was so good, it was just ecstasy but then things turned because he got sicker before he got better again and then that became very difficult because I didn't know if...because he wasn't doing well that I could lose him again I had to go through those same emotions again or if it was just gonna take longer and are we prepared for this fight ahead of us" .

\section{Physical Health}

Some participants reported health issues while providing care for their loved ones, while others felt there were no changes to their health status as related to their caregiving roles and responsibilities. Some caregivers acknowledged that they were healthy while performing their caregiving roles but admitted that their caregiving roles caused more stressors and psychological effects. Other caregivers thought they had neglected caring for their own health because of their commitment to the family members.

“I’ve been healthy; I'm a very healthy person luckily, but I was stress; I think it was more stress, I had to go outside and walk for a minute and breathe in and that was my sanity, I guess he was on medication causing the mood swings and stuff so I had to make sure that I didn't show that stress. I had to take time to deal with my father and have to go outside the house sometime and breathe. My health has been ok but it was more my stress levels were off the roof because, you know, not only had to take care of my father but I do have two children and a husband to care for so, it was very stressful".

"Before the lung transplant, I was fine I never had any problems physically, I only had some, knee problems. While I was at the hospital the doctor pulled me aside at over at the ICU and he said look you need to take care of yourself cause he's seeing me there every day, I was staying for a long period of time, he said you got to take care of yourself at the 
same time as you take care of your wife and I explained to him that she's, nervous when I'm not here so I have somebody there at all times"

"Well I've always been pretty healthy I'm skinny but, sometimes while in the hospital with my wife, I am so tired I would fall asleep standing, and they said you need to take care of yourself, because you will not be able to take care of her. My blood pressure went up, some of the nurses did take care of me, you know, and they say, you need to see your doctor or called your doctor after they took my blood pressure and my vitals. They say you need to go to a doctor, so I called my doctor and the doctor took care of me. Even at work, you know, they could see, I was not the same. It did take a toll on me, I mean, my blood pressure went up that's not resolved. I check my blood pressure, my blood sugar, I now pretty careful, but yes, at one point I did feel like I was going nuts".

"My health - I think I paid more attention to my health before this problem with my husband because I became so conscious of everything that went on with him because it was his lungs. Now after the transplant, I keep putting it off and say I'll take care of me, I'll do it, you know, I'll go in. I will go get a physical and then not do everything else, so it was hard; but people would say you need to take care of yourself, I was like but how am I going to do it and ignore him and this is critical because I got kids also to take care of'.

"Well, I was very active, I was a lot thinner and I wasn't tired, I'm exhausted, I'm very tired now; we I don't have any rest time I'm always running around doing stuff. I let go of myself, definitely let go of myself sometimes I think that the thirty months that I spent focused on my father when he was going through the... all the exams to get to... on the list really took a toll on me. I mean I quit my job and it was like nothing mattered except for my father's health so I did let go, I gained a lot of weight from eating, I don't feel the same, I feel old, I feel tired and I...sometimes I wonder if it's something maybe because I'm older now, I sometimes think maybe menopause but no, I just think it's the whole situation with dad and how we still have to keep on top of his doctors, medication, appointments and I still have to take him to everyone. I put my health aside for him because all of a sudden something pops up and I have to...like tomorrow I have a dental appointment so I canceled my appointments today because I haven't the time...so I can take him tomorrow so who knows when I will do the dental appointment"

"I was younger before and...so I did ok physically but mentally, it was difficult. Now I'm older and I'm feeling the stress physically but not as much emotionally because he's getting better. I fell and broke my arm and I have trouble sleeping sometimes and then just recently, we discovered I blew out my thyroid again so we've had to increase the medicine".

"I had to take him three times a week to his therapy and then I went to work and that began wearing me down and I didn't know, I was dying and I didn't even know; I always 
tell people that taking care of people think of yourself first; in order to be able to take care of you... somebody else, you have to take care of yourself, it's very hard, it's very hard".

"My health has been deteriorating too, I had my neck broken three places and my lower back in two and a couple knee surgeries and it was kind a tough for me getting around especially when I had to help her get in and out of the bathtub. At least I could breathe; I couldn't imagine being suffocated like that, not being able to breathe".

"I have emphysema from smoking and believe me I smoked a lot more during her time on the transplant list and thank goodness, I stopped smoking but added to my health issues. My arteries, I had a stent put in within.... seven months ago. I'm taking all kind of medicine and secondary quitting cigarette and the anxiety I can't control, I have to take medicine for that and this...to keep me stabilized, for some reason, the slightest thing puts me on the edge"

"Before I have... a problem with thyroids so I had taken drugs called synthroid and then another medicine in order to keep my thyroid under control and I was able to continue doing that and then, I had a mini stroke... since his operation I've had a mini stroke; I do not contributed it to anything that he did, I guess it was just my time, I'm, seventy-seven years old and so he being seventy-five when he was accepted into the program, we were so thankful because he was the oldest transplant patient at University of Miami".

\section{Financial Issues}

More than half of the participants reported some form of financial difficulties while caring for their loved ones who had a lung transplant. The participants reported using credit cards, personal savings, conducting fund raising events and receiving financial assistance from family members and friends to assist with the expenses incurred during the transplant process. Some participants stated although they had experienced some financial strain they were able cope financially during this period. Additionally, some caregivers' financial status was further compromised by the loss of employment due to their caregiving commitments and also from reduction in time worked resulting in less income earned.

"Well a lot of things he needed because it slowed him up from working two jobs to now, really minimum, and so then he had to go for to social security, he had to fill out all 
of that, it was really hard because he says I'm, not down and out, I can work and, you know he was not able to work. It was hard for me because I lessen my hours to try to be around to help.....all our needs were met, we didn't go without lacking, bills were paid, we were just blessed us, we got checks in the mail from friends, family just to help us but are getting back on our feet now".

"I used up my money sources...you don't get paid for the leave of absence so we did a fund me online and my brother and my sister-in-law were very helpful in setting it up. I was involved in it a little bit, we got get some money and it was enough to keep us going. I mean my savings account, took a hit, luckily I had some money to fall back on over the years ,my job was supportive in the beginning they really were; during the course of this I got a boss change, and when the new guy came in he wasn't supportive, they only hold your job for a year, when the year come around I had to make a decision to go back to work or care for my wife and I couldn't do it so I told him no, I can't come back to work so luckily after a few months later she was able to, fend for herself so I was able to go back to work...but I took a lesser role so...I'm not making the same money I was making but you know I'm making enough to pay my bills and I still got the time to take care of her"

"Before the transplant we were doing, we were all working, we were all putting away money to, plan out little trips because for us, it is very important to get the grandchildren and everybody together at least once a year. I'm talking like a weekend in Orlando or something; nothing extravagant; But now...we worked hard every day and we pay bills; it's day to day now, we wait for our paychecks to pay. When my dad began with this issue we wonder how we going to pay the medical bills, how... and, of course, credit cards, that's all we can think about, is credit cards, that's what we'll do whatever we have to do; if we have to sell our house we, do whatever, we re-mortgage, whatever, there was no question about what we needed to do to get through. We were fortunate enough that his Medicaid paid a lot of it but everything else fell on to us; the breathing machine, $\$ 5,000$; we didn't have $\$ 5,000$; there goes the credit card, you know and so, we're paying and our interest rates are crazy but those are secondary to compare with my dad. We still have to pay your bills; and still have to maintain ourselves, so we cut a lot, we don't go on trips, there is no money, and there are no funds. My brothers, you know, worked extra hours at $\mathrm{k}$ to try to make up for whatever we need and I'm working the summers, I'm a teacher, I'm working the YMCA in the summers where I didn't have to work before, I could stay home and take care of him. I can't, I, you know...we have to work that money back and so we can also put away for the future cause we don't know when is it going to stop or what else will in the future. The dental, is not covered, we have to pay his dental, what are we going to do...\$7,000, what do you do, you have to provide it, so it's always credit card, it's...we're in a hole but what do you do, you have to provide what we need".

"I had a steady job before the transplant and I still do, but after the transplant and during, I had to take a whole month off, you know, only sixty percent of your pay so that 
was a big loss, and, we live far away from here, so I'm the one who provides for everything whether is gas, lunch, breakfast. Right now, you know, if he needs something to eat on the weekend, then we take him food...luckily I have a partner who help me tremendously, my husband does that but If I depend only on my income I wouldn't have been able to do it if I didn't have somebody supporting me because one trip just to come to Miami, it could be fifty/sixty dollars with gas and everything and it was weeks that we were coming; three days a week, so, imagine that a hundred dollars/a hundred and fifty dollars extra a week that comes out of your paycheck, it does add up so it...it's been an adjustment for my family, luckily, it didn't affect my family just because I had a partner but if it did definitely, I would have to ask for some type of help or something".

There were also mixed feelings among the participants as a few stated their caregiving role and activities did not have any significant impact on their financial status.

"Well it's been solid; we're not rich; but yes, it did create some problems. At my work, I have not had a raise and, a bonus in the last three or four years because they say I am not here and then...but that's just a way for them to excuse themselves from not giving me a raise; even though I do perform, I do my work and everything. That also for them to say well you need to be here all the time and you're not, even though wherever I am doing my work. I haven't gotten a raise nor bonus but it is what it is, I do have a job, and we have insurance and it... helps to take care of all her needs".

"My financial situation has changed somewhat --my husband retired sooner than he wanted to just because he couldn't handle his responsibilities and he thought he was going to die so we prepared together what our life would be like without him and... that was difficult but because my husband was a partner in a business, it was time for him to put our son in that partnership and he want to know everything was in place for him so he retired and...so once he retired, the financial situation changed. We are fortunate that we planned for retirement and we have good insurance, probably luckier than most, so we're doing fine financially".

"It affected my income, some, but taking care of my friend was more important to me than paying my bills on time; not working on the weekends took away money from me and from my children but being over there with her and taking care of her, was more important than paying FPL or paying whoever".

\section{Employment Status}


Maintaining a steady and meaningful employment posed a challenge to the participants as they engaged in their caregiving responsibilities. Some participants were forced to seek early retirement and reduce their workhours in order to participating in their caregiving roles, while others were faced with the difficult task of balancing their work activities with their caregiving responsibilities.

"I worked from home, I don't think I could have worked at all if I wasn't working from home and it became more and more difficult. It...it was more stressful because when I was working I needed to be with my husband, when I was with husband I needed to be working and it was just this vicious cycle, I couldn't; I could never get caught up. I never felt I did enough over here. I knew that I couldn't go on so my husband retired January 16 th and I pretty much shut my business down. I knew I had done the right thing; just ... by getting rid of that stress, it helped me even cope better with the stress with my husband".

Another participant who was also faced with the difficulties of balancing his work load while he cared for his wife. In the dialogue, he revealed that in order for him to be able to continue his employment while caring for his wife during her hospital stay and visit to the clinics, he brought his work equipment such as computer to each visit, thus allowing him the opportunity to continue his work activities.

"Well, it did change my attitude completely I mean an event like this will completely change your outlook of life if I have somebody that is sick, I want to do the best that I can. When I could go to work the back of my mind is somewhere else and then I'm with her, my mind is also at work. I would sit right next to her when she was in bed, with my little desk in there and my computer and working, answering phone calls because, I wanted to be able to be in contact so that my boss would know that even though I was not in the office, and they could rely on me. When I go to the clinic, I was carrying my computer with me and... and I open it up right there when you guys are talking to her and I'm doing my thing so...even to this day, I mean, it's still... is like a balancing act, you know, which is hard to keep up with".

A wife who cared for her husband commented:

"Before I had friends, who would stop by, and check in on him and or come by the house or call when, when I was at work and sometimes I would cut my hours. I have 
somebody to fill in for me because anytime, because we were going back and forth to Miami often, so I had people to they take the hours for me, filled in and then some days, some weeks I had to stay home with him; it was a challenge"

Another participant shared her employment experiences caring for her father. She mentioned using family medical leave of absence from work, thus providing her with the time she needed to care for father.

"I had to request family leave from my job I was lucky enough that, I was able to get approved to take the days, first couple days out and then I had to take more for the days to come here (clinic) so it affects me more. I was behind with my work cause, when I come here to the clinic three days a week then the other, four days or the three or two... I had to try to finish everything. I cannot complete in three days so when I go back to work, I had to depend on a lot of people to do those things, if not, I couldn't have done it because, you know, two days to get five days of work done is not possible".

One participant had to make the difficult decision of quitting his job to participate in his caregiving activities, while others mentioned establishing certain rules with the boss or making special arrangements that would allow them time to freely participate in the care.

"I had a letter from my job saying that she was gonna have surgery, she could be called at any time and if I have to go, so my boss knew that. Therefore, I got that letter saying that I have to take care of my friend; I would only work, driving my bus Monday to Friday; Friday afternoons I'm gone to...take care of her. I just had to let my boss know anytime she's called, I have to go and they knew it, they had it in writing".

One participant stated despite not being allowed to communicate on her phone during her work hours she was compelled to do this as it allowed her to be able to participate in her caregiving roles. She further mentioned in order for her to maintained gainful employment she had to establish some rules with her boss that would give her the flexibility at work to continue her caregiving roles.

"It's hard because I had to carry the phone with me; I had to establish certain rules with my boss and, he knows that I have to carry that phone and that it's on at all times. Sometimes when you receive a phone call, you freak, you get nervous right away cause 
you think it's him or you think it's the hospital or, you know, the labs came back wrong or something, so I'm on alert all the time it's not something easy ...I never kept my phone with me and now the phone became my best friend so that's...it's hard".

Other participants reflected on their ability to maintain their work status as they strived to balance their employment and their caregiving activities.

"I was working at the time when he had the first onset; and thank God I was working at the hospital where he first came. I was working at the hospital so I was able to go to my position and then leave there and go and sleepover at night with him, staying at the hospital basically twenty-four hours, so I was sleeping with him and then go back to work. Or I would switch my shift from morning to night. My floor assisted me with that, they accommodated me with whatever I needed, whether I needed to work day or night so that was one of the plus points for me. After the transplant, I had retired and wasn't working afterwards anymore".

"Yes, I was working twelve hours a day and then I would come home and take care of him but then I started cutting down on my hours...because I was a massage therapist, and I didn't think anything of it cause, I was short of breath all the time and I went to the doctor and I thought I had pneumonia and it wasn't pneumonia, it was just water collecting in my lungs and I thought I was ok and I continued working, taking care of him but then all of a sudden he saw what I was going through and he is the one to call 911 cause I was dying. I was dying before his eyes, it was hard, it was hard, it's... its hard; that kind a reality, you know, and you feel alone and you feel angry. I only worked while he was waiting for the transplant. My boss they were very good, they were very good with me, they let me take him to whatever he needed to do in the morning and I went in half a day; they were very compassionate cause they knew what I was going through".

"Actually, I had problems with my work they pushed me to retire. They told me I had too many problems at home; my wife calling me, my daughter calling me, I had to ask for time off, sometime leave early, stuff like that and it got to interfere on my job and they kept pushing me to retire they would tell me...you need this time off. With, the work it wasn't easy, so I finally realized that I can't deal with those situations, they made it worth my while and I would retire. So, they considered it and we worked out, more or less, a deal where everybody was happy and I left".

"I had stopped working when he got sick and had to go on oxygen but before that I was with his brother who is a doctor by bringing patients to him like those who were on walkers...couldn't walk good. I didn't pick up any wheelchair patients because I couldn't lift the wheelchair but I picked up all the walker-type patients, people who needed a ride; people who didn't had a ride. I did that pretty much full time. I really didn't do too much 
working outside the home because I wanted to be there with him, make sure the oxygen was right and whatever he needed was done. I was basically watching after my husband"

"Oh well, for me, I didn't stop working believe it or not; I was working; he was in the hospital and I was working, I used to finish my job and go to the hospital and spend a few time.... a few hours with him and then go back. I couldn't stop from working because if I didn't work, I didn't get paid. At this moment, I don't know how I did it but I did it (laugh) because in the day I used to wake up at 5:00 o'clock in the morning, go to my first job then to my second job then go to the hospital; thank God one of my jobs was very close to the hospital and spend there with him, maybe, four hours, then come back home, sleep for a few hours and then go back. My only day off was on Sunday and then on Sunday, I used to spend the whole day with him".

\section{Theme \# 4: Support:}

The participants discussed the different sources of support they received during their caregiving experiences. Some reported receiving support from family, friends, health professionals, community and spiritual supports. However, the availability of the support varied among the caregivers, as some caregivers described sharing their caregiving responsibilities among family members, friends, health aides, while others had performed the caregiving activities exclusively by themselves.

\section{Family/Friends}

Approximately one third of the participants reported receiving much needed support from family and friends.

"I mean I'm blessed and thankful the family that I have my in-laws, my husband, my kids, my mother. Everybody who is part of it would help with taking care of him; I couldn't do it without my family supporting me, so it can't be one person. It's impossible for one person, I could not do it...I do today and every day, to this day if I can't I will call my mom and say my dad is driving me crazy or my brother or my husband or...or my kids".

Other participants added 
"It was a change of life and thank God for mother-in-law who lived close by she could help with the care. With all of that around me and having love from church family and my family coming back and forth to help, I also received some help from the principal of my school he was really, really good to us. We also have a lot of people that are nursing aides, or nurses, including my sister who was willing to help with his care. We always had enough people that I would come to the house to help me with caring for my husband".

"You do need a lot of support, not just from you, you can't do it yourself, you really have to have a good strong support group at home to be able to help and manage the medications and the routines and the cleanliness of the house and the preparation of the food. We have always been a close family but this really just brought us together even more because we had to fall on each other for that strength".

"My wife has a big family, has six brothers and sisters and they are all very supportive and I also have a family that helped. When I need help if I call they would come and I also have my daughter who help"

"I have some family members that would be willing to come...step in and help, I also have a lot of support from church that will also help me with the caring for my son".

Although some participants reported that there are other family members available to help they were however hesitant to ask for help. A wife who was caring for her husband after the transplant described her experience with her son

"We had a good support system, more so after the transplant, I just depend on family because he was just too sick and anybody else who can help us, you know, and even with that support system, sometimes I wouldn't step up and ask for help; when I had to I would but there could have been times that I should go ahead and call my son and I wouldn't do it. Because I know that he's really busy with the business and work and I know he'll come; there was never a doubt that he would come and he was so good about coming when we needed him I just didn't want to take disadvantage of that".

Some participants reported receiving some support from home health caregivers. One participant described how a home health nurse's aide was able to help his wife during the immediate post- operative period, while another participant described receiving support from a nurse's aide after she broke her arm. 
"I did have a home nurse that came at...in the beginning three times a week and she was helpful but they only come for a little bit and they make sure everything is ok, they show you how to do stuff but basically you're the caregiver".

A wife who sustained a fracture arm during her caregiving activities described how she obtained support from a home health aide to care for her husband.

"When I broke my hand, I had my son take my husband to the clinic that day and I got a home health aide to help with caring for my husband I know I couldn't do it, I knew I couldn't do it the way I have been, I just know I can't do what I've done in the past with a broken arm. I can't I have to take care of that so it heals properly; so that person started the next day, stayed with us until my hand healed and she comes periodically to help me."

Another participant added

"We did have some nurses in beginning when she first came out because she was still, in delicate condition; they would come, for an hour or two after then we hired another aide that would come in and... To stay with her also for a few hours while I was out and her sister that came, for two or three times, you know, to the United States and stay here for a week or so to help with her care"

On some occasions, participants reported not receiving help from family members or friends due to family members or friends not living in close proximity or just simply having no families or friends available

"I didn't have much support from my closest relative or friends--- I was the only one taking care of my wife along with the support from home health nurses or aides"

sigh) "It was very hard, I thought I was alone (crying) and I am alone, nobody is there, you expect family to help you; his family, when you need them, they're not there and I almost died in the process; I had a congestive heart failure but I said I was gonna live so I could take care of him; sometimes I get very angry, not at him but at the lack of compassion; there's isn't any; you think you have people willing to help you but it's very hard, it's very hard, nobody is there". 


\section{Professional Support}

The majority of the participants were pleased with the support they received from the transplant team. The written information they received was used to guide them through their recovery period. They expressed their appreciation for the transplant team and were thankful they were able to keep in contact with the team. They also stated they had trust in their team.

"I'm grateful for the team of doctors, and I count our blessings all the time; I don't know what I'd do without the team down there for support; even though friends are great and my son is great, if we didn't have the support down there... and I've never felt that I couldn't call and ask a question, so I think that's also a big plus especially when you just don't know day to day what's gonna happen so that's good".

"I was so grateful that she went into that hospital. Jackson is there to help people and the care that they give my wife is more than I expected and to me is awesome, it's...just something that I would always be grateful for, you know...if I ever get sick I hope take me to Jackson there not anywhere else".

A husband who cared for his wife who had a lung transplant praised the transplant team for the support he received while taking care of his wife, he added:

"I would say the team of people that I worked with at Jackson Memorial were they were topline professional, they helped us every step of the way, and they still do, so I mean they are still concerned and they help you answer any questions, you pick up that phone and if no one answer the phone and a message is left for the team someone calls you back immediately"

Other participants continued to share similar comments

"Want to talk about this transplant team you guys have; I think it's great, not only for what was done for my friend but while waiting in that waiting room, I met other people and everybody had nothing but good things to say about the way you guys worked and everything was done really, really good, really good, I...I hope I never have to go through it or know anybody that has to go through it, but if somebody is in that situation, needed to go through something like that, I would tell them, you need to go to Jackson, (laughing) 
you need to go to Jackson, they have done well for my friend. If...she doesn't tell you she had surgery you could never know".

"I had wonderful nurses that taught me to totally care for her including bath and tending to her needs. I thank the team for the care she has received, the team gives us the impression that they really care for my wife and that makes working with them a pleasure. I thank everyone from the bottom of my heart"

\section{Support Groups}

It is cited in the transplant literature that support groups help caregivers to deal with stress associated with their caregiving roles. During the interview, few participants shared their feelings regarding the help received from the support groups. The conversation between the participants indicated that although some were knowledgeable about the support groups, they were not able to participate for various reasons. However, one participant shared her experience and how the support received from the group was helpful to her and her son.

"I know the transplant team offered the support groups and everything they are for us, coming out of work, it's... difficult to get there and that's why we haven't done the support group because we are all working till five/five thirty, by the time we come home, we have to cook and attend to our house... our household; we are all married with children, we are doing homework with the kids; it's not easy transporting dad with that traffic. If...if the traffic was not as bad as it is, maybe, but it takes us a good hour to get there, so for us... and I know he wants to go cause he's retired but it's hard for us to say yes, dad, let's go to these meetings in the middle of the week when we have to get up and get the kids ready for school the next day".

“in my case I'm gonna leave West Palm to come over here for a group; it's very difficult because that's time I'm taking away from him, when he needs me that much and those first two/three months of his transplant to come over here and it takes me at least four hours, an hour to come in, two hours here an hour to get back, so that's four hours that I'm not with him, who's gonna watch him, who's gonna take care of him".

One participant shared a different view of the support groups, she added: 
"Support meetings and I went with him, I try to go to everyone so that helped both of us to sit there and see people that have gone through this and the survival rate and stuff that they gone... through and how they were coping with it, that was very enlightening for me and him. I noticed that because he would talk about it (with) me, (it) was very, very important for both of us, and we try not to miss them so, we are there all the time, that alone was very good".

Though the participants shared their experiences of receiving support from family, friends, health care professionals and support groups, few spoke of continued or renewed and positive spiritual support and strength from members of churches with which they were affiliated.

"He had a lot of support from my church, their prayer, I think that, encourage him more and gave him the, faith and to be positive. I think that alone helps the healing of anybody while he's going through this situation. I see that his...made him more spiritually aware and more appreciative of life".

"To see my family and my church family pull up and just step right in like nothing was missing which made it easy for me to do what I needed to do for him, so I'm appreciative".

\section{Summary}

The results of this study had shown that caregivers of lung transplant recipients shared some common lived experiences. Participants may not agree on all experiences, however, it was evident that the themes emerged depicted that the caregivers shared comparable experiences that are stressful, frustrating, scary and rewarding. Caregivers were affected by the establishment of their loved ones diagnosis and learning that transplant was the only treatment option for survival for their loved ones. Caregivers spoke of being shocked by the diagnosis. Throughout the interview the caregivers shared their feelings of uncertainty, nervousness, frustration and shock on learning of their loved one's diagnosis. Many did not know much about the transplant, nor did they know what to expect. Most of 
the participants attempted to gain knowledge of the transplant from various sources such as doctors, internet, and other health professionals.

All the participants expressed words that referred to unanticipated changes and fear of death as their loved one's health deteriorated. As their loved one's condition got worst, unable to breath, walk, or to continue doing simple chores, the caregivers began to think that the times is approaching where they would eventually lose their loved ones.

As the loved ones' health declined the need for oxygen became eminent. This time was viewed as stressful in the caregiver's life. The act of managing the heavy oxygen tanks played an important role in the caregiver's daily caregiving role. One common concern shared by the caregivers was the fear of their loved one not having the available oxygen tanks when needed

One of the important highlights of the caregivers' experience is receiving the call for the lung transplant-- whether they had the possibility to follow their loved ones to the hospital or not, -- whether the call was followed by another call in which the transplant was cancelled. The caregivers shared mixed feelings. Some described this moment as devastating, feeling nervous, scared, confused, while others were eager and happy for their loved ones.

Caregivers perceived their caregiving roles as full- time job, stressful, their main purpose in life, scary and energy draining. During the interviews, the caregivers shared their experiences of balancing multiple priorities in their life to participate in their caregiving roles. Additionally, the caregivers revealed that frustration, stress and fear played a part in their caregiving experiences with varying effects on their health status, 
finances, life styles and social activities. Most participants had to change their life styles to facilitate their loved one's treatment and schedules. Participants expressed feelings of commitment and accepted the caregiving responsibilities as a "full time job", neglecting their families as they assumed their caregiving roles. At times caregivers felt conflicting emotions including anger, fear, frustration and described the caregiving experiences as a "roller coaster"

Although almost $80 \%$ of caregivers described their caregiving experiences as stressful, some caregivers found their caregiving experiences as positive and rewarding. Most of the caregivers described their experiences also as a time of significant financial strain. Participants were forced to leave their jobs, work reduced hours resulting in reduced wages.

Sources of support were also discussed by caregivers. In addition to help from immediate family members, friends and extended families, some participants shared their experiences of receiving some support from members of their church or community. Most of the caregivers voiced the pre transplant phase as the most stressful period during their caregiving experiences, because of the uncertainty and fear of losing their loved ones before an organ is available for the transplantation. 


\section{CHAPTER V}

\section{DISCUSSION}

The purpose of the study was to examine and explore the lived experiences of caregivers of lung transplant recipients. During the interviews caregivers shared their experiences, feelings, thoughts and meaning of caregiving. Based on the caregivers' interviews and data analysis 4 themes and 12 subthemes emerged. The themes were: 1) Establishing the Diagnosis; 2) Caregivers Roles; 3) Caregivers Psychological and Psychosocial Issues; and 4) Support (family/friend, professional, community). The twelve sub themes were:1) Caregivers Reaction to Transplant option; 2) Caregivers' lack of basic knowledge as related to Lung Transplant; 3) Disease Progression: Reality of unanticipated changes/Fear of death; 4) Pre -transplant experiences; 5) Hospital Course;

6) Home Care; 7) Lifestyle Changes and Social Activities; 8) Physical Health and Emotional Health; 9) Financial and Employment issues;10) Friends/Family; 11) Professional Support; 12) Support.

This chapter presents a discussion of the study findings in relation to the current literature on organ transplantation, study limitations and recommendations for future research and clinical practice.

\section{Theme \# 1.}

\section{Establishing the diagnosis.}

In this study caregivers shared their lived experiences when they first heard that their loved ones needed a lung transplant. The caregivers used various words to express and describe their reactions on learning of their loved one's diagnosis and that transplant was 
the only option for survival. Each participant articulated feelings of shock, fear, uncertainty, nervousness, anger, sadness, and being overwhelmed after the diagnosis was established. One caregiver described his reaction after learning that his wife needed a lung transplant as a "brand new adventure". He continues to comment that he was not fully aware of the impact of his wife's illness and he had never heard of a lung transplant before. Similar feelings were also shared by other caregivers. Other caregivers recalled their primary physician sharing the grim news with them that there was nothing he could offer, no medicine or other treatment, except the transplant.

Caregivers spoke of being shocked by the diagnosis. Many had no idea that their loved one needed a lung transplant as a life- saving option, while others thought their loved one's illness was just something curable or at least treatable. Not all caregivers were present when the diagnosis was established. Those caregivers who began their caregiving roles after their loved ones began to exhibit marked disability and decline in health, had a more difficult time accepting the diagnosis and performing their caregiving roles. Once the diagnosis was established and the caregivers became aware of the severity of their loved one's lung disease, it became evident in the caregiver's interviews that they had no clear knowledge of what a lung transplant was and what to look for during this waiting period, or pre -transplant phase. Most caregivers sought information from health professionals, internet, television and through other media. Caregivers' lack of transplant knowledge was made clear during the interview as caregivers used phrases such as:

"It took me a while until I realize because we never heard of a lung transplant before, you hear about a heart transplant, you hear about the kidneys, things like this but I 
never heard of a lung transplant". "I never heard of lung transplant then and so immediately I got out of the car and then I went back to the office of the doctor".

The reality of unanticipated changes and fear of losing their loved ones became a focus of the caregiver's life as their loved one's disease progressed and decline in health increased resulting in loss of basic physical capabilities and ability to participate in their activities of daily living. The majority of the caregivers spoke of seeing their family members not being able to do simple chores, such as washing the dishes, cooking, cleaning the house, bathing themselves, and doing the laundry. More than fifty percent of the caregivers recalled seeing their family members become bed ridden, sleep in a recliner rather than sleep in the bed, and try to breathe. The fear of losing their loved ones was frequently mentioned in the caregiver's dialogue. Phrases used by the caregivers to convey their thoughts and feelings were

“he had to sleep sitting up and at night, sometimes we wouldn't sleep watching him to make sure he wouldn't pass during the night; so, it was very, very scary". "Before, you know he just progressively got worse and the difficulty there was knowing there isn't much we could do and that the outcome would be...I would finally lose him". "I think he wasn't gonna last very much longer, and then the way he was living he was gasping for air every minute make it very scary and frightening". "No, it was terrible because for me, I think maybe today is gonna be his last day, because you don't know if he's gonna make it or not."

More than fifty percent of the caregivers expressed sadness on seeing their loved one struggle with the decline in their physical status. Watching their loved ones struggling to breathe and become less participative in activities or outings that were once enjoyable and 
pleasurable to them was difficult to accept. These present study findings are consistent with those of others. As Rosenberger and colleagues note, caregivers may feel confined and inconvenienced by having to be available to help their loved ones at any time and may also feel disappointed that the illness had substantially changed their loved one (Rosenberger et al, 2012). Research has shown that caregivers of patients waiting for a heart or lung transplant are worried about a rapid disease progression and death while the patient is waiting for the new organs (Meltzer \& Rodrigue, 2001, Goetzman et al, 2012). Similarly, Claar et al, (2005), found that $4 \%$ of caregivers of patients waiting for lung transplant reported feelings of anxiety, and Bohachick et al (2001), found $61 \%$ of spousal caregivers of patients waiting for a heart transplant reported feelings of anxiety and frustrations.

Oxygen became an important treatment modality as the caregivers' loved ones' conditions worsened. The caregiver's responsibilities and concerns during this time were centered around the management of oxygen and ensuring oxygen was available for their family members at all times. Some of the caregivers described this period in their caregiving activities as the most stressful time with the caregiving experience taking a toll on them. They recalled taking the heavy oxygen tanks around to the various appointments and ensuring there was enough oxygen available for their loved ones at all times. This added to the caregiver's stress and anxiety during this time.

The waiting period for a transplant is described in the transplant literature as the most stressful period, however, frequently the caregivers stress, frustration, and anxiety during this time period was relieved by the call indicating that a lung was available for transplant. A crucial point for the caregivers in this study was the transplantation call. A new phase of the transplantation process began when a lung candidate received the call 
that an organ was available. Lung transplant candidates often talk about this day, but most were unaware of the feelings and reactions triggered by this news until they arrived at the hospital and were prepared for surgery. Anxiety, excitement and fear were normal reactions and emotions of the unknown when the surgery becomes a reality. Upon the receipt of the news that an organ was available the candidate was now faced with limited time to get to the hospital. Admission for the surgery is always an urgent and nervous occasion and the transplant candidates and the caregivers had limited time to prepare for the trip, make final arrangements and to get their affairs in order.

In this study the caregivers shared their experiences with mixed feelings when such a call was received. Some caregivers referred to the transplant call as devastating, feeling nervous, overwhelmed and confused, while others were eager, happy and welcomed such good news. The caregivers shared their experiences of receiving the initial call for a transplant and having the transplant cancelled at the last minute because of incompatibility. Some caregivers indicated that on receiving the call they became very confused and unable to concentrate on making the necessary arrangements for the trip to the transplant center. Others described this experience as a "glorious morning" and "it was like having a baby, I had to rush before they took it away". However, interestingly some caregivers did not share joy at this moment. They were reluctant to assist their loved ones in making the decision to accept the organ when the call was received. They had fear the transplant would not be successful and did not want to be blamed for an unsuccessful transplant outcome. This finding was similar to that of Invarsson et al (2014) who studied relative's experiences before and after a lung transplant. The investigators found that caregivers were reluctant to participate in the decision whether their loved one should accept the new organ. These 
caregivers indicated that they wanted this final decision to be made by their loved one since they did not want to feel guilty if the outcome was poor.

According to the general transplant literature some caregivers and transplant candidates experience one or more dry runs in which caregivers and their loved ones go to the hospital and were prepared for the surgery, only to be told that the lungs were not adequate (Sadala et al, 2013). When this happens both caregivers and their loved one have to go home and resume their normal daily existence knowing that the opportunity to receive a lung transplant has been postponed.

The present study findings were similar to results of studies found in the general transplant literature. The transplantation process began as the patients and family members began to consider the idea of transplantation. At this time the caregivers and the transplant candidates may have just been given the news that transplantation was the only option. Many needed time to adjust to the prospect of a lung transplant. Some of the emotions felt by these caregivers and the candidates included shock, hope, uncertainty and denial. Many candidates and caregivers struggled through the decision-making process. Making the decision to be evaluated for a transplant or not was a decision all candidates and their caregivers had to explore. Once the decision was made by the potential lung transplant candidates to pursue a lung transplant, they then progressed to the evaluation phase. These candidates and their caregivers approached and underwent the evaluation process for transplantation with a mixture of conflicting feelings, distress and ambivalence. There were feelings of hope of having a healthy future and a normal life style, combined with fear and risk of surgery including possibility of a failed procedure, and what it meant to live with someone else's organ. 
Barbour, Blumenthal, \& Palmer, (2006) described the pre-transplant evaluation period to be stressful for patients and their family members. During this time the potential transplant candidate's organ failure can cause significant fatigue, appetite or sleep changes, cognitive decline and or general malaise. According to Meltzer \& Rodrigue, (2001) \& SaxeBraithwaite \& Chapman ((1992), during the pre- transplant phase, being listed for a transplant as the primary hope for survival can illicit feelings of fear and uncertainty among caregivers and transplant recipients. The feeling of uncertainty is one of the greatest contributions to reported stress levels among transplant caregivers.

Rosenberger et al, (2012) in studying the psychosocial issues facing lung transplant candidates, recipients and caregivers, noted that transplant recipients and caregivers experience a range of psychosocial and psychological issues that begin at the initiation of the transplant evaluation, and continues throughout the candidate's waiting period, peri- operative, recovery and post- operative period. The caregivers and transplant candidates enter into the most stressful period of the transplantation process. Generally, transplant candidates and their caregivers experience persistent anxiety about when, if ever the call will come that a donor organ has become available. Additionally, they experience frustration and monotony over their physical functional limitations associated with their advanced disease, especially if they require oxygen (Rosenberger, Dew, DiMartini, DeVito, Yusen, 2012). Similar findings were reported by Haugh \& Salyer, (2007), as they examined the needs of patients and families during the wait for a donor heart. The authors noted that caregivers find themselves overwhelmed during the pre-transplant period as they face the idea that their loved ones might die, not knowing when the transplant would occur or if the donor heart would come on time for their loved 
one. Other researchers suggested that transplant candidates spend considerable time at the hospital during the waiting period as their lung disease worsens and they require interventions such as oxygen therapy and mechanical cardiac assist devices. This increases the caregivers stress and burden during their caregiving experiences (Sadala \& Stolf, (2008); Cullen, (2006); Goetzinger et al, (2012). The period waiting for a lung transplant is marked by numerous anxieties and frustrations. During this time transplant caregivers and recipients must cope with numerous health related stressors on a daily basis, including decreased exercise tolerance, frequent hospitalizations, oxygen dependence and continued weight loss (Myaskovsky et al, 2005).

\section{Theme \# 2}

\section{Caregivers' Roles:}

According to Rosenberger et al, the role of the transplant caregiver begins immediately when the decision is made by the potential candidate to receive a lung transplant. Caregivers provide crucial supports in maintaining patients' physical and mental health throughout the transplantation process. During the various stages of the transplant process in which patients experience severe illness and disability, caregivers carry out practical activities that patients often took for granted in daily life (Rosenberger et al, 2012). These caregivers also played an integral part in the recovery and survival of their loved ones as they provide emotional and practical support. (Olbrisch, et al 2002). During the pre-transplant period the caregivers' role includes a variety of tasks including accompanying the candidate to and from medical appointments and diagnostic testing, resulting in caregivers rearranging their work schedules, planning for family and other personal demands and occasionally relocating temporarily to be closer to the hospital. 
From the caregiver's interview in this study it was clear that caregiving responsibilities and roles were stressful and complex and began when the transplant diagnosis was established and continued throughout the transplant process. From the caregiver's conversation it was clear that the caregivers viewed taking care of their loved ones as their main purpose. Words used by the caregivers to describe these experiences included, stressful, frustrating, energy draining, fearful, full time job and main purpose in life and being an advocate for their loved ones. The caregivers described some of daily challenges during their caregiving experiences as management of their loved ones' medications, proper meal planning and cooking, doing the laundry and helping their loved ones with their activities of daily living such as bathing. Caregivers also shared other day to day challenges that included management of different aspects of their loved ones care including providing transportation to different appointments, calling the pharmacy for refills of medications, keeping doctor's appointments, grocery shopping and providing gas for transportation. These findings are consistent with those of Kurtz who found that keeping the rigid time schedule for medications, laboratory testing and clinic appointments and simply meeting the needs of the transplant recipients to be exhausting (Kurz, 2002).

As the caregivers' roles and responsibilities continued through the post-operative period the caregivers shared their caregiving experiences during their loved ones' hospitalization and during care at home. The majority of the caregivers reflected on their loved ones stay in the intensive care units as a period of nervousness, energy draining, and a time of commitment, vigilance and frustration. One caregiver described his experience as a "rollercoaster." He described the three months his wife spent in the ICU as a time of 
"up and downs", due to the instability of his wife's progress. He also mentioned his commitment in staying with his wife during her stay in the ICU and how nervous and fearful his wife became when he attempted to leave her. He attributed his wife's fear and nervousness to her slow recovery process. This finding was similar to that of Kurz et al, (2001) as they examined well spouses' experiences as caregivers after a lung transplant. In their study it was noted that there was an over- riding theme among caregiver's experiences described as a "Roller Coaster Ride." They also described their experiences as "up and downs" while caring for their loved one and at the same time appreciating their moments and togetherness. Caregivers in the present study shared their feelings of commitment while staying with their loved ones during the hospitalization. They voiced their main concern for being with their loved ones as the fear of their loved one's worsening condition in their absence. However, not all caregivers shared this period of hospitalization as a time of commitment. One caregiver shared his frustration and desperation over his wife's inability to display satisfactory progress in her recovery. He wondered out loud about the length of time he would have to spend in the hospital with his wife.

Discharge from the hospital was a turning point in the caregivers' experiences. They were now faced with the realization that their caregiving roles and responsibilities had intensified and they would no longer be able to depend on the transplant team as they did during the hospital stay. Most caregivers were laden with the fear of not been able to effectively care for their loved one once they were discharged home. Words such as demanding, stressful, afraid, full time job and overwhelming were used by the caregivers to describe their caregiving experiences after discharge from the hospital. Most of their caregivers in this study described their main caregiving goals as ensuring their loved ones 
were taking their medications correctly, eating an appropriate diet, monitoring blood pressure, and coordinating the various clinic appointments. After discharge from the hospital some transplant recipient's required specialized treatments to be performed at home by their caregivers such as dressing changes and tracheostomy care. One caregiver described his caregiving experience as care of his wife's tracheostomy and ensuring she was suctioned when needed. Caregivers also shared their experiences of neglecting other family members in order to be able to participate effectively in their caregiving roles and to be able to effectively coordinate and plan all caregiving activities so that they did not interfere with the time spent with their children and spouse.

Although almost $80 \%$ of the caregivers found their caregiving experiences as stressful and frustrating, more than half of the caregivers also found caregiving activities as rewarding. Feelings of joy, happiness, and gratitude filled the caregivers dialogue as they described their reactions in seeing their loved ones performing chores such as cooking, washing dishes, laundry, dancing, going to the park, or even more rewarding seeing their loved ones breathing without the use of oxygen. After the transplant, seeing their family members taking a well-deserved vacation was also delightful and rewarding to the caregivers. Some caregivers also voiced their pleasure in seeing their loved ones dancing and attending Zumba classes. One caregiver described the most rewarding aspect of his caregiving experience as "I got her back, my wife is back." Finally, caregivers viewed their caregiver's experiences as a time in which families were brought together and were able to depend on each other for support during the caregiving experiences. The caregivers in this study voiced feelings of satisfaction as they played the role of an advocate for their loved ones. They thought that they were doing the best they could to ensure optimal survival and 
positive outcomes for their loved ones. The caregivers expressed feelings of joy and happiness when they participated in social activities with their loved ones.

Studies conducted on transplant caregivers shared similar findings with the results of this study. Meltzer \& Rodrigue (2001), in examining the psychological distress in caregivers of lung transplant recipients found that caregivers experience both benefits, rewards and stressors caring for a transplanted recipient. The most common stressors were the uncertainty of the post treatment expectations, the waiting period, fears and worry. The benefit of caring is helping the recipient. Kurz \& Cavanaugh (2001), in their research study reported caregivers considered their caregiving experiences as" a breath of fresh air" while others considered them as stressors. They also noted that although caregiving is generally reported as positive there are also some negative aspects. Positive aspects of caregiving reported by the caregivers in the present study were support from family and friends, learning to cope with unpredictably and growing closer to recipients. These results are consistent with results of previous studies that indicate caregiving activities are typically rewarding for caregivers, but generally care giving in combination with the caregivers' roles and responsibilities can take its toll on the caregivers' quality of life. Complex home regimes and changing family dynamics can lead to caregivers' overall daily mood (Dew et al, 2004, Myaskovsky, 2006, Tiechman et al, 2000). Xu et al (2012), found that transplant caregivers perceived their caregiving activities to be gratifying and self-satisfying, however, adjusting the changing family dynamics, house hold responsibilities and jobrelated issues associated with transplant compounded the burden of caregiving. Hence caregivers reported spending less of their day in a positive mood. Rodrigue \& Baz (2007) 
found that caregivers reported positive outcomes of caregiving such as discovering inner strength and support from others and realizing the importance of life.

As Kurz et al (2001) comment, during the post-transplant period when the recipient is discharged from hospital there are an array of inter related and permanent post-transplant tasks and activities that the caregiver will share with the transplant recipients. These tasks include daily medications, blood pressure monitoring, dietary guidelines, physical exercises, periodic medical tests and invasive procedures such as lung biopsies. Although the care provided by the caregivers is always comforting to the recipients it can also be physical and psychologically demanding, and hence affect the quality of care provided by the caregiver. Rodriguez \& Baz (2007) shared similar findings in their study as they indicated that caregivers who are exposed to the chronic stress of caregiving and transplantation often have a lower quality of life, feel confined and inconvenienced because of the demand to be available to help their loved ones at all times.

\section{Theme \# 3}

\section{Psychological and Psychosocial Issues.}

The burden of caregivers of lung transplant recipients can be compared to family caregivers of persons with long term chronic conditions who experience multidimensional events including constant care of their loved ones, financial constraints, coping with disruption of family routines and changes in family roles. Informal caregivers while providing care to their loved ones are confronted with increased financial, emotional, physical and health issues. They are face with restrictions in their social life, isolation and reduced or loss of employment (Brazil, Bainbridge \& Rodriguez, 2010). 
Caregivers in this study revealed that stress and anxiety played a role in their caregiving experiences with varying effects on their life style, social activities, employment, work and finances. As their caregiving role intensified and became more demanding they were forced to rearrange their priorities, shift roles and responsibilities, make life style changes, redirect emotional and physical energy, readjust personal and work plans and make drastic financial changes. Caregivers endured many psychological stressors over the course of their caregiving experiences. Most caregivers reported that they experienced feelings of fear, frustration, and helplessness at some point during their caregiving experiences. These findings are consistent with those of Brazil et al, (2010) who commented that caregivers while providing care to their loved ones are confronted with increased financial, emotional, physical and health issues. They are also faced with restrictions in their social life, isolation and reduced or loss of employment. Others report that many caregivers are faced with severe psychological distress and are often forced to deal with verbal and physical aggression, confusion, frustration and anger which is associated with their loved ones illness (Pinquart \& Sorensen, 2003). Pinquart and colleague conducted a meta-analysis of articles on differences between caregivers and noncaregivers perceived stress, depression, physical health and general well-being. Waldrop et al (2005) examined 74 caregivers of a family member who had received hospice care for a least 2 weeks and found that emotional distress from watching their loved one suffering as their condition deteriorates; anticipatory grief, graft survival failure, feelings of guilt and resentment all have a profound effect on the caregiver's physical and psychological status. Caregivers in the study ages ranged from $21-87$ with $68 \%$ of caregivers female and over 
$60 \%$ were spouses and Caucasian. Despite the difference in sample characteristics of each study their results were similar to findings in this study.

\section{Life style and Social Activities}

The caregivers in the present study discussed several life style changes that were made to ensure their loved one received appropriate care and at same time minimized their exposure to infections. These changes included rearranging furniture in the home, ensuring the house was clean, limiting visitors or sick contacts, and proper hand hygiene. Most of the caregivers stated they neglected other family members and caring for their loved one became their priority. Some caregivers who were parents were forced to relinquish their parental role so they were able to participate in their loved one's care. A caregiver reflected on occasions when she was forced to have her mother in law or husband pick up the kids from school. Another mother commented on neglecting her family as the care for her father became her priority. Angry and despair was not only displayed by the caregivers, but was also transferred to the children. One caregiver shared her experience with her son who became very angry because her attention was centered on taking care of his grandfather, and ultimately his grades in school were affected

Most caregivers acknowledged that their lives were different and more stressful with the caregiving responsibilities. They participated in less socialization with friends and attended fewer social activities and gatherings. They lamented the fact that they are unable to take vacations or get away for any length of time because of their commitment to take care of their loved one. Caregivers admitted that their social life had changed drastically since the transplant and almost all social activities became nonexistent. The caregivers spoke of not being able to go on a dinner date, hang out with friends or simply participate 
in activities that once were deemed enjoyment and fun. Another caregiver shared that after his wife's transplant it seemed everything had gone away. He was no longer able to continue do fun activities such as being an umpire at a baseball game or referee at a football game. These findings are similar to those of Ullrich et al (2004), who reported caregiver's stressors as using vacation time to take care of their loved one, arranging accommodations, frequent travelling to appointments, and loss of income.

\section{Emotional Health}

Approximately fifteen of the caregivers in this study reported many conflicting emotions throughout the transplant process such as lack of control over their loved one's needs during hospitalization and fear of the ability to cope during the post-transplant recovery. More than half of the caregivers mentioned that their caregiving experiences were filled with moments of tears and frustrations and anxiety. These tear-filled moments were either tears of joy as the caregivers were happy with the successful surgery outcome or tears of frustration and dismay as the caregivers questioned their ability to continue their caregiving roles. Despite being frustrated and tearful the caregivers were careful not to transfer their emotions to their loved ones. These findings were consistent with results of a study conducted by Goetzinger et al (2012) who examined stress and coping in caregivers awaiting solid organ transplant. Results demonstrated that caregivers of solid organ transplantation recipients experienced elevated symptoms of depression and anxiety during the pre-transplant period.

\section{Physical Health}

In transplantation, the issue of the caregiver's health is important because the survival of the transplanted recipient depends on the care they received from their caregivers. In 
this study caregivers shared mixed feelings in regard to their health status during their caregiving experiences. Some participants reported health issues while others felt there were no changes to their health status. Caregivers who experienced changes in their health status during caregiving described these changes as a broken neck, lower back pains, thyroid problems, fractured arm, heart problems leading to stent placement, stroke and increased blood pressure. Caregivers in this study admitted to neglecting their own health as their attention was centered on their loved ones recovery process. In the general caregiving literature, Scott (2013), noted that caregivers do not participate in health prevention activities such as seeking physician's assistance for health maintenance checkups, exercises, and eating a healthy diet hence resulting in a decline in caregivers' physical health. Additionally, Schultz et al (2003), and Vitaliano et al, (2003) also suggested that caregivers stress can result in changes in the caregiver's health behaviors used to promote their health and well-being. The great demand on the caregiver's time and energy caused them to neglect their own health problems and they are subsequently faced with worsening preexisting illness or increased vulnerabilities to new stress related problems. Caregivers physical and emotional health is frequently compromised from the stressors and burdens associated with the caregivers' responsibilities and role. Goetzinger et al (2012), found that caregivers are forced to relinquish social activities and employment in order to immerse themselves in their caregiving activities. Caregiver's psychological well-being and health needs are overlooked as their loved ones health issues take precedence as the primary focus and becomes the caregiver's top priority. The caregiver's own needs are neglected, resulting in increased caregiving burden and susceptibility to psychological distress, interpersonal conflicts and somatic symptoms. Pinquart \& 
Sorensen, (2003), Kurz (2001), and Collins et al, (2000) reported that caregiver's impaired quality of life and physical health status can lead to negative downstream consequences for the transplant recipient including problems with adherence and increased risk of morbidities. A caregiver's impaired health status can affect the care that is provided to the transplant recipient. Similar findings were also reported by Meltzer et al (2001), Myaskovsky et al, (2005), Rodrigue \& Baz, (2007), Casida, (2005), and Dew et al (2000). These authors also reported that the critical role the caregivers played in the health and well-being of the transplant recipients coupled with the toll that caregiver's responsibilities placed on the caregivers can adversely affect caregiver's health.

\section{Financial Issues}

Approximately seventy five percent of caregivers reported experiencing some financial problems during their caregiving experiences. The caregivers described various means that were used to help finance their loved one's transplant surgery. The use of credit cards, personal savings, conducting fund raising events and financial assistance from friends and family members were some of the means that caregivers used to meet the financial needs of their caregiving activities. Some caregivers felt pressured financially to pay for mounting medical expenses and transportation expenses to and from appointments or from health care facilities. The caregiver's financial strain was also enhanced by the loss of employment and reduction in work hours. Some caregivers also shared the idea of other family members having a second job and working extended hours in order to meet the financial obligations during their caregiving experiences. Another caregiver spoke of her appreciation of having her spouse who assisted her financially when she was unable to work. Other caregivers shared that their caregiving experiences 
did not significantly impact their financial status. One caregiver commented that although he did not receive a bonus for several years he was thankful he had a job and good insurance that allowed him to be financially stable. These findings are consistent with those of others who note that caregiving can affect a caregiver's work and financial status such as balancing their job while providing care to loved one. Some of the caregiver's financial strains are related to caregiving expenses, cost of medications, transportation or monetary loss in employment due to the caregiver performing the caregiver's roles (Lai, 2012, Haddock et al 2006).

\section{Employment status}

The status of the caregiver's employment was another aspect of the caregiver's experience that each caregiver struggled with. Maintaining a steady and meaningful employment was challenging for these caregivers. Challenges included taking early retirement, reduced work hours and difficulties of balancing work activities with their caregiving roles and responsibilities. One caregiver was forced to close her business so she would focus on the care of her husband, while others experienced conflicts and feelings of guilty as they tried to balance their work their caregiving roles. Other caregivers spoke of having other coworkers assist with their workload, whether to filling in for a day or two at work or simply to completing unfinished assigned work tasks. Making arrangements and establishing certain rules with their boss gave the caregivers' privileged time to participate in the caregiving roles. A few of the caregivers voiced their gratitude toward their bosses describing them as "very good, flexible, and compassionate. However, not all caregivers shared the same sentiments in regard to their boss. One caregiver commented that he was forced to retire because his boss felt his caregiving 
activities were interfering with his performance on the job. Surprisingly, one caregiver was able to work two jobs simultaneously without any problems with or interference with her job performance or caregiving responsibilities.

As Rianer et al (2010) note, frequently, caregiving responsibilities cause the transplant caregiver to decrease, suspend or end work leading to a reduction in or loss of income. Additionally, if the transplant recipient requires copious assistance the transplant caregiver can be forced to terminate their job. Subsequently this can negatively affect the house hold economic status and ultimately result in house hold economic burden. These situations can adversely affect the quality of both caregivers and recipients through the decrease in work and financial instability (Rianer et al 2010). Similarly, Eldredge et al, (2006) \& Boyle et al (2000), described transplant caregivers struggles to meet competing demands such as

continuing to work outside the home while caring for the transplant recipient. Inability to meet conflicting work demands and caregiving might require caregivers to stop working, adding to an already stressful situation. Worrying about financial concerns that arose from suspension of employment can result in caregivers faced with psychological crisis. Although both studies were conducted on caregivers of autologous blood and marrow transplantations, the results from these studies were similar to the findings in this study.

\section{Theme \# 4}

\section{Support}

The caregivers in this study discussed the various sources of support they received during their caregiving experiences. Caregivers reported receiving support from family, friends, health care professionals, community and spiritual support. Social support from family, friends, support groups or health care providers is reported as an important aspect 
of the caregiving experience (Ullirich, 2005). Despite the availability of these varied sources of support, some caregivers had to perform the caregiving roles and responsibilities by themselves.

Approximately one third of the caregivers described support received from family and friends, which included in laws, mother, kids, brothers, sisters, friends. According to White et al, (2004), social support in the form of close friends and family members has shown in the literature to be an important aspect of caregiving. Some of the dialogue used by the caregivers in this study to describe the support received by friend and families included:

"thank God for mother-in-law who lived close by -she could help with the care. With all of that around me and having love from church family and my family coming back and forth to help."

"My wife has a big family, has six brothers and sisters and they are all very supportive and I also have a family that helped"

Some caregivers in the study shared their reluctance in asking for help from others. Receiving support from health care professionals and support groups was also discussed during the interview. Some caregivers shared their experiences of receiving support from a health aide during his wife's immediate post-operative period and another referred to receiving some support from the health aide when she had broken her arm and was unable to perform her caregiving activities. The majority of the caregivers were elated and appreciative of the support they received from other health care professionals such as doctor, nurses and other members of the transplant team. The caregivers expressed how grateful they were for the information they received and lessons they were taught transplant team, that proven beneficial in their caregiving activities. The caregivers valued that they 
were allowed to contact the transplant team and felt trust and support from the team. They felt encouraged to call if they had questions or were anxious and most important, the information they received was clear and concise. Wang et al (2006) and Haugh et al (2007) report that health care professionals have the most important role in providing such support by sharing information with transplant caregivers and recipients.

Support groups and church were other forms of support that were shared by a few of the caregivers during the present study interviews. Kurz, (2001), reported that more than half of transplant caregivers in their study felt a support group played an important role in assisting caregivers to deal with stressors of caregiving, In the present study, despite been knowledgeable about these support groups, some caregivers admitted to not being able to attend and participate because of the distance from the transplant center or the constraints of work. However, a few caregivers shared their experiences in attending these groups which they described as helpful, providing them the opportunity to meet other transplant recipients. In describing their transplant experiences, they also learned about issues related to lung transplantation such as survival rates for lung transplant recipients. One caregiver described her feelings about the support group as "I try to go to everyone so that helped both of us to sit there and see people that have gone through this and the survival rate and stuff that they gone... through and how they were coping with it, that was very enlightening for me and him. I noticed that because he would talk about it (with) me, (it) was very, very important for both of us, and we try not to miss them so, we are there all the time that alone was very good". Few spoke of the continued or renewal spiritual involvement as a source of strength and support, through prayers and encouragement from members of their church. Few came from a very spiritual and religious community that they could count on. 
Support has been frequently considered as one of the most important psychosocial variables in the context of transplantation, since the availability of a supportive social environment is essential in all transplant stages (Olbrisch \& Levenson, 2002). Social support also appeared to be an important factor in lung transplantation. Low levels of support after transplant are related to low rates of survival, on adherence with medical regimens and poor psychological adjustment (Dew et al, 2008, Dobbels et al, 2009). Support is important to the transplant recipients because after receiving the transplant they will have to rely on another person to drive them to medical appointments, pick up prescriptions, go grocery shopping, assist with house work and sometimes provide child care (Fusar et al, 2007). Poor or inadequate support systems were identified in the literature as presenting challenges for caregivers who experienced an increase in caregiving burden (Nguyen, 2009, Belasco \& Sesso, 2002). Lim and Zembrack (2004 also suggested that many different types of support contribute to a caregiver's well-being.

\section{Study Limitations}

One study limitation was recruitment of participants from only one transplant center. Having caregivers from other transplant centers would allow more in-depth understanding of the caregivers' experiences and potentially provide different perspectives of the caregiver's experience. Interview duration may also be a limitation. Each interview was limited to 45 minutes to avoid fatigue and to reduce participant's time commitment. This may have truncated the caregiver's contributions. To gain a more comprehensive presentation of the phenomenon, the use of more than one data collection point may help. In this study data were collected only once through in-depth interview. Sample variation 
based on recipients' age, gender, educational level, relationship to caregiver, employment and financial status is a study strength.

\section{Recommendations for Future Research and Implications for Practice}

Lung transplantations are increasing in the US. Recipients are now spending shorter periods in the hospital resulting in care at home by family members and friends. However, transplantation will always poise a challenge to caregivers and can be a frightening experience for those involved in the care of the transplant recipients (Kurz, 2002). Few research studies have been conducted on lung transplant caregivers; most transplant research has been conducted on transplant recipients, donors and candidates waiting for transplant. There remains a gap in the literature regarding the experiences of lung transplant caregivers. More research is needed that will use the present study findings in other clinical contexts, implement different designs and methodologies such as mixed methods, grounded theory designs with larger sample sizes or descriptive correlation and predictive studies. These studies could examine in depth factors related to the caregiver's experiences including psychosocial and psychological status, caregiver's relationship between health professionals, families and community. These different perspectives would provide a more comprehensive understanding of the caregiver's experiences caring for a transplant recipient and assist health care professionals to identify appropriate interventions aimed at reducing stress associated with the caregiving experiences. Future research is also needed to examine the impact of caregiving on caregivers coping styles, social support and quality of the caregivers - recipient relationship. Caregivers and transplant recipients share responsibilities and the strength of their relationship is an important factor in predicting caregivers' burden and distress for caregivers and recipients. (Kurtz, 2001, Dew et al 2004). 
The issue of employment poised a challenge to caregivers, which can add burden to caregivers' responsibilities. It would be beneficial for future research to use a longitudinal method to track changes in employment status.

The results of this study indicate that caregiving for a lung transplant recipient can be a stressful and tedious process. Many of the caregivers expressed their caregiving experiences with feelings of anxiety, frustration, and guilt, anger, being overwhelmed. Caregiver's also experienced financial strain due to loss of income, cost of medications and transportation and increased work load and psychological strain. Having adequate support and information from a variety of sources including family, friends, health care professionals and transplant team members was considered throughout the transplant procedure. It is important that health care professionals realize that the transplant recipients do not undergo the transplant alone but should provide the caregivers with targeted information and support. The findings from this study further highlight the need to develop effective interventions to reduce lung transplant caregivers strain and emotional distress during the caregiving process, especially during the pre-transplant period. Health care professionals should aim to develop a multidimensional approach that provides some respite care, encourages more participation in supports groups, helps caregivers find personal meaning in their experiences and promotes coping strategies with problem solving and positive reappraisal techniques. Support groups have proven to be beneficial in helping caregivers deal with the stressors of caregiving. However, these support groups may be scarce and often not accessible to caregivers due to distance. Creating new methods of connecting the caregivers with support groups is essential. Health care professionals should consider other means such as tele conferences or web sites sponsored by specific 
organizations such as the United Network of Organ Sharing (UNOS). A patient education interactive website with easy access to experienced transplant coordinators or health care professionals prepared with information for caregivers would be a valuable resource/tool to ensure caregivers and transplant recipients receive appropriate guidance and information needed-

Caregivers shared their experiences of searching independently for information on the internet and other media sources. Information that is publicly generated and made available through the internet can be incorrect or misleading (Hanif et al, 2009). Therefore, health care professionals should aim to provide information from reputable sources such as transplant centers so reliable, appropriate and accurate information can be shared with caregivers.

The findings from this study suggested that lung transplant caregivers valued the support received from health care professionals. It is important that health care professionals recognize the caregivers' role in the transplant process, to ask and listen to the caregivers' needs and to include them in the plan of care. As transplant coordinators it is vital for them to work closely with transplant recipients and their caregivers by providing education and support, through problem solving, orientation and listening to fears and complaints. In accordance with these measures the transplant coordinator can assist to facilitate a collaborative relationship with caregivers, recipients and healthcare providers to understand each perspective and meaning of the experience. Involving and supporting these caregivers will provide an avenue to broaden and strengthen caregivers caring potential, hence resulting in better care for the transplant recipients and enhanced caregiver resilience (Sadala et al 2013) 
This study's findings also revealed that sociocultural factors and the caregivers' perspective influences the caregiver's experiences. There is paramount need for health care providers to understand the factors that contribute to negative or positive experiences for the caregivers. This knowledge will equip health providers to develop and implement suitable intervention programs to help the transplant caregivers. Health care providers should promote caregiver's capabilities by teaching coping strategies and providing more information and formal support. Programs and services to support caregivers should be advocated. Additionally, employment policy to better accommodate the caregiving responsibilities of the employees should be considered by employers. Health policies are geared toward resolutions, procedures and arrangements that will help to achieve specific heath care goals. Health care workers such as nurses have the capability to direct health policy issues through public policies, reinforced by government for the benefits of care recipients and caregivers. These caregiver's experiences shared in this study can encourage nurse leaders to engage in health policy significant guidelines aimed at providing support and resources for caregivers. Health policies and programs are also needed to address the financial needs and security of these caregivers. These caregivers are often faced with multiple demands in employment while caring for their loved ones, and simultaneously attempting to secure gainful employment and stability.

\section{Conclusion}

This study used a hermeneutic phenomenology approach to examine the caregivers' experience of lung transplant recipients. A phenomenology approach was used to search for the meaning of the caregiving experiences of caregivers of lung transplant recipients 
and to provide a foundation from which to build on and to foster the understanding of what it is like to be a caregiver of lung transplant recipients through the caregiver's perceptions. Caregiving is a complex phenomenon which produces negative impact on the lives of the caregivers. However, at the same time some caregivers feel positive about their caregiving roles and responsibilities. The results from this study revealed that although caregivers reported positive self-esteem, rewarding experiences, and overall favorable levels of quality of life, there are areas of the caregiving experiences that are problematic to the caregivers. These include feelings of fatigue, depression, anxiety, nervousness, frustration, and financial and health problems and an emotional impact of transplantation. Consequently, if lung transplant caregivers are feeling overwhelmed, exhausted, fearful of the uncertain future, playing multiple roles, worried about work, financial concerns and lack of support, the potential for their coping ability and strategies are unlikely. Hence understanding of how the caregivers appraise their experiences, their ability to access resources or support and their ability to care for themselves will help health care providers understand caregiver's well-being. This understanding is necessary in order to develop and implement evidenced based interventions. Caregivers working closely with transplant coordinators will allow transplant coordinators to recognize and affirm the vital role caregivers play in supporting the transplant recipient's physical, psychological, social and spiritual well-being. Lack of continuous support and care for the lung transplant caregivers will jeopardize both caregivers and recipient's health and well-being.

Finally, the results of this study demonstrated that the information and support needed and received by caregivers varied and there are gaps where interventions will be welcomed. The quality of patient's care is severely reduced when basic care related knowledge, 
support and resources are not available to caregivers. This eventually will contribute to the caregiver's uncertainty, stress as well as deterioration in the recipient's health. It is very important that health care providers and policy makers work to secure more care related knowledge, skills and support. In addition, the implementation of appropriate interventions such as psychoeducational interventions and connecting caregivers to resources will assist caregivers to deal with the many stressors associated with their caregiving responsibilities. The caregiver's experiences shared in this study will add to the limited body of knowledge existing on caregivers of lung transplant recipients.

Most of the research conducted on lung transplantation focuses on lung transplant recipients rather than on experiences of lung transplant caregivers. The limited research conducted on the lung transplant caregivers demonstrated the stress and demands associated with the caregiving responsibilities. However, in the lung transplant caregiver's literature the researchers failed to demonstrate the caregivers' lack of knowledge of the transplant process, including transplant and its profound effect on caregiver's experience and is a contributory factor to the caregiver's stress. The result of this study fills the gap in the transplant literature by demonstrating that the caregiver's lack of transplant knowledge, dynamic changes in caregiver's life style and socioeconomic status are sources of stress experienced by caregivers of lung transplant caregivers. The different caregiver's perspectives in this study provided a more concise and meaningful understanding of the caregiver's experiences, thus allowing health care providers and policy makers to implement informational, psychological and emotional interventions and policies to assist caregivers during their burdensome and stressful caregiving activities. 


\section{REFERENCES.}

Acton, G., Kang, J (2001) Interventions to reduce the burden of caregiving for an adult with Dementia: A Meta-Analysis. Research in Nursing; 24:349-360

Aneshensel, C, S., Pearlin, L, L., Mullan, J, T., Zarit, S, H., Whitlatch C. ( 1995) Profiles in Caregiving: The unexpected career. San Diego: CA Academic Press.

Asada, T, Kinsoshita, T \& Kakuma (2000) Analysis of behavioral disturbances among Community-dwelling elderly with Alzheimer's disease. Alzheimer Disease and Associated Disorders. 14, 160-167.

Boyle D., Blodgett L., Gnesdiloff ,S et al (2000). Caregiver quality of life after autologous bone marrow transplantation. Cancer Nurs. 23; 193-200

Burns, S (2000) The burden of Alzheimer's disease. International Journal of Neuropsychopharmacology; 3, 31-38.

Canning, R, D., Dew, M, A., Davidson, S. (1996) Psychological distress among caregivers to heart transplant recipients. Social Medicine.42; 3

Claar, R. L., Parekh, P, L., Palmer, S, M. (2005). Emotional distress and quality of life in caregivers of patients awaiting lung transplant. Journal of Psychosomatic Research 59,1

Chapell, N, L., \& Reid, C (2002) Burden and well-being among caregivers: Examining the Distinction. The Gerontologist, 42; 772-780

Cohen, M, Z., Kahn, D., \& Steeves, R, H (2000) Hermeneutic phenomenological research A practical guide for nurse researchers, Thousand Oaks, Ca: Sage Publications

Decima Research (2002). National profile of family caregivers in Canada-2002 Retrieved September 26, 2013 from Health Canada website: http://www.hc.gc.ca/english/pdf/care/nat profile02.pdf.

Creswell, J. W (2012) Qualitative inquiry and research design. Thousand Oaks, Ca. Sag Publications.

Denzil, N., \& Lincoln, Y (2005) The Sage handbook of qualitative research. Thousand Oaks, Ca: Sage

Dew, M.A., Goycoolea, J. M., Harris, R. C., Lee, A., Zomak, R., Dunbar-Jacob, J., et al. (2004) An internet -based intervention to improve psychosocial outcomes in heart 
transplant recipients and family caregivers: development and evaluation. Journal of Heart and Lung Transplantation, 23(6).745-758.

Dew, M. A., Myaskovsky, L., DiMartini, A, F., Switzer, G, E., Schulberg, H, C., \& Kormos, R. L (2004) Onset timing and risk for depression and anxiety in family caregivers of lung transplant recipients. Psychological Medicine, 34; 1065-1082.

Dilworth-Anderson, P, Goodwin, P, Wallace, W (2004) Can culture explain the physical health effects of caregiving over time among African American caregivers? Journal of Gerontology: Social Sciences, 59; 138-145

Etters L, Goodall, D \& Harrison, B, E (2008) Caregiver burden among dementia patient Caregivers: a review of literature. Journal of the American Academy of Nurse Practitioner, 20(8) 423-428.

Eldredge, D, H., Nail, L, M., Maziarz, R, T., Hansen, L, K., Ewing, D., Archbold, P, G (2006) Explaining family caregiver role strain following autologous blood and marrow Transplantation. J. Psychosocial Oncology, 51:53-74.

Feurer, I, D., Harrison, C., Pinson, C. W (2002), Health related quality of life before and after Solid organ transplantation. Measurement considerations reported outcomes and future Directions. Minerva Chirugica, 57(3); 257-271

Fillit, H. (2000) The pharmacoeconomics of Alzheimer's disease. The American Journal of Managed Care.6; 1139-1148

Goycoolea, J. M., Stukas, A. A., Switzer, G .E. Simmons, R. G., Roth, L.,et al. (1998). Temporal profiles of physical health in family members of heart transplant recipients: Predictors of health change during care giving. Health Psychology, 17(2), $138-151$.

Gaugler, J. E., Given, W.C., \& Linder, J. (2008). Work, gender, and stress in family cancer caregiving. Supportive Care in Cancer, 16, 347-357.

Gaugler, J, E., Wall, M, Kane, R, L., Mark et al (2011) Does caregiver burden mediate the effect of behavior disturbances in nursing home admissions. Gerontology; $16,497-506$.

Goetzinger, A. M., Blumenthal, J., OHayer, C, Babyak, C et al (2012). Stress and coping in caregivers of patients awaiting solid organ transplantation. Clinical Transplantation, 26, 97-104.

Grady, M, L., Makulowich, G. (Long term caregivers range in age. Agency for Healthcare Research and Quality. http://www.ahrq.gov/research/novo00/100RA19.htm 
Hanif F., Read, J, C., Goodacre, J, A., Chaudhry, A., Gibbs, P (2007). The role of quality tools in assessing reliability of the internet for health information. Inform Health Soc. Care, 34(4); 231-43.

Haugh, K, H., Salyer, J (2007). Needs of patients and families during the wait for a donor An organ. Heart \& Lung; 36(5):319-29

Hseih, H, F., Shannon, S, E (2005) Three approaches to qualitative content analysis. Qual Heal Res; 15 (9); 1277-1288

Holtzman, S., Abbey, S, E., Singer, G, Ross, H., Stewart, D, E (2011). Both patient and caregiver gender impact depressive symptoms among organ transplant caregivers: Who is at risk and why? Journal of Health Psychology 16(5) 843-856

International Society for Heart and Lung Transplantation Registry. Adult Lung Transplantation Statistics. https://www.ishlt.org/registeries/slides.asp?slides=heartlungRegistry (Accessed on September 3, 2015).

Kurz, J. M. (2001a) Desire to control, coping and quality of life in heart and lung Transplant. Progress in Transplantation, 11(3): 224-230.

Kurz, J. M. (2001b). Experiences of well spouses after lung transplantation. Journal of Advanced Nursing, 34(4), 493-500.

Kurz, J. M. (2002). Vulnerability of well spouses involved in lung transplantation. Journal of Family Nursing, 8(4), 353-370.

Kurz, J. M., \& Cavanaugh, J.C (2001). A qualitative study of stress and coping strategies used by well spouses of lung transplant candidates. Families, Systems \& Health, 19(2), 181-197.

Lanuza, D. M., Lefaiver, C. A., McCabe, M, A., \& Garrity Jr, E. R. (2001). Quality of life symptoms experiences during the first year of post lung transplantation. American Journal of Respiratory and Critical Care Medicine, 16(5), 57-66.

Lefaiver, C, A., Keough, V., Letizia, M., Lanuza, D, M (2009) Using Roy Adaptation model to explore the dynamics of quality of life and the relationship between lung transplant candidates and their caregivers. Adv.Nurs.Sci. 30(3); 266-274.

Lefaiver, C, A., Keough, V., Letizia, M., Lanuza, D, M (2009), Quality of life in caregivers providing care for lung transplant candidates. Progress in Transplantation, $19 ; 142-152$ 
Lamura, G., Mnich, E., \& Nolan, M. (2006) Experiences of family caregivers of elderly elderly people claiming benefits in Europe. The Gerontologist, 39, 429-442.

Lanuza, D M., McCabe, M.A (2001) Care before and after lung transplantation and quality of life research. AACN, Clinical Issues, 12(2); 186-201.

Laverty, S. M. (2003). Hermeneutic phenomenology and phenomenology: A comparison of historical and methodological considerations. International Journal of Qualitative Methods, 2(3), 1-23.

Lincoln, Y., \& Guba, E (1985) Naturalistic inquiry. Newbury Park, Ca: Sage

McCurry, A. H., \& Thomas, S.P. (2002). Spouses' experiences in heart transplantation. Western Journal of Nursing Research, 24(2), 180-194.

Merleau-Ponty, M (1962) Phenomenology of perception. London, UK: Routledge

Meltzer, L.J., \& Rodrigue, J. R. (2001). Psychological distress in caregivers of liver and lung transplant candidates. Journal of Clinical Psychology in Medical Settings, $8(3)$

Montgomery, R. J., Goneya, J, \& Hooyman, N. (1985). Caregiving and the experiences of subjective and objective burden. Family Relation, 34, 19-26

Moore, M, J., Zhu, C, W., \& Clip E, C (2001) Informal cost of dementia care Estimates From the National Longitudinal Caregiver Study. Journal of Gerenoyology, 56; 219228

Mousatakas, C (1994). Phenomenological research methods. Thousand Oaks, CA: Sage

Myaskovsky, L., Dew, M. A., Switzer, G, E., Hall, M., Kormos, R. 1., Goycoolea, J. M., et al. (2003). Avoidant coping with health problems is related to poorer quality of life among lung transplant candidates. Progress in Transplantation. 13(3), 183-192.

Myaskovsky, L., Dew, A, M., Switzer, E, G., McNutty, L, M., DiMartini, A, McCurry K, R. (2005) Quality of life and coping strategies among lung transplant candidates and their family caregivers. Social Science and Medicine, 60; 2321-2332

National Family Caregiver Association. (2009), March. Caregiving Statistics. Retrieved September 25,, 2015, from http://www.nfcacares.org/who/stats.cfm

National Alliance for Caregiving \& AARP, Family Caregiving in the US. Findings From National Survey http://www.caregiving.org/data04finalreport.pdf, Accessed January 2017 
National Institute of Nursing Research. Executive Summary, Research in Informal Caregiving: State of the Science Workgroup meeting. The National Institute of Nursing Research, 2001.

Neugaard, B., Andersen, E., McKune, S., \& Jamoom, M (2008). Health-related quality of life in a national sample of caregivers. Journal of Happiness Studies, 9, 559575.

Olbrisch, M., Benedict, S. \& Ashe, K, et al (2002). Psychological assessment and care of organ transplant patients. Journal of Clinical Psychology.70, 668-771.

Organ Procurement and Transplantation Network, (2015). Additional resources

available on new lung allocation policy change. Retrieved September 10.2015, from www.optn.org/news/newsDetail.asp?id=377

Patton, M. (1990). Qualitative evaluation and research methods. Newbury Park, CA: Sage Publications.

Pinquart, M., Sorensen, S (2003) Associations of stressors and uplifts of caregiving with caregiver burden and depressive mood a meta-analysis. J Gerontol B Psychol Sci Soc Sci 58(2): 112-128

Pinquart, M \& Sorensen, S (2004). Associations of caregiver stressors and uplifts with Subjective well-being and depressive mood: a meta-analytic comparison. Aging \& Mental Health, 8,438-449

Pinquart, M, \& Sorensen, S (2011) Spouses, adult children, and children in-law as caregivers Of older adults: a meta-analytic comparison. Psychology and Aging, 26, $1-14$

Polit, D. F., \& Beck, C. T. (2012). Nursing research: Generating and assessing evidence for nursing practice (9th ed.). Philadelphia, PA: Lippincott Williams \& Wilkins.

Rainers, G. M. (2012). Understanding the differences between Husserl's (descriptive) and Heidegger's (interpretive) phenomenological research. Journal of Nursing Care, 1(5), 1-3.

Rodrigue J, R., Baz, M, A (2007). Waiting for lung transplantation: quality of life, mood Caregiving strain and benefit, and social intimacy of spouses, Clinical Transplantation, 21; 722-727

Rodrigue, J, R., Widows, M, R., Baz, M, Carr, M, A (2006) Caregivers of lung transplant candidates; do they benefit when the patient is receiving psychological services? Progress In Transplantation, 16(4); 336-342. 
Saxe-Braithwaite, M, E., \& Chapman, J.S (1992). Life on hold: The experience of the support person involved in a lung transplant program. Canadian Journal of Nursing Research, 24)3).69-80.

Sawtzky, J, E., Fowler-Kerry, S (2003) Impact of caregiving listening to the voice of Informal caregivers. Journal of Psy. Mental Health Nurs. 10, (3); 277-286

Selwood, A, Johnson, K, Katona, C, et al (2007) Systemic review of the effects of psychological Interventions on family caregivers of people with dementia. Journal of Aff.Disorder, 100, 75-89.

Schulz, R., Sherwood, P, R. (2008) Physical and mental health effects of family caregiving American Journal of Nursing, 108(9) Supl.23-27

Schulz, R., Burgio, L., Burns, R., Eisdorfer, C., Gallagher-Thompson, D., Gitlin et al (2003). Resources for Enhancing Alzheimer's Caregivers Health. The Gerontologist, $43,514-520$.

Shank, G. D. (2006). Qualitative research: A personal skills approach (2nd ed.). Upper Saddle River, NJ: Pearson

Shanks-McElory, H, A., \& Strobino, J (2001) Male caregivers of spouses with Alzheimer's disease : Risk factors and health status. American Journal of Alzheimer's Disease and other Dementias.16, 3:167-175

Son, J, Emo, A, Dennis G et al (2007) the Caregiver stress process and health outcomes Journal of Aging Health, 19(6); 871-887

Streubert, H., \& Carpenter, D. (2011). Qualitative research in nursing: Advancing the humanistic imperative (5th ed.). Philadelphia, PA: Lippincott William \& Wilkins.

Tarter, R. E., Switala, J., Kabene, M., \& Van Thiel, D H (1990) Long term psychological following liver/lung transplantation: Gender comparisons of patients and their spouse Family System Medicine, 8(4), 359-364

Teichman, B, J., Burker, E, J., Weiner, M, Egan, T, M. (2000) Factors associated with Adherence to treatment regimens after lung transplantation. Progress in Transp.10; $113-121$

Ullrich, G., Jansch, H., Schmidt, S., Struber, M \& Neidermeyer, J. (2004) The experience of the support person involved in a lung transplant program: results of a pilot study European Journal of Medical Research, 9(12), 555-652.

Ullrich, G., Jansch, H., Schmidt, S., Struber, M \& Neidermeyer, J. (2005) Consulting the "experts" a pilot study on perceptions of professional support among lung transplant 
recipients accompanying relatives. Prog.Transplant, 15(2), 115-122.

United Network for Organ Sharing. (2015, September 10) Data Reports. Retrieved September 10, 2015 from http://www.unos.org/data

van Manen, M. (1990). Researching lived experiences: Human science for an action sensitive pedagogy. Albany, NY: State University of New York Press

Von Kanel, R, Mausbach, B, I., Patterson, T, L, et al (2008) Increased Framingham coronary Heart disease in risk score in dementia caregivers relative to non-caregiving controls Gerontology, 54: 131-137.

van Ryn, M, Saunders, S, Khan, K et al (2011) Objective burden resources and other stressors among informal caregivers: A hidden quality issue. Psychooncology, 20; 44-52.,

Vitaliano, P., Zhang, J., \& Scanlan, J. (2003). Is caregiving hazardous to one's physical Health? A meta-analysis. Psychological Bulletin 129 (6) 946-972.

Wicks, M, N., Milstead, E., Hathway, D, K., Getingok, M (1998) Subjective burden and Quality of life in family caregivers of end stage lung disease. ANNA Journal; 24.527

Xu, J, Oluwatobi, A., Wagley, E. \& Aubrecht, J. (2012). Daily Burdens of recipients and family caregivers after lung transplant. Progress in Transplantation 22(1), 41-45.

Yee, J, L., Schultz, R (2000) Gender differences in psychiatric morbidity among caregivers A review and analysis. Gerontologist 40(2):147-164.

Zhang, J., Vitaliano, P, P., \& Lin, H, H. (2006) Relations of caregiving stress and health depend on the health indicators used and gender. International Journal of Behavioral Medicine. 


\section{APPENDIX 1}

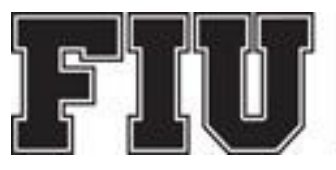

\section{FLORIDA \\ INTERNATIONAL \\ UNIVERSITY}

To:

Dr. Dorothy Brooten

CC:

File

From: $\quad$ Maria Melendez-Vargas, MIBA, IRB Coordinator

Date: June 9, 2017

Protocol Title: "The Lived Experiences of Caregivers of Lung Transplant Recipients" MEMORANDUM

Office of Research Integrity

Research Compliance, MARC 414

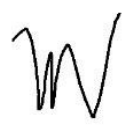

$\begin{array}{llll}\text { IRB Protocol Approval \#: } & \text { IRB-17-0194 } & \text { IRB Approval Date: } & 06 / 06 / 17 \\ \text { TOPAZ Reference \#: } & 105815 & \text { IRB Expiration Date: } & 06 / 06 / 18\end{array}$

The Health Sciences Institutional Review Board of Florida International University has approved your study for the use of human subjects via the Expedited Review process. Your study was found to be in compliance with this institution's Federal Wide Assurance (00000060).

As a requirement of IRB Approval you are required to:

1) Submit an IRB Amendment Form for all proposed additions or changes in the procedures involving human subjects. All additions and changes must be reviewed and approved by the IRB prior to implementation.

2) Promptly submit an IRB Event Report Form for every serious or unusual or unanticipated adverse event, problems with the rights or welfare of the human subjects, and/or deviations from the approved protocol.

3) Utilize copies of the date stamped consent document(s) for obtaining consent from subjects (unless waived by the IRB). Signed consent documents must be retained for at least three years after the completion of the study.

4) Receive annual review and re-approval of your study prior to your IRB expiration date. 
Submit the IRB Renewal Form at least 30 days in advance of the study's expiration date.

5) Submit an IRB Project Completion Report Form when the study is finished or discontinued. 


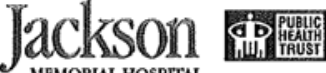 Miracles made daily.

June 29, 2017

\author{
Ms. Joy A. Glaze \\ 2705 SW $129^{\text {th }}$ Avenue \\ Miramar, FL 33027 \\ Dear Ms. Glaze:
}

The JHS Clinical Research Review Committee (CRRC) reviewed the study referenced below on June 28,2017 . This data collection study is now approved and may commence at Jackson Health System.

FIU IRB Protocol Number:

IRB-17-0194

FIU Principal Investigator:

Dorothy Brooten, PhD, RN, FAAN

JHS Site Investigator:

Joy A. Glaze, RN, MSN, ARNP

Department:

Miami Transplant Institute - Lung Transplant

Study Title:

The Lived Experiences of Caregivers

of Caregivers of Lung Transplant Recipients

Type of Study:

Survey

Funding:

Investigator-Initiated

ClinicalTrials.gov Identifier:

Not Assigned

Kindly apprise the Director and/or Nurse Manager of the relevant unit on the conduct of the study prior to commencement at the facility. 


\section{RECRUITMENT FLYER}
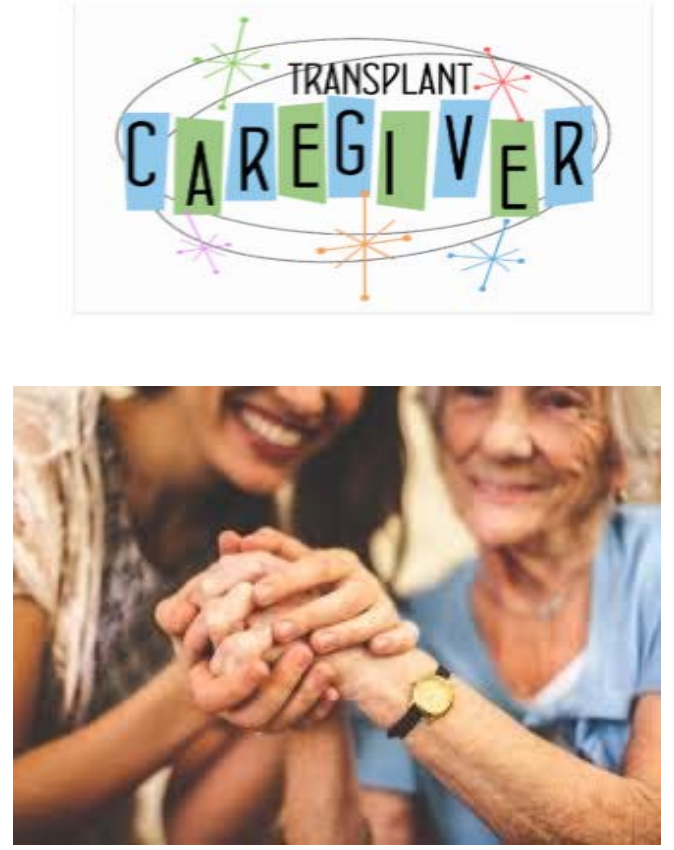

PARTICIPANTS NEEDED FOR NURSING RESEARCH

\section{Are you the caregiver of a lung transplant recipient?}

You are invited to participate in a research study: Exploring the lived experiences of caregivers of lung transplant recipients.

Participants Requirements:

- Family members or friends (male or female) who identify themselves as the caregiver of a lung transplant recipient 1- 6 years post-transplant.

- 18 years or older

- Ability to understand written and spoken English or Spanish

- Willing to have an interview video- taped and transcribed. 
If you meet these requirements and would like to participate, please contact the researcher:

Joy Glaze, RN, MSN (Doctoral Student)

Phone: 786-521-3352

Florida International University Faculty Sponsor:

Dorothy Brooten, PhD, FAAN

Phone: 305-348-7715

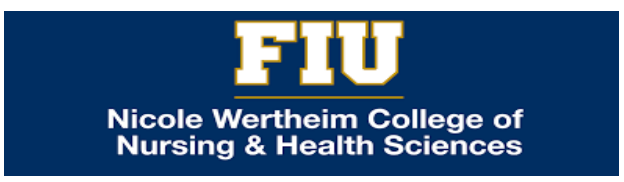




\section{BOLETIN DE RECLUTAMIENTO}
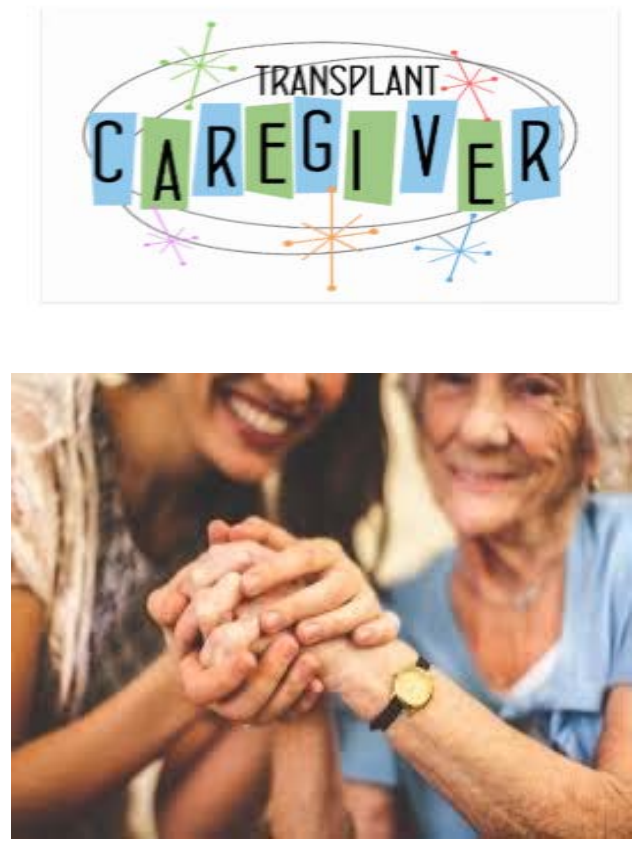

SE NECESITAN PARTICIPANTES PARA UNA INVESTIGACION DE ENFERMERIA

Es usted la persona encargada del cuidado de un paciente que ha recibido transplante de pulmon?

Usted esta invitado a participar en una investigacion de enfermeria; Explorando las experiencias de personas a cargo del cuidado de pacientes que han recibido transplante de pulmon.

Requisitos para participar:

- Miembros de familia o amigos (femenino o masculino) que se identifiquen como responsables del cuidado de un paciente que ha recibido transplante de pulmon, 1-6 anos despues del transplante.

- 18 años de edad o mayor

- Tener la abilidad de entender el idioma Ingles o Espanol escrito y leido. 
- Aceptar ser entrevistado y grabado en video, dicha entrevista luego sera transcrita.

Si usted llena los requisitos y le gustaria participar, favor de contactar al investigador; Joy Glaze, RN, MSN (Estudiante del programa de Doctorado)

Telefono; 786-521-3352

Universidad Internacional de la Florida, miembro patrocinador;

Dorothy Brooten, PhD, FAAN

Telefono; 305-348-7715 


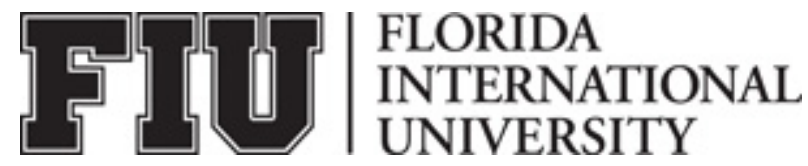

ADULT CONSENT TO PARTICIPATE IN A RESEARCH STUDY

The Lived Experiences of Caregivers of Lung Transplant Recipients

\section{PURPOSE OF THE STUDY}

You are being asked to be in a research study. The purpose of this study is to achieve a better understanding of what caregivers of lung transplant recipients experience while providing care to an individual who receives a lung transplantation.

\section{NUMBER OF STUDY PARTICIPANTS}

If you decide to be in this study, you will be one of 20 people in this research study.

\section{DURATION OF THE STUDY}

Your participation will require you to participate in this study for a duration of about 1 hour. Four study participants, chosen at random, will be asked to review their transcribed interviews to make sure that they have been transcribed and interpreted accurately. For these 4 participants the readings and review may take up to one to three weeks.

\section{PROCEDURES}

If you agree to be in the study, we will ask you to do the following things:

You will be asked to take part in a face to face taped interview with the principal investigator Joy Glaze, ARNP, a doctoral student from Florida International University School of Nursing and Health Sciences. The interview will last approximately $45 \mathrm{mins}$ and will be held at a time and location that is convenient for you. During the interview, you will be asked to share your caregiving experiences while caring for a person who has a lung transplant. You will be encouraged to speak freely during the interview. You may take as long as you like to answer the questions and relate your experiences. Following the interview, some participants (4) will be asked to read the transcript from the interview and the principal investigator's interpretation to make sure it is a good description of their experience. These 4 participants may be called back for second or third interview if there is need to clarify some of their responses. These additional interviews should not last more than 30 minutes.

\section{RISKS AND/OR DISCOMFORTS}

We do not anticipate any risks to you for participating in the study. However, there may be some discomfort answering questions related to caring for someone with a lung transplant. You may refuse to answer any questions that make you feel uncomfortable. You may withdraw from the study at any time. There are no risks for refusing to participate. 


\section{BENEFITS}

No benefits can be promised to you from your participation in this study. However, we hope that learning about your caregiving experiences while caring for someone with a lung transplant will help health care providers use the data from the study to provide direction for interventions and to help caregivers cope with the many stressors associated with caregiver's roles and responsibilities. Study findings may also provide data that will inform health policy.

\section{ALTERNATIVES}

There are no known alternatives available to you other than not taking part in this study. However, any significant new findings developed during the course of the research which may relate to your willingness to continue participation will be provided to you.

\section{CONFIDENTIALITY}

The records of this study will be kept private and will be protected to the fullest extent provided by law. In any report, we might publish, we will not include any information that will make it possible to identify a study participant. Research records will be stored securely and only the research team will have access to the records. However, your records may be reviewed for audit purposes by authorized University or other agents who will be bound by the same provisions of confidentiality.

All voice file and electronic copies of the interview that were transcribed from the recorder will be stored in a password protected computer hard drive. The password protected computer hard drive, paper copy of transcription and signed consent will be stored securely in a locked filing cabinet at FIU. The transcribed paper copy of the recordings and the signed consent forms will be kept in the locked cabinet for a period of 5 years after completion of the study and then will be destroyed. The participants will be informed that no names or any identifiable information will be contained in the document and all data that could identify the participant will be erased.

When the results are published, excerpts from the interview may be used to illustrate the findings of the study. No names or identifying information will be used in any publication related to the findings of this study. The U.S. Department of Health and Human Services (DHHS) may request to review and obtain copies of your records.

\section{COMPENSATION \& COSTS}

There are no costs associated with your participation in this study and you will not be paid for the time spent in completing the interview.

\section{RIGHT TO DECLINE OR WITHDRAW}


Your participation in this study is voluntary. You are free to participate in the study or withdraw your consent at any time during the study. Your withdrawal or lack of participation will not affect any benefits to which you are otherwise entitled. The investigator reserves the right to remove you without your consent at such time that they feel it is in the best interest of the research.

\section{RESEARCHER CONTACT INFORMATION}

If you have any questions about the purpose, procedures, or any other issues relating to this research study you may contact Joy Glaze at Miami Transplant Institute, 786-521-3352, jglaz004@fiu.edu.

\section{IRB CONTACT INFORMATION}

If you would like to talk with someone about your rights of being a subject in this research study or about ethical issues with this research study, you may contact the FIU Office of Research Integrity by phone at 305-348-2494 or by email at ori@fiu.edu.

\section{PARTICIPANT AGREEMENT}

I have read the information in this consent form and agree to participate in this study. I have had a chance to ask any questions I have about this study, and they have been answered for me. I understand that I will be given a copy of this form for my records.

Printed Name of Participant 


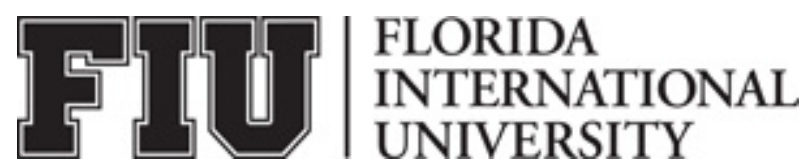

\section{CONSENTIMIENTO PARA UN ADULTO QUE PARTICPA EN UN ESTUDIO DE INVESTIGACION.}

Las Experiencias vividas por personas en el cuidado de pacientes que han recibido un transplante de pulmon.

\section{PROPOSITO DE EL ESTUDIO}

A usted se le ha pedido particpar en un estudio de investigacion. El proposito de este studio es lograr un major entendimiento acerca de las experiencas vividas por personas ques asisten en el cuidado de pacientes que han recibido un transplante de pulmon.

\section{NUMERO DE PARTICIPANTES.}

Si usted toma la decision de participar en este studio, usted sera uno de los 20 participantes.

\section{TIEMPO DE DURANCION DE EL ESTUDIO.}

Su participacion en el estudio tendra una duracion de aproximadamente una hora. 4 participantes seran escogido al azar y se les preguntara a cada uno que revise la informacion en cada una de las entrevistas transcritas para asegurar que se hayan intrepretato y transcritas correctamente. Para 4 de los participantes la lectura y revision de las entrevistas transcritas puede tomar de una a tres semanas.

\section{PROCEDIMIENTOS}

Si usted acuerda en participar en este studio se le pedirá hacer lo siguiente:

Se le pedirá su participacion en una entrevista gravida cara a cara conducida por la investigadora principal de este estudio Joy Glaze, ARNP una estudiante de el programa de doctorado de enfermeria de la Universidad Internacional de la Florida. La entrevista durara aproximadamente 45 minutos y usted decidirá la ahora ,el dia y lugar de acuerdo a su conveniencia. Durante esta entervista se le pedirá que comparta sus experiencias como proveedor de cuidados a personas los cuales han recibido un transplante de pulmon.

Usted sera motivado a hablar libremente durante la entrevista. Usted se puede tomar el tiempo necesario para responder preguentas y compartir sus experiencias. Al finalizar la entrevista algunos de los participantes (4) se les pedirá que lean la transcripcion de sus entrevistas y la intrepretacion de la investigadora prinicipal para asegurar que se una buena descripcion de sus experiencias. Los 4 participantes pudieran ser llamados de regreso para una segunda o tercera entrevista si hay necesidad de clarificar algunas de las respuestas. Estas entrevistas adicionales no deben durar mas de 30 minutos. 


\section{RIESGOS Y/O MOLESTIAS.}

No anticipamos riesgos para usted por participar en este estudio. Sin embargo le puede causar alguna molestia al responder algunas preguntas relacionadas con el cuidado de pacientes que ha recibidio un transplante de pulmon. Usted puede rehusarse a responder cualquier pregunta que le huga sentir incomodo/a. Usted puede retirarse del estudio en cualguier momento. No hay riesgos por rehusarse a participar en este estudio.

\section{BENEFICIOS}

No le podemos prometer ningun beneficio por su participacion en este studio, sin embargo esperamos que aprendiendo de sus experiencias como proveedor en el cuidado de un paciente transplantado de pulmon, ayudara al personal medico a usar estos datos para proporcionar una guia que permita implementar intervenciones y ayudar a los proveedores de cuidado del paciente a enfrentar situaciones estresantes asociadas con las responasabilidades que el papel de personas en el cuidado de pacientes trasplantados de pulmon causa. Resultados de este estudio podria a su vez proporcionar datos para desarrollar polizas de salud.

\section{ALTERNATIVAS}

No hay otras alternativas disponibles para usted, solamante que opte no participar en este estudio. Sin embargo usted sera informado de cualquier descubrimento significativo que ocurra durante el curso de este estudio que pueda afectar su dispocision en continuar su participacion en este estudio.

\section{CONFIDENCIALIDAD}

El registro de este estudio se mantendrá privado y protejido como es establecido por la ley. En caso de que se publique algun reporte, no vamos a incluir ninguna informacion que pueda hacer posible identificar a algun participante de este estudio. Los archivos de la investigacion van ha ser guardados en un lugar seguro y solomante el equipo de investigacion va ha tener acceso a los archivos. Sin embargo, sus archivos pueden ser revisados con propositos de auditoria por personal authorizado de la Universidad u otros agentes los cuales estaran regidos por las mismas clausulas de confidencialidad. Todas las copias electronicas y conversaciones de las entrevistas que fueron transcritas del grabador de voz seran guardadas en el computador protejidas por una palabra de contraseña. La palabra de contraseña del computador, las copias de papel transcritas y el consentimento firmado,seran almacenados en un gabinete bajo llave en FIU.

Las copias de la conversacion grabada y transcrita y las planillas firmadas de consentimiento van a ser almacendas en el gabinete bajo llave por un period de 5 años despues de haberse completado el studio y luego seran destruidas. A los participantes se le informará que no habran nombres o ninguna informacion de identificacion sera contenida en el documento y toda aquella informacion que pueda identificar a los participantes sera borrada. Una vez que los resultados sean publicados, palabra textuales de las entrevistas pueden ser usadas para ilustrar 
los resultados de el estudio. El Deparamente de Salaud y Servicos Humanos de Estados Unidos (DHHS) pudiera pedir revisar y obterar copias de sus archivos.

\section{COSTOS Y COMPENSACIONES}

No habran costos para usted por su participacion en este estudio y tampoco recibira pago por el tiempo empleado al completer esta entrevista.

\section{DERECHO HA ABANDONAR O NEGARSE A PARICIPAR EN EL ESTUDIO.}

Su participacion en este estudio es voluntaria .Usted es libre de participar en el estudio o retirar su consentimento en cualquier momento durante el estudio. Su retiro del estudio o su deseo de no participar en el estudio no affectara ningun beneficio previamente otorgado a usted. El investigator tiene derecho de removerlo del estudio sin su consentimento en el momento dado que considere que es lo mas indicado para la investigacion.

\section{INFORMACION PARA CONTACTAR AL INVESTIGADOR.}

Si usted tiene alguna pregunta acerca de el proposito, procedimiento o alguna otro preocupacion en relacion a este estudio usted puede contactor a Joy Glaze al Instituto de Transplante

(786-521-3352), jglaz004@fiu.edu.

\section{INFORMACION PARA CONTRACTOR AL IRB.}

Si usted desea hablar con alguien acera de sus derechos como sujeto en esta investigacion o acerca de problemas eticos con el estudios de investagcion, usted puede contactar las officinas de integridad e investigacion de FIU al telefono (305-348-2494 o al correro electronico ori@fiu.edu.

\section{ACUEDRO DE EL PARTICIPANTE.}

Yo he leido la informacion cotendia en esta planilla de consentimento y estoy de acuerdo en participar en este studio. Yo he tenido la oportunidad de hacar preguentas acerca de estes estudio y ellos me han dado las respuestas adecuedas. Yo fui informado que se me entregara una copia de esta planilla para mis archivos.

Firma del Participante

Fecha

Nombre completo del Participante

Firma de la person que obtiene el consentimiento

Fecha 


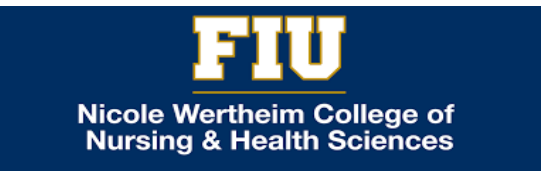

FLORIDA INTERNATIONAL

DEMOGRAPHIC QUESTIONNAIRE

Participant Number.

Please provide the answer for the following questions by circling your answers:

1. AGE:

21-29

30-49

50-64

65 and over

2. GENDER:

Female

Male

3. MARTIAL STATUS:

Single

Married

Divorced

Separated

Widowed

4. ETHNICITY:

African American/Black

Asian/Asian American

Hispanic/Latino

White

5. LEVEL OF EDUCATION:

Elementary School or less

Some High School

Completed High School

Some College

College Graduate 
Graduate/Professional Degree

6. PRIMARY LANGUAGE:

English

Spanish

Other

7. FAMILY YEARLY INCOME

Less than $\$ 25,000$ per year

\$25,000-@49,999 per year

$\$ 50,000-99,000$ per year

$\$ 100,00-\$ 250,000$ per year

8. CAREGIVER/RECIPIENT RELATIONSHIP:

Spouse

Sibling

Parent

Friend

Other

9. YEARS OF BEING A CAREGIVER:

1-2 years

2-4 years

4-6 years

10. EMPLOYMENT STATUS:

Full-time

Part-time

Not Working 


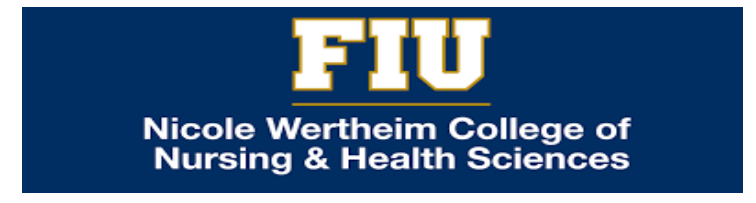

Universidad Internacional de la Florida

Cuestionario demográfico

Participante numero;

Por favor responda las siguientes preguntas circulando la respuesta apropiada

1. Edad

21-29

30-49

50-64

65 o más

2. Sexo

Femenino

Masculino

3. Estado civil

Soltero

Casado

Divorciado

Separado

Viudo

4. Etnia

Afroamericano/negro

Asiatico/Asiatico Americano

Hispano/Latino

Blanco

5. Nivel de educación

Escuela primaria o menos

Escuela secundaria parcial

Diploma de escuela secundaria

Universidad parcial

Graduado de Universidad

Graduado con Maestria 
6. Lenguaje primario

Inglés

Español

Otro

7. Ingreso familiar annual

Menos de $\$ 25,000$ anual

$\$ 25,000-\$ 49,000$ anual

$\$ 50,000-\$ 99,000$ anual

$\$ 100,000-\$ 250,000$ anual

8. Relacion con el paciente transplantado de púlmon

Conjugue

Hermano

Padre/madre

Amigo

Otro

9. Años de ser la persona al cuidado del paciente transplantado

1-2 Años

2-4 Años

4-6 Años

10. Estado de empleo

Tiempo completo

Medio tiempo

Desempleado 


\section{VITA}

\section{JOY GLAZE}

1991-Present

1989

1998

2001

2013-2018

\section{RN/ARNP}

Jackson Memorail Hospital

Miami, Florida

Diploma in Nursing

Kingston, Jamaica

Bachelor of Science in Nursing Florida International University Miami, Florida

Master of Science in Nursing Florida International University Miami, Florida

Doctoral Candidate Florida International University Miami, Florida.

\section{PUBLICATIONS:}

Youngblut, J., M, Brooten, D., Glaze, J., Promise, T., Yoo, C (2017). Parent Grief 1-13 Months after Death in Neonatal and Pediatric Intensive Care Units. Journal of Loss \& Trauma; 22(1):77-96. 